Universidade de São Paulo

Escola Superior de Agricultura "Luiz de Queiroz"

Efeito da resistência de Spodoptera frugiperda (J.E. Smith, 1797) (Lepidoptera: Noctuidae) a lambda-cyhalothrin na interação com o milho geneticamente modificado (MON810) e na resposta imunológica ao parasitismo por Campoletis aff. flavicincta (Hymenoptera: Ichneumonidae)

\title{
Danielle Thomazoni
}

Tese apresentada, para obtenção do título de Doutor em Ciências. Área de concentração: Entomologia

Piracicaba 
Danielle Thomazoni

Biólogo

Efeito da resistência de Spodoptera frugiperda (J.E. Smith, 1797) (Lepidoptera:

Noctuidae) a lambda-cyhalothrin na interação com o milho geneticamente modificado

(MON810) e na resposta imunológica ao parasitismo por Campoletis aff. flavicincta

(Hymenoptera: Ichneumonidae)

Orientador:

Prof. Dr. CELSO OMOTO

Tese apresentada para obtenção do título de Doutor em Ciências. Área de concentração: Entomologia 


\section{Dados Internacionais de Catalogação na Publicação}

DIVISÃO DE BIBLIOTECA - ESALQ/USP

\section{Thomazoni, Danielle}

Efeito da resistência de Spodoptera frugiperda (J.E. Smith, 1797) (Lepidoptera: Noctuidae) a lambda-cyhalothrin na interação com o milho geneticamente modificado (MON810) e na resposta imunológica ao parasitismo por Campoletis aff. flavicincta (Hymenoptera: Ichneumonidae) / Danielle Thomazoni.- - Piracicaba, 2012.

122 p: il.

Tese (Doutorado) - - Escola Superior de Agricultura "Luiz de Queiroz", 2012.

1. Inseticidas piretróides 2. Insetos parasitóides 3. Lagartas - Resistência 4. Milho 5. Manejo integrado 6. Plantas transgênicas I. Título

CDD 633.15

T465e 


\title{
A Deus,
}

Pelo dom da vida, pelas oportunidades e proteção durante toda minha caminhada

\section{AGRADEÇO}

Aos meus amados pais, Aristeu e Eni Thomazoni,

Exemplos de dedicação, incentivo, amor, carinho e paciência

\author{
Carinhosamente
}

\section{DEDICO}

Aos meus irmãos, Dhyego e Thyago Thomazoni,

Pelo amor sincero, amizade, ajuda, preocupação, incentivo e paciência Ao meu noivo, Miguel Ferreira Soria

Pelo amor, auxílio, incentivo, companheirismo, carinho, preocupação e paciência

\section{OFEREÇO}




\section{AGRADECIMENTOS}

A Deus por ser minha fortaleza e refúgio, presença constante em todos os momentos de minha vida.

À minha família, meus pais e irmãos, minha querida Tia Veni, e ao meu noivo Miguel, que nunca desistiram de acreditar em mim e sempre estiveram presente me fortalecendo.

Ao Professor Celso Omoto pela orientação, oportunidades e ensinamentos transmitidos durante o período do curso.

Ao Professor Fernando Luís Cônsoli, pelo espaço concedido para execução dos bioensaios no Laboratório de Interações em Insetos (ESALQ/USP), pela orientação, oportunidades e ensinamentos transmitidos durantes o período do curso.

A todos os professores do Departamento de Entomologia e Acarologia da Escola Superior de Agricultura "Luiz de Queiroz", pelos ensinamentos transmitidos ao longo do período do curso.

À Dra. Anne-Nathalie Volkoff, pela amizade, compreensão, orientação, preocupação, paciência, dedicação e agradável companhia durante o período de realização do meu estágio de Doutoramento na Université Montpellier II (Sciences et Techniques)-INRA, Montpellier, França.

Ao Eng. Agrônomo Paulo Edimar Saran pela coleta e envio de lagartas parasitadas da região de Luís Eduardo Magalhães-BA.

Ao Dr. Valmir Antonio Costa do Instituto Biológico de Campinas (IBCB), pelo auxílio prestado no início da identificação e criação do parasitoide Campoletis aff. flavicincta.

À Dra. Angelica Penteado Dias da Universidade Federal de São Carlos (UFSCAR) pela dedicação na identificação do parasitoide Campoletis aff. flavicincta.

Ao pesquisador e Entomologista Dr. Pierre Jean Silvie (IRD/CIRAD), pela amizade e orientação durante todos esses anos de caminhada profissional. 
Ao Professor Paulo Eduardo Degrande da Universidade Federal da Grande Dourados (UFGD) pelo incentivo e orientação durante minha caminhada profissional.

À Coordenação de Aperfeiçoamento de Pessoal de Nível Superior (CAPES) pela concessão da bolsa de estudos.

A todos os colegas do Laboratório de Resistência de Artrópodes a Táticas de Controle da ESALQ/USP: Karina Cordeiro Albernaz, Patrick Marques Dourado, Oderlei Bernardi, Alex Sandro Poltronieri, Oscar Arnaldo Batista Neto, Everaldo Batista Alves, Pablo Fresia, Rodrigo José Sorgatto, Daniel Bernardi, Felipe Antônio Domingues, e em especial à Nádia Fernanda Bertan Casarin, Beatriz Maria Ferrari, José Bruno Malaquias, Edgar Francisco Gaona Mena, Vítor Antonio Correa Pavinatto, Dariane Sagasetta de Souza e Juliano Ricardo Farias, pela sincera amizade, pelos momentos de convívio, excelente companhia e auxílio prestados.

Aos técnicos e funcionários do Laboratório de Resistência de Artrópodes a Táticas de Controle (ESALQ/USP): Eloísa Salmeron, Luís Ricardo Sesso, e em especial à Gislaine A. Campos pelos auxílios prestados, amizade, convivência e sábias palavras nos momentos que mais precisei.

Aos estagiários do Laboratório de Resistência de Artrópodes a Táticas de Controle: Karen Komada, Guilherme Libardi Miraldo, Ricardo Ferraz Silveira, Dalton Campacci Pavan, Alexander Onishi, Rebeca da Silva Ribeiro, Bruna Laís Merlin, Vitória Grisotto, Isabella Magnetti Dal Pozzo, Renato Jun Horikoshi e Vinícius Durrer pela amizade, excelente convivência, auxílios prestados, momentos de lazer e presença nos momentos difíceis e alegres.

Aos colegas e agregados do Laboratório de Interações em Insetos (ESALQ/USP): Priscila Fortes, Fernanda Appel Müller, Fábio Cleisto Dossi, Aline Peruchi, Amanda Rodrigues de Souza, Jaci Mendes, Patrícia Milano, Amanda Oliveira, Helen Breyer, Luís Gustavo de Almeida, Tiago Zucchi, Karina Lucas Brandão, Simone de Souza Prado e Aline Sartori Guidolin, pela amizade, agradável convivência e auxílios prestados, e em especial ao colega Guilherme Duarte Rossi pela amizade e grande auxílio prestado na condução dos experimentos. 
A todos os colegas da Pós-graduação em Entomologia (ESALQ/USP), em especial à minha querida e dedicada amiga: Ana Beatriz Riguetti Zanardo, pela sincera amizade, convívio, incentivo, momentos de alegria e de tristeza, paciência e preocupação.

Às bibliotecárias Eliana Maria Garcia e Silvia Maria Zinsly da Biblioteca Central (ESALQ/USP), pelo auxílio na formatação deste trabalho.

Aos colegas, amigos (as), funcionários do DGIMI (Diversité, Génomes et interactions microorganismes-insectes), Equipe: Biologie Intégrative des Interactions Hôte/Parasitoïdes da Université Montpellier II (Sciences et Techniques)-INRA, Montpellier, França: Amélie Moulin, Iméne Seninet, Cecília Multeau, Véronique, Pascaline Dumas, Fanny, Tristan Doremus, Gabriel Clavijo, Clotilde, Doriane Mutuel, Sylvie Gimenez, Laure, Aurélie, Yuan Wang, Dr. Phillipe Fournier, Dr. Patrick Taillez, Dr. Phillipe Claire, Dra. Milene, Dr. JéanMichel e Magali, pela bela amizade, momentos de trabalho e de lazer, companheirismo e dedicação, e em especial à Gabriel Clavijo e Dr. Phillipe Claire, pelos ensinamentos com o PCR em tempo real. Merci beaucoup!

À minha querida e dedicada professora de Língua Francesa: Ana Paula Ferreira pela amizade, dedicação e ensinamentos transmitidos.

Às minhas queridas amigas: Jessika Anne Gomes de Alencar, Carolina Piccinin Borges, Marília Zilli, Fernanda Michelon, Mayara Rodrigues e Greicy Sigaki, que mesmo longe sempre estiveram comigo me incentivando.

A todos aqueles que direta ou indiretamente estiveram comigo durante esta etapa profissional, presente ou distante, os meus sinceros agradecimentos! 
"Há um tempo em que é preciso abandonar as roupas usadas, que já tem a forma do nosso corpo, e esquecer os nossos caminhos, que nos levam sempre aos mesmos lugares. É o tempo da travessia, e se não ousarmos fazê-la, teremos ficado para sempre à margem de nós mesmos."

Fernando Pessoa 


\section{SUMÁRIO}

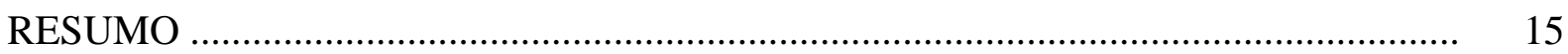

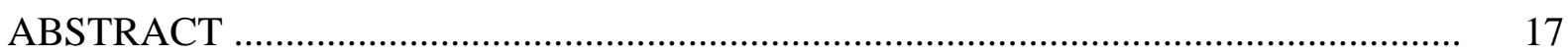

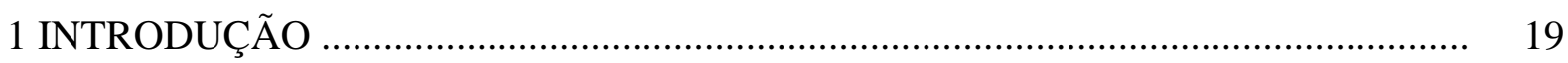

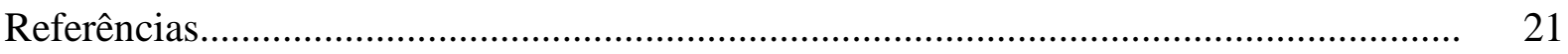

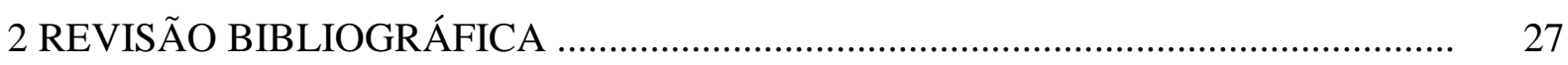

2.1 Resistência de $S$. frugiperda a inseticidas na cultura do milho................................... 27

2.2 Milho geneticamente modificado resistente a insetos no manejo integrado de pragas (MIP).

2.3 Efeito do milho geneticamente modificado resistente a insetos sobre inimigos naturais

2.4 Implicações do custo adaptativo associado à resistência a inseticidas na resposta imunológica de insetos

Referências.

3 CUSTOS ADAPTATIVOS EM Spodoptera frugiperda (J. E. Smith, 1797) (LEPIDOPTERA: NOCTUIDAE) ASSOCIADOS À RESISTÊNCIA A LAMBDACYHALOTHRIN E IMPLICAÇÕES DA INTERAÇÃO COM MILHO GENETICAMENTE MODIFICADO (MON810) NO PARASITISMO POR Campoletis aff. flavicincta (HYMENOPTERA: ICHNEUMONIDAE)......................................... 51



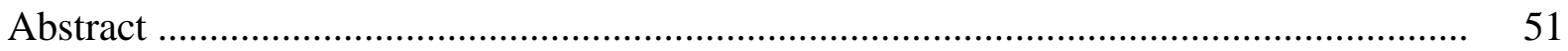

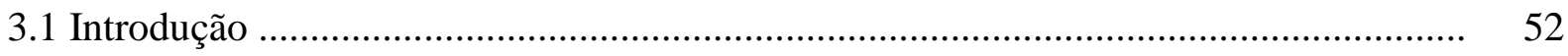



3.2.1 Linhagens de $S$. frugiperda suscetível e resistente a lambda-cyhalothrin................. 53

3.2.2 Obtenção e estabelecimento da criação de Campoletis aff. flavicincta...................... 54

3.2.3 Biologia de $S$. frugiperda suscetível e resistente a lambda-cyhalothrin.................... 54

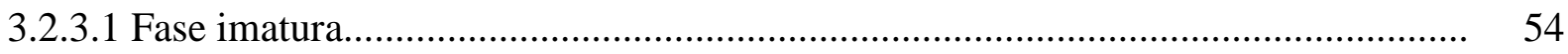

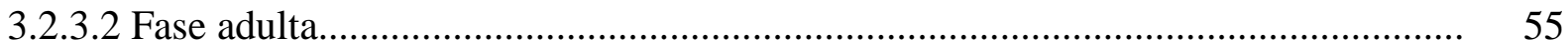

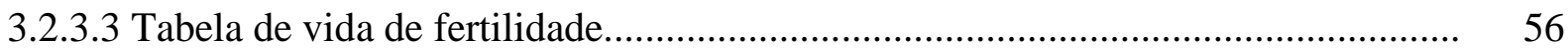

3.2.4 Biologia e parasitismo de Campoletis aff. flavicincta em linhagens de $S$. frugiperda suscetível e resistente a lambda-cyhalothrin............................................... 57

3.2.4.1 Desenvolvimento e morfologia dos imaturos................................................... 57 
3.2.4.2 Aceitação de $S$. frugiperda por Campoletis aff. flavicincta.....

3.2.4.3 Parasitismo por Campoletis aff. flavicincta após interação de S. frugiperda com milho Bt.

3.3 Resultados.

3.3.1 Biologia de $S$. frugiperda suscetível e resistente a lambda-cyhalothrin.

3.3.2 Tabela de vida de fertilidade de linhagens de $S$. frugiperda suscetível e resistente a lambda-cyhalothrin

3.3.3 Biologia e parasitismo de Campoletis aff. flavicincta em linhagens de $S$.

frugiperda suscetível e resistente a lambda-cyhalothrin.

3.3.3.1 Desenvolvimento e morfologia das fases imaturas.

3.3.3.2 Aceitação de $S$. frugiperda por Campoletis aff. flavicincta......

3.3.3.3 Interação do milho geneticamente modificado (MON810) e do parasitoide Campoletis aff. flavicincta

3.4 Discussão.

3.5 Conclusões

Referências

4 EFEITO DA RESISTÊNCIA DE Spodoptera frugiperda (J. E. Smith, 1797) (LEPIDOPTERA: NOCTUIDAE) A LAMBDA-CYHALOTHRIN NA EXPRESSÃO DE GENES RELACIONADOS AO METABOLISMO E RESPOSTA IMUNOLÓGICA AO PARASITISMO POR Campoletis aff. flavicincta (HYMENOPTERA: ICHNEUMONIDAE).

Resumo.

Abstract.

4.1 Introdução...

4.2 Material e Métodos.

4.2.1 Linhagens e criação de S. frugiperda e de Campoletis aff. flavicincta.

4.2.2 Coleta das amostras para extração de RNA......

4.2.3 Extração de RNA.

4.2.4 Transcrição reversa.

4.2.5 Quantificação de transcritos por PCR em tempo real.

4.3.1 Efeito da resistência a lambda-cyhalothrin na expressão de genes relacionados ao metabolismo e resposta imuonlógica de S. fugiperda na ausência e presença do 
parasitismo por Campoletis aff. flavicincta............................................................... 88

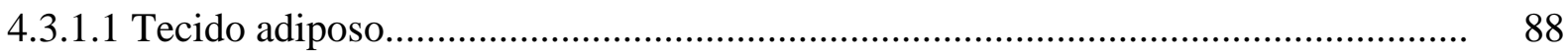

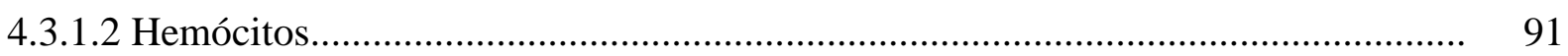

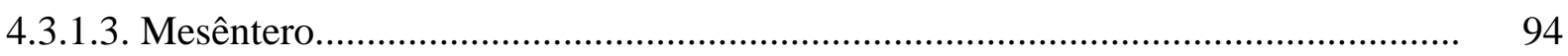

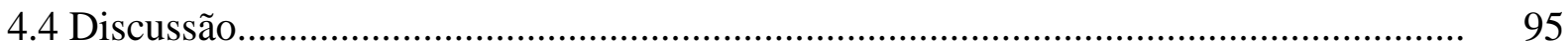

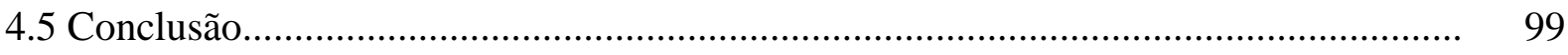

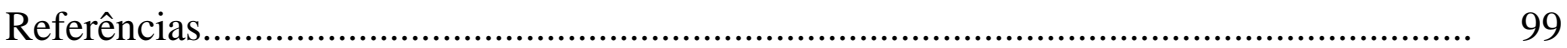

5 EFEITO DA RESISTÊNCIA A LAMBDA-CYHALOTHRIN NA RESPOSTA IMUNOLÓGICA DE Spodoptera frugiperda (J. E. Smith, 1797) (LEPIDOPTERA: NOCTUIDAE) AO PARASITISMO POR Campoletis aff. flavicincta (HYMENOPTERA: ICHNEUMONIDAE)............................................................ 107

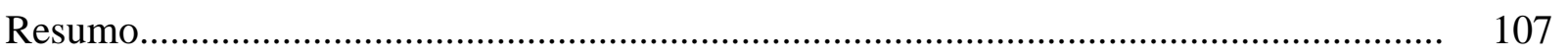

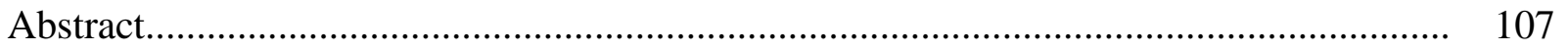

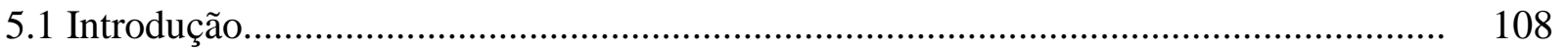

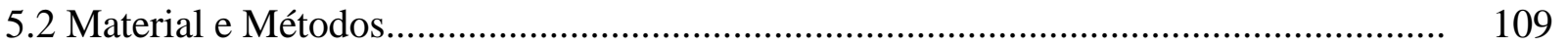

5.2.1 Efeito da resistência a lambda-cyhalothrin na resposta imunológica celular e humoral de S. frugiperda na ausência e presença do parasitismo por Campoletis aff.



5.2.2 Resposta celular - Contagem total do número de hemócitos.................................. 110

5.2.3 Resposta humoral - Atividade das fenoloxidases (PO) ........................................ 110

5.2.4 Resposta humoral - Concentração de óxido nítrico (NO) ......................................... 111

5.2.5 Resposta humoral - Atividade antimicrobiana.................................................... 112

5.2.6 Resposta humoral - Atividade lisozimática........................................................ 113

5.2.7 Análise Estatística......................................................................................... 113

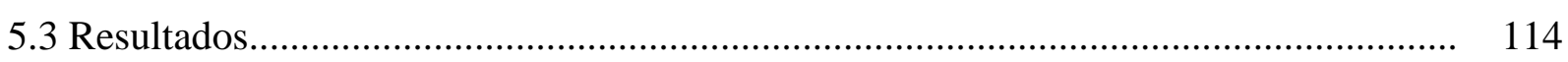

5.3.1 Ausência do parasitismo por Campoletis aff. flavicincta ........................................ 114

5.3.2 Presença do parasitismo por Campoletis aff. flavicincta ......................................... 115

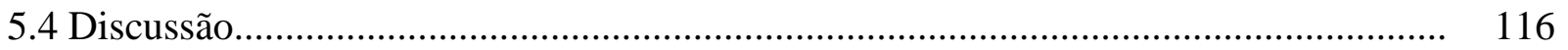



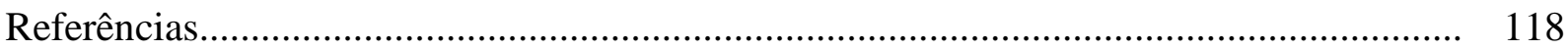




\section{RESUMO \\ Efeito da resistência de Spodoptera frugiperda (J.E. Smith, 1797) (Lepidoptera: Noctuidae) a lambda-cyhalothrin na interação com milho geneticamente modificado (MON810) e na resposta imunológica ao parasitismo por Campoletis aff. flavicincta (Hymenoptera: Ichneumonidae)}

Os custos adaptativos associados à resistência de insetos a inseticidas podem ser explorados mediante a integração com outras estratégias de controle de pragas em programas de Manejo Integrado de Pragas (MIP). No presente estudo, objetivou-se verificar custos adaptativos associados à resistência de Spodoptera frugiperda (J. E. Smith) (Lepidoptera: Noctuidae) ao inseticida piretroide lambda-cyhalothrin e suas implicações na utilização do hospedeiro pelo parasitoide larval Campoletis aff. flavicincta (Hymenoptera: Ichneumonidae) e as interações com milho geneticamente modificado (MON810) que expressa a proteína Cry1Ab de Bacillus thuringiensis Berliner (milho Bt) e na resposta imunológica ao parasitismo por Campoletis aff. flavicincta. Foram verificados presença de custos adaptativos associados à resistência de $S$. frugiperda a lambda-cyhalothrin, dado o prolongamento no desenvolvimento larval e duração pupal, redução do peso de pupas fêmeas e longevidade das fêmeas, razão sexual, taxa líquida de reprodução $(R o)$, taxa intrínseca de aumento $(\mathrm{rm})$ e taxa finita de aumento $(\lambda)$ de insetos resistentes ao inseticida. Não foi verificada diferença na aceitação de lagartas de $S$. frugiperda suscetível e resistente a lambda-cyhalothrin por Campoletis aff. flavicincta. Entretanto, o parasitismo de lagartas resistentes foi maior que de suscetíveis em estudos de gaiolas com milho Bt e não-Bt. Posteriormente, foram conduzidos estudos para avaliar, por PCR em tempo real, a expressão diferencial de genes associados ao metabolismo (proteína rica em metionina), resposta imunológica (calreticulina, lisozima, colágeno IV-2, hemócito protease-3, serina protease, imunolectina, receptor "scavenger" classe C) e detoxificação de xenobióticos (glutationa-S-transferase 145 e as monoxigenases P450 Cyp9A31 e Cyp333B2) expressos em diferentes tecidos (tecido adiposo, hemócitos e/ou mesêntero), na ausência e presença de parasitismo de lagartas das duas linhagens de $S$. frugiperda por Campoletis aff. flavicincta. No geral, a expressão gênica em lagartas suscetíveis foi superior àquela de lagartas resistentes a lambda-cyhalothrin, independente do período de desenvolvimento, do tecido avaliado e da presença ou não do parasitismo por Campoletis aff. flavicincta. E por fim, foram conduzidos estudos para avaliar o efeito da resistência de $S$. frugiperda a lambda-cyhalothrin nas respostas imunológica celular (contagem total de hemócitos) e humoral (atividade das fenoloxidases, lisozimática e antimicrobiana e concentração de óxido nítrico) de lagartas, tanto na ausência como na presença do parasitismo por Campoletis aff. flavicincta. A resistência de $S$. frugiperda a lambda-cyhalothrin induziu somente a pequenas alterações no sistema imunológico do hospedeiro (aumento do número total de hemócitos, redução da atividade antimicrobiana e aumento da atividade lisozimática), as quais não interferem a ponto de resultar em custos adaptativos que leve à maior exploração de lagartas resistentes na presença do parasitismo por Campoletis aff. flavicincta. Portanto, o manejo de S. frugiperda mediante o emprego da tecnologia de milho Bt e do controle biológico via parasitoide Campoletis aff. flavicincta pode favorecer o restabelecimento da suscetibilidade de $S$. frugiperda a lambda-cyhalothrin.

Palavras-chave: Resistência a inseticidas; Milho Bt; Resposta imunológica; Custo adaptativo; Lagarta-do-cartucho 


\begin{abstract}
Effect of resistance of Spodoptera frugiperda (J.E. Smith, 1797) (Lepidoptera: Noctuidae) to lambda-cyhalothrin on the interaction with genetically modified maize (MON810) and the immune response to parasitization by Campoletis aff. flavicincta (Hymenoptera: Ichneumonidae)
\end{abstract}

Fitness costs of insect resistance to insecticides can be exploited by integrating other pest control strategies in Integrated Pest Management (IPM) programs. The objective of this research was to evaluate the existence of fitness costs associated with the resistance of Spodoptera frugiperda (J. E. Smith) (Lepidoptera: Noctuidae) to the pyrethroid insecticide lambda-cyhalothrin and their implications for host use by the larval parasitoid Campoletis aff. flavicincta (Hymenoptera: Ichneumonidae) and interactions with the genetically modified maize (MON810) that expresses Cry1 Ab toxin of Bacillus thuringiensis Berliner (Bt maize) and in the immune response to parasitization by Campoletis aff. flavicincta. Fitness costs associated to resistance of $S$. frugiperda to lambda-cyhalothrin were detected by the delay in larval and pupal development, reduction in the pupal weight and longevity of females, sex ratio, net reproductive rate $(R o)$, intrinsic rate of natural increase $\left(r_{m}\right)$ and the finite rate of increase $(\lambda)$. No differences were detected in host acceptance and survival of Campoletis aff. flavicincta in susceptible and lambda-cyhalothrin-resistant larvae of $S$. frugiperda. However, larval parasitization was higher on the resistant than on the susceptible strain of $S$. frugiperda in cage studies with Bt and non-Bt maize plants. Then, studies were conducted by using Real time-PCR to evaluate the differential expression of genes associated with metabolism (methionine-rich protein), immune response (calreticulin, lysozyme, collagen IV-2, protease-3 hemocyte, serine protease, immunolectin, scavenger receptor class C) and xenobiotic detoxification (glutathione-S-transferase 145 and P450 monooxygenases Cyp9A31 and Cyp333B2) expressed in different tissues (fat body, hemocytes and/or midgut), in the absence and presence of larval parasitization of both strains of $S$. frugiperda by Campoletis aff. flavicincta. Overall, gene expression in susceptible larvae was higher than that of lambdacyhalothrin-resistant larvae, regardless of the period of development, tissue evaluated and presence or not of parasitization by Campoletis aff. flavicincta. Finally, studies were conducted to evaluate the effect of the resistance of $S$. frugiperda to lambda-cyhalothrin on cellular (total hemocyte count) and humoral (phenoloxidases, lysozyme and antimicrobial activities and nitric oxide concentration) immune responses in the absence or presence of parasitization by Campoletis aff. flavicincta. The resistance of $S$. frugiperda to lambdacyhalothrin conferred only minor changes in the host immune system (increased total hemocyte count, reduced antimicrobial activity and increased lysozyme activity), which may not interfere with fitness costs leading to higher exploitation of resistant larvae in the presence of parasitization by Campoletis aff. flavicincta. Therefore, the management of $S$. frugiperda by using the Bt maize technology and the biological control via parasitoid Campoletis aff. flavicincta can favor the resetting to susceptibility of $S$. frugiperda to lambda-cyhalothrin.

Keywords: Insecticide resistance; Bt maize; Immune response; Fitness costs; Fall armyworm 


\section{INTRODUÇÃO}

A evolução da resistência a inseticidas em Spodoptera frugiperda (J. E. Smith) (Lepidoptera: Noctuidae) ameaça a eficiência de seu controle e compromete o Manejo Integrado de Pragas (MIP) em diversas culturas. A resistência deste lepidóptero ao piretroide lambda-cyhalothrin no Brasil (DIEZ-RODRÍGUEZ; OMOTO, 2001) e a inseticidas de outros grupos químicos em outros países (YU, 1991; RÍOS-DÍEZ; SALDAMANDO-BENJUMEA, 2011) já tem sido documentada. No Brasil, este fato é agravado em regiões onde se cultiva o milho durante todo o ano, proporcionando condições para intensa pressão de seleção de indivíduos resistentes com os inseticidas aplicados para o controle dessa praga.

O uso de táticas de controle alternativas para S. frugiperda como híbridos de milho geneticamente modificado (GM) resistentes a insetos-praga que expressam proteínas da bactéria Bacillus thuringiensis Berliner (milho Bt) (BUNTIN et al., 2001; BOKONONGANTA et al., 2003; BUNTIN et al., 2004; CHILCUTT et al., 2007) pode contribuir para o retardamento da evolução da resistência de insetos a inseticidas. A adoção dessa nova tecnologia pode reduzir a pressão de seleção com inseticidas e possibilitar a reversão para a suscetibilidade, seja pela presença de custo adaptativo associado à resistência ou pela imigração de genótipos suscetíveis da praga (GEORGHIOU, 1972; ROUSH; McKENZIE, 1987; GEORGHIOU; TAYLOR, 1977).

No Brasil, a liberação comercial dos eventos MON810 e Bt11, que expressam a proteína Cry1 $\mathrm{Ab}$ de $B$. thuringiensis, foi aprovada pela Comissão Técnica Nacional de Biossegurança (CTNBio) em 2007 e 2008, respectivamente (CTNBio, 2007, 2008). No entanto, o uso destas variedades apresenta o fato da constatação de atividade de controle moderada da proteína Cry1Ab sobre S. frugiperda (WILLIAMS et al., 1997; LYNCH et al., 1999; BURKNESS et al., 2001, 2002; FERNANDES et al., 2003; MENDES et al., 2011), não atendendo o conceito de alta dose, ou seja, da concentração da proteína expressa na planta Bt necessária que garanta a mortalidade de heterozigotos resultantes do cruzamento de indivíduos resistentes da área de milho Bt com indivíduos suscetíveis da área de refúgio (milho não-Bt), que tem sido a base para o Manejo da Resistência de Insetos (MRI) em culturas Bt (GASSMANN et al., 2009).

Neste contexto, a constatação de efeito moderado da proteína Cry1Ab expressa em milho $\mathrm{Bt}$ ocasionando o retardamento do desenvolvimento larval de $S$. frugiperda (WILLIAMS et al., 1997; FERNANDES et al., 2003; MENDES et al., 2011) pode proporcionar maior exposição da lagarta à ação de seus inimigos naturais (VENDRAMIM, 
1990; SIMS; FRITZ, 1990; ODE, 2006), os quais poderão utilizar-se da redução de vigor, mobilidade e desenvolvimento (MUSSER et al., 2006; ROSE; DIVELY, 2007) da praga, ou mesmo de alterações em condições fisiológicas, como a inibição do sistema imunológico (GASSMANN et al., 2009), potencializando o controle de $S$. frugiperda em milho Bt, diante da possibilidade de alteração de suscetibilidade ao agente de controle natural (RAMIREZROMERO et al., 2007; SANDERS et al., 2007; SHARMA et al, 2008). Em casos em que a exploração do hospedeiro por inimigos naturais é beneficiada pela existência de custos adaptativos (FOSTER et al., 2005), o controle biológico natural pode contribuir para diluição dos alelos de resistência na população e, consequentemente, para o retardamento da evolução da resistência (GOUSE et al., 2006; GASSMANN et al., 2009).

O conhecimento da resposta imunológica celular e humoral em lagartas suscetíveis e resistentes a um determinado inseticida, pode afetar a aptidão biológica do inseto resistente e influenciar o desenvolvimento e aplicação de táticas de manejo de resistência de S. frugiperda a inseticidas, através do maior sucesso esperado na exploração do hospedeiro pelo parasitoide, dada à redução da capacidade de resposta imunológica de lagartas de S. frugiperda resistentes, devido aos custos associados à resistência, contribuindo na diluição de alelos de resistência na população, promovendo o retardamento da evolução da resistência até mesmo reversão de suscetibilidade ao inseticida aplicado (WU et al., 2005), e ainda alteração da suscetibilidade de lagartas resistentes a inimigos naturais (IQBAL; WRIGHT, 1996; BOIVIN et al., 2001; PATHAN et al., 2010; FOSTER et al., 2011).

O conhecimento da expressão de genes que possam estar envolvidos nesta resposta de defesa e no metabolismo de $S$. frugiperda suscetíveis e resistentes a xenobióticos (FEYEREISEN, 1999; BARAT-HOUARI et al., 2006), podem fornecer informações para estudos futuros sobre os mecanismos moleculares responsáveis pela regulação gênica de custos adaptativos associados à resistência e caracterização da resistência a piretroides em $S$. frugiperda (SASABE et al., 2004), já que a resistência de lepidópteros a piretroides é decorrente de mutações nos canais de sódio (DONG, 2007), e se apresenta através de mecanismos como a redução da sensibilidade do sítio-alvo de ação do inseticida ou aumento da detoxificação metabólica (SCHULER et al., 1998; HECKEL, 2009) o que pode alterar a fisiologia do inseto devido à existência de custos adaptativos, podendo resultar na alteração do padrão diferencial de expressão de genes entre suscetíveis e resistentes ao piretroide (COSTAU et al., 2000; TAYLOR; FEYEREISEN, 1996), que estejam relacionados a diferentes processos fisiológicos, os quais resultam em modificações na aptidão biológica do inseto, influenciando consequentemente o desenvolvimento de programas de manejo da 
resistência deste inseto ao controle químico, promovendo sua interação com o controle biológico e o uso de milho Bt (NARANJO, 2009).

Diante do exposto, o presente trabalho foi desenvolvido para verificar possíveis efeitos da resistência de $S$. frugiperda ao piretroide lambda-cyhalothrin na interação com milho geneticamente modificado (MON810) e na resposta imunológica ao parasitismo por Campoletis aff. flavicincta (Hymenoptera: Ichneumonidae) para:

- Verificar a existência de custos adaptativos associados à resistência de $S$. frugiperda ao inseticida lambda-cyhalothrin e suas implicações na interação com milho Bt no desenvolvimento e eficiência de parasitismo por Campoletis aff. flavicincta;

- Verificar o efeito da resistência a lambda-cyhalothrin na resposta imunológica celular e humoral de $S$. frugiperda suscetíveis e resistentes ao piretroide em diferentes estágios de desenvolvimento larval, sob as condições de ausência e presença do parasitismo por Campoletis aff. flavicincta;

- Avaliar o efeito da resistência de $S$. frugiperda a lambda-cyhalothrin no padrão de expressão de genes candidatos envolvidos na resposta imunológica e metabolismo de S. frugiperda, na ausência e presença do parasitismo por Campoletis aff. flavicincta, via análise comparativa de vários genes candidatos em diferentes tecidos e tempo de desenvolvimento de linhagens de $S$. frugiperda suscetível e resistente a este produto.

\section{Referências}

BARAT-HOUARI, M.; HILLIOU, F.; JOUSSET, F-X; SOFER, S.; DELEURY, E.; ROCHER, J.; RAVALLEC, M.; GALIBERT, L.; DELOBEL, P.; FEYEREISEN, R.; FOURNIER, P.; VOLKOFF, A. N. Gene expression profiling of Spodotera frugiperda hemocytes and fat body using cDNA microarray reveals polydnavirus-associated variations in lepidopteran host genes transcript levels. BMC Genomics, London, v. 7, p. 1-20, 2006.

BOIVIN, T.; D'HIÉRES, C. C.; BOUVIER, J. C.; BESLAY, D.; SAUPHANOR, B. Pleiotropic of insecticide resistance in the codling moth, Cydia pomonella. Entomologia Experimentalis et Applicata, Dodrecht, v. 99, p. 381-386, 2001.

BOKONON-GANTA, A.H.; BERNAL, J.S.; PIETRANTONIO, P.V.; SÉTAMOU, M. Survivorship and development of fall armyworm, Spodoptera frugiperda (J. E. Smith) (Lepidoptera: Noctuidae), on conventional and transgenic maize cultivars expressing Bacillus thuringiensis Cry9C and Cry1A(b) endotoxins. International Journal of Pest Management, London, v. 49, n. 2, p. 169-175, 2003. 
BUNTIN, G.D.; LEE, R.D.; WILSON, D.M.; McPHERSON, R.M. Evaluation of Yieldgard transgenic resistance for control of fall armyworm and corn earworm (Lepidoptera: Noctuidae) in corn. Florida Entomologist, Gainesville, v. 84, n. 1, p. 37-42, 2001.

BUNTIN, G.D.; FLANDERS, K.L.; LYNCH, R.E. Assessment of experimental Bt events against fall armyworm and corn earworm (Lepidoptera: Noctuidae) in corn. Journal of Economic Entomology, Lanham, v. 97, n. 2, p. 259-264, 2004.

BURKNESS, E.C.; HUTCHISON, H.C.; BOLIN, P.C.; BARTELS, D.W.; WARNOK, D.F.; DAVIS, D.W. Field efficacy of sweet corn hybrids expressing a Bacillus thuringiensis for management of Ostrinia nubilalis (Lepidoptera: Crambidae) and Helicoverpa zea (Lepidoptera: Noctuidae). Journal of Economic Entomology, Lanham, v. 94, p. 197-203, 2001.

BURKNESS, E.C; HUTCHISON, H.C.; WEINZIERL, R.A.; WEDBERG, J.L.; WOLD, S.J.; SHAW, J.T. Efficacy and risk of sweet corn hybrids expressing a Bacilllus thuringiensis toxin for lepidopteran pest management in the Midwestern US. Crop Protection, Guildford, v. 21, p. 157-169, 2002.

CHILCUTT, C.F.; ODVODY, G.N.; CORREA, J.C.; REMMERS, J. Effects of Bacillus thuringiensis transgenic corn on corn earworm and fall armyworm (Lepidoptera: Noctuidae) densities. Journal of Economic Entomology, Lanham, v. 100, n. 2, p. 327-334, 2007.

COMISSÃO TÉCNICA NACIONAL DE BIOSSEGURANÇA. Liberação comercial de milho geneticamente modificado. Brasília: Ministério da Ciência e Tecnologia, CTNBio, 2007. 19 p. (Parecer Técnico, 1100/2007).

Liberação comercial de milho geneticamente modificado. Brasília: Ministério da Ciência e Tecnologia, CTNBio, 2008. 24 p. (Parecer Técnico, 1255/2008).

COUSTAU, C.; CHEVILLON, C.; FRENCH-CONSTANT, R. Resistance to xenobiotics and parasites: can we count the cost? Trends in Ecology and Evolution, Amsterdam, v. 15, p. 378-383, 2000.

DIEZ-RODRÍGUEZ, G.I.; OMOTO, C. Herança da resistência de Spodoptera frugiperda (J.E. Smith) (Lepidoptera: Noctuidae) a Lambda-Cialotrina. Neotropical Entomology, Londrina, v. 30, n. 2, p. 311-316, 2001.

DONG, K. Insect sodium channels and insecticide resistance. Invertebrate Neuroscience, Heidelberg, v. 7, p. 17-30, 2007.

FERNANDES, O.D.; PARRA, J.R.P.; NETO, A.F.; PÍCOLI, R.; BORGATTO, A.F.; DEMÉTRIO, C.G.B. Efeito do milho geneticamente modificado MON810 sobre a lagarta-docartucho Spodoptera frugiperda (J.E. Smith, 1797) (Lepidoptera: Noctuidae). Revista Brasileira de Milho e Sorgo, Sete Lagoas, v. 2, p. 25-35, 2003.

FEYEREISEN, R. Insect P450 enzymes. Annual Review of Entomology, Stanford, v. 44, p. 507-533, 1999. 
FOSTER, S. P.; DENHOLM, I.; THOMPSON, R.;POPPY, G. M.;POWELL, W. Reduced response of insecticide resistant aphids and attraction of parasitoids to aphid alarm pheromone; a potential fitness trade-off. Bulletin of Entomological Research, Farnham Royal, v. 95: 37-46, 2005.

FOSTER, S.P.; DENHOLM, I.; POPPY, G.M.; THOMPSON, R.; POWELL, W. Fitness trade-off in peach-potato aphids (Myzus persicae) between insecticide resistance and vulnerability to parasitoid attack at several spatial scales. Bulletin of Entomological Research, Farnham Royal, v. 101, p. 659-666, 2011.

GASSMANN, A.J.; CARRIÉRE, Y.; TABASHNIK, B.E. Fitness costs of insect resistance to Bacillus thuringiensis. Annual Review of Entomololgy, Stanford, v. 54, p. 147-163, 2009.

GASSMANN, A. J.; JEFFREY, A. F.; SISTERSON, M. S.; HANNON, E. R.; STOCK, P. S.; CARRIÉRE, Y.; TABASHNIK, B. E. Effects of pink bollworm resistance to Bacillus thuringiensis on phenoloxidase activity and susceptibility to entomopathogenic nematodes.

Journal of Economic Entomology, Lanham, v. 102, p. 1224-1232, 2009.

GEORGHIOU, G.P. The evolution of resistance to pesticide. Annual Review of Ecological System, Stanford, v. 3, p. 133-168, 1972.

GEORGHIOU, G.P.; TAYLOR, C.E. Genetic and biological influences in the evolution of insecticide resistance. Journal of Economic Entomology, Lanham, v. 70, p. 319-323, 1977.

GOUSE, M.; PRAY, C.; SHIMMELPFENNIG, D.; KIRSTEN, J. Three seasons of subsistence insect-resistant maize in South Africa: have smallholders benefited?

AgBioforum, Columbia, v. 9, p. 15-22, 2006.

HECKEL, D.G. Molecular genetics of insecticide resistance in Lepidoptera. In. Molecular biology and genetics of Lepidoptera. London: CRC Publ., 2009. p. 239-269.

IQBAL, M.; WRIGHT, D. Host resistance to insecticides can confer protection to endo-larval parasitoids. Bulletin of Entomological Research, Farnham Royal, v. 86, p. 721-723, 1996.

LYNCH, R.E.; WISEMAN, B.R.; PLAINSTED, D.; WARNIK, D. Evaluation of transgenic sweet corn hybrids expressing Cry1Ab toxin for resistance to corn earworm and fall armyworm. Journal of Economic Entomology, Lanham, v. 92, p. 246-252, 1999.

MENDES, S.M.; BOREGAS, K.G.B.; LOPES, M.E.; WAQUIL, M.S.; WAQUIL, J.M. Respostas da lagarta-do-cartucho a milho geneticamente modificado expressando a toxina Cry 1A(b). Pesquisa Agropecuária Brasileira, Brasília, v. 46, p. 239-244, 2011.

MUSSER, F. R.; NYROP, J. P.; SHELTON, A. M. Integrating biological and chemical controls in decision making: European corn borer (Lepidoptera: Crambidae) control in sweet corn as an example. Journal of Economic Entomology, Lanham, v. 55, p. 1538-1549, 2006.

NARANJO, S.E. Impacts of Bt crops on non-target invertebrates and insecticide use patterns. CAB reviews: Perspectives in Agriculture, Veterinary Science, Nutrition and Natural Resources, Warsaw, v. 4, p. 1-23, 2009. 
ODE, P.J. Plant chemistry and natural enemy fitness: effects on herbivore and natural enemy interactions. Annual Review of Entomology, Stanford, v. 51, p. 163-185, 2006.

PATHAN, A. K.; SAYYED, A. H.; ASLAM, M.; LIU, T. X.; RAZZAQ, M.; GILLANI, W. A. Resistance to pyrethroids and organophosphates increased fitness and predation potential of Chrysoperla carnae (Neuroptera: Chrysopidae). Journal of Economic Entomology, Lanham, v. 103, p. 823-834, 2010.

RAMIREZ-ROMERO, R.; BERNAL, J. S.; CHAUFAUX, J.; KAISER. L. Impact assessment of Bt-maize on a moth parasitoid, Cotesia marginiventris (Hymenoptera: Braconidae), via host exposure to purified Cry1 Ab protein or Bt-plants. Crop Protection, Guildford, v. 26, p. 953-962, 2007.

RÍOS-DÍEZ, J.D.; SALDAMANDO-BENJUMEA, C.I. Susceptibility of Spodoptera frugiperda (Lepidoptera: Noctuidae) strains from Central Colombia to two insecticides, Methomyl and Lambda-Cyhalothrin: a study of the genetic basis of resistance. Journal of Economic Entomology, Lanham, v. 104, p. 1698-1705, 2011.

ROUSH, R.T.; McKENZIE, J.A. Ecological genetics of insecticide and acaricide resistance. Annual Review of Entomololgy, Stanford, v. 32, p. 361-380, 1987.

ROSE, R.; DIVELY, G. P. Effects of insecticide-treated and lepidopteran-active Bt-transgenic sweet corn on the abundance and diversity of arthropods. Environmental Entomology, College Park, v. 36, p. 1254-1268, 2007.

ROUSH, R.T.; McKENZIE, J.A.. Ecological genetics of insecticide and acaricide resistance. Annual Review of Entomololgy, Stanford, v. 32, p. 361-380, 1987.

SANDERS, C.J.; PELL, J.K.; POPPY, G.M.; RAYBOULD, A.; GARCIA-ALONSO, M.; SCHULER, T.H. Host-plant mediated effects of transgenic maize on the insect parasitoid Campoletis sonorensis (Hymenoptera: Ichneumonidae). Biological Control, Orlando, v. 40, p. 362-369, 2007.

SASABE, M.; WEN, Z.; BERENBAUM, M.R.; SCHULER, M.A. Molecular analysis of CYP321A1, a novel cytochrome P450 involved in metabolism of plant allelochemicals (furanocoumarins) and insecticides (cypermethrin) in Helicoverpa zea. Gene, Amsterdam, v. 338, p. 163-175, 2004.

SANDERS, C. J.; PELL, J. K.; POPPY, G. M.; RAYBOULD, A.; GARCIA-ALONSO, M.; SCHULER, T. H. Host-plant mediated effects of transgenic maize on the insect parasitoid Campoletis sonorensis (Hymenoptera: Ichneumonidae). Biological Control, Orlando, v. 40, p. 362-369, 2007.

SHARMA, H.C.; DHILLON, M.K.; ARORA, R. Effects of Bacillus thuringiensis $\delta$ endotoxin-fed Helicoverpa armigera on the survival and development on the parasitoid Campoletis chlorideae. Entomologia Experimentalis et applicata, Dordrecht, v. 126, p. 1-8, 2008. 
SCHULER, T.H.; MARTINES-TORRES, D.; THOMPSON, A.J. Toxicological, electrophysiological, and molecular characterization of knockdown resistance to pyrethroid insecticides in the diamondback moth, Plutella xylostella (L.). Pesticide Biochemestry, New York, v. 59, p. 169-182, 1998.

SCHULER, T.H.; van EMDEN, H. F. Resistant cabbage cultivars change the susceptibility of Plutella xylostella to Bacillus thuringiensis. Agricultural and Foresty Entomology, Malden, v. 2, p. 33-38, 2000.

SIMMS, E.L.; FRITZ, R.S. The ecology and evolution of host-plant resistance to insects. Trends in Ecology and Evolution, Amsterdam, v. 5, p. 356-360, 1990.

TAYLOR, M.; FEYEREISEN, R. Molecular biology and evolution of resistance to toxicants. Molecular Biology and Evolution, Chicago, v. 13, p. 719-734, 1996.

VENDRAMIM, J.D. A resistência de plantas e o manejo de pragas. In: CROCOMO, W.B. (Ed.). Manejo integrado de pragas. São Paulo: CETESB, 1990. p. 177-197.

WILLIAMS, W.P.; SAGERS, J.B.; HANTEN, J.A.; DAVIS, F.M.; BUCKLEY, P.M. Transgenic corn evaluated for resistance to fall armyworm and southwestern borer. Crop Science, Madison, v. 37, p. 957-962, 1997.

WU, K.; MU, W.; LIANG, G.; GUO, Y. Regional reversion of insecticide resistance in Helicoverpa armigera (Lepidoptera: Noctuidae) is associated with the use of Bt cotton in northern China. Pest Management Science, Sussex, v. 61, p. 491-498, 2005.

YU, S.J. Insecticide resistance in the fall armyworm Spodoptera frugiperda (J. E. Smith). Pesticide Biochemistry and Physiology, San Diego, v. 39, p. 91-94, 1991. 


\section{REVISÃO BIBLIOGRÁFICA}

\subsection{Resistência de $S$. frugiperda a inseticidas na cultura do milho}

O manejo integrado de pragas (MIP) na cultura do milho visando o controle da lagarta-do-cartucho Spodoptera frugiperda (J. E. Smith) objetiva integrar táticas de controle para a manutenção da densidade populacional desta praga abaixo do nível de dano econômico. Dentre as dificuldades existentes no controle deste lepidóptero, destaca-se a localização da lagarta dentro do cartucho e a decisão de controle baseado no sintoma externo de folhas injuriadas (YU; NGUYEN, 1994; FANCELLI; DOURADO-NETO, 2000), sem comprovar a presença do inseto no interior do cartucho.

Apesar dos avanços nos programas de MIP para esta cultura, o fato do cultivo do milho no Brasil ser realizado o ano inteiro em algumas regiões, associado a alguns fatores bioecológicos de $S$. frugiperda, tais como a alta capacidade de reprodução, polifagia e hábito migratório (METCALF et al., 1962; GIOLO et al., 2002; SARMENTO et al., 2002), essa praga tem ocasionado sérios problemas em diversas culturas e o uso de inseticidas tem sido a forma de controle mais utilizada. Consequentemente, a utilização isolada desta tática de controle tem apresentado custos elevados na cultura do milho, sendo verificado em algumas regiões brasileiras o número de 10 pulverizações de inseticidas em uma única safra de milho, sem obtenção de controle desejado de $S$. frugiperda (WAQUIL et al., 2008).

Estudos de detecção e caracterização da resistência de $S$. frugiperda a inseticidas têm evidenciado a presença de grande variabilidade genética com relação à suscetibilidade de populações desta praga a diversos grupos de inseticidas (YU, 1991, 1992, 2006). Na Flórida a intensidade da resistência de S. frugiperda a piretroides variou de 2 a 216 vezes, para fosforados de 12 a 271 vezes e para carbamatos de 14 a 192 vezes YU (1991). Estudos complementares revelaram a existência de resistência ao fluvalinate de 263 vezes e ao methyl parathion de 516 vezes, com aumento de 1,2 a 11 vezes na concentração de enzimas detoxificadoras em populações de campo quando comparadas às de laboratório (YU, 1992). No Brasil, DIEZ-RODRIGUEZ; OMOTO (2001) verificaram que a intensidade de resistência de $S$. frugiperda ao piretroide lambda-cyhalothrin foi de aproximadamente 13 vezes com padrão de herança de resistência incompletamente recessiva. Na Venezuela, MORILLO; NOTZ (2001) detectaram intensidades de resistência de 19 a 42 vezes para lambdacyhalothrin, enquanto que na Colômbia, a herdabilidade da resistência a este piretroide foi alta variando de 0,23 a 0,42 (RÍOS-DÍEZ; SALDAMANDO-BENJUMEA, 2011). 


\subsection{Milho geneticamente modificado resistente a insetos no Manejo Integrado de Pragas} (MIP)

O milho geneticamente modificado resistente a insetos (milho $\mathrm{Bt}$ ) foi originalmente desenvolvido para controle de Ostrinia nubilalis Hübner (Lepidoptera: Pyralidae), importante praga nos Estados Unidos da América, propiciando que as lagartas que se alimentassem do tecido foliar das plantas pudessem ingerir a toxina Cry1 Ab da bactéria de solo Bacillus thuringiensis Berliner (Bt), morrendo por inanição antes de causarem danos econômicos à cultura (GLARE; O'CALLAGHAN, 2000; ANDOW; HILBECK, 2006), proporcionando assim maior proteção de grãos armazenados (ILSI, 1999; GILLES et al., 2000), redução dos níveis de micotoxinas nas espigas (MUNKVOLD et al., 1999; OBRYCKI et al., 2001) e produção de grãos.

No Brasil, a Comissão Técnica Nacional de Biossegurança (CTNBio) já realizou a liberação comercial de 6 eventos de milho geneticamente modificados resistentes a insetos expressando a proteína de Bt Cry1Ab, dentre estes, os eventos YieldGard ${ }^{\circledR}$ (MON 810) e Bt11 (Syngenta) (CTNBio, 2007, 2008) apresentam característica de resistência às pragas-alvo $S$. frugiperda, Helicoverpa zea Boddie, 1850 (Lepidoptera: Noctuidae) e Diatraea saccharalis Fabr., 1794 (Lepidoptera: Pyralidae), mediante a expressão contínua em seus tecidos foliares da delta-endotoxina Cry1 Ab, preconizando a redução do número de aplicações de inseticidas a estes lepidópteros, preservando seus inimigos naturais e aumentando a produtividade da cultura do milho.

No entanto, o cultivo de híbridos de milho geneticamente modificados resistentes a insetos contendo a proteína Cry1 $\mathrm{Ab}$, demonstrou em experimentos conduzidos tanto em laboratório quanto em campo, atividade de controle moderada da toxina de Bt (Cry1 Ab) sobre o desenvolvimento e sobrevivência de lagartas de S. frugiperda (LYNCH et al., 1999; BURKNESS et al., 2001, 2002; MENDES et al., 2011), evidenciando redução do tempo de desenvolvimento da praga e não um controle efetivo, não atendendo desta forma os preceitos para o manejo da resistência (MRI) deste inseto.

Nos estudos realizados em laboratório, foi observada redução na sobrevivência larval de $67 \%$ em milho Bt e $89 \%$ em milho não-Bt, quando alimentadas de tecido vegetal e estigma liofilizados adicionados à dieta artificial (WILLIAMS et al., 1997) e de 70\% em milho-Bt e 97\% em não-Bt (BOKONON-GANTA et al., 2003). A variedade de milho doce (Bt11) também apresentou supressão no desenvolvimento de lagartas de S. frugiperda, sendo observado que após 4 dias de alimentação neste híbrido, as lagartas sobreviventes que 
continuaram a causar danos apresentaram redução na sobrevivência e peso corporal independente da idade (LYNCH et al., 1999; BURKNESS et al., 2001, 2002). Considerando o efeito da toxina Cry1Ab purificada sobre parâmetros biológicos de S. frugiperda, RamirezRomero et al. (2007), verificaram que quando a lagarta foi alimentada com esta toxina utilizando-se 3 concentrações (0,46, 9,13 e 182,6 mg de Cry1Ab/ml) em dieta artificial, efeitos negativos sobre sua sobrevivência, tempo de desenvolvimento e taxa de crescimento foram observados em todas as concentrações testadas, além de inibição da alimentação larval.

Nos experimentos conduzidos em campo, a redução no desenvolvimento de lagartas de S. frugiperda foi observada nos eventos transgênicos MON810, Bt11 e ICP4, as quais apresentaram tamanho correspondente a $3^{\circ}$ e $4^{\circ}$ ínstares quando comparadas àquelas alimentadas em não-Bt que se apresentavam no $5^{\circ}$ e $6^{\circ}$ ínstares (FERNANDES et al., 2003). Outro fato observado foi o estabelecimento das lagartas nas espigas e danos foliares (BUNTIN et al., 2001, 2004). O número de lagartas de $1^{\circ}$ e $2^{\circ}$ ínstares de $S$. frugiperda encontradas sobre cartuchos de híbridos dos eventos MON810 e Bt11 em campo, foi considerado elevado (CHILCUTT et al. 2007), sendo que lagartas de $3^{\circ}$ e $4^{\circ}$ ínstares apresentaram número similar entre os híbridos Bt e não-Bt, enquanto que lagartas de $5^{\circ}$ ínstar apresentaram-se em número menor em milho Bt.

No Brasil, estudos de biologia de $S$. frugiperda alimentada com milho Bt e não-Bt realizados por FERNANDES (2003), demonstraram em laboratório que a duração da fase larval de S. frugiperda alimentada com milho Bt MON810 foi significativamente maior, sendo prolongada em 5,1; 4,0 e 7,5 dias quando comparada ao não-Bt. Em relação a danos em plantas (FERNANDES et al., 2003; MENDES et al., 2008), foi verificado que em plantas de milho Bt mesmo havendo sobrevivência inicial de $S$. frugiperda o dano não evoluiu a prejuízos significativos e que nos estádios V10/V11 das plantas, houve um nivelamento do percentual de plantas com sintomas de danos para plantas Bt e não-Bt.

Diante da constatação do prolongamento da fase larval de $S$. frugiperda em milho Bt por Cry1 Ab, outras formas de controle, como o biológico e o químico poderão figurar como táticas de ação conjunta, já que as lagartas apresentam esta redução no desenvolvimento larval, proporcionando maior exposição a seus predadores e parasitoides, os quais poderão retardar o processo de adaptação da praga a plantas transgênicas (ARPAIA et al., 1997), como também melhor eficácia de controle por inseticidas com a redução do número de aplicações e dose destes produtos a insetos-alvo da toxina (HUANG et al., 2002; SHELTON et al., 2002; CATANNEO et al., 2006), evidenciando possíveis efeitos sinérgicos ou aditivos a partir das interações destas táticas de controle (VENDRAMIM, 1990; GIUSTOLIN, 1996). 
No entanto, apesar destes benefícios existem algumas limitações em relação à adoção de cultivo das plantas Bt, como o preço da tecnologia inserida nas sementes (ARMSTRONG et al., 2003), a ressurgência de pragas secundárias com o aumento do número de pulverizações a pragas não-alvo (HILBECK et al., 2006), ocorrência de fluxo gênico com parentes silvestres por meio da dispersão de grãos de pólen, seleção de indivíduos resistentes na população de insetos alvo de controle e impacto negativo das toxinas sobre inimigos naturais (SCHULER et al., 2004).

Dentre estas limitações, o potencial das populações de insetos alvo na evolução da resistência a Cry1 Ab constitui-se em uma das principais ameaças ao emprego desta tática de controle adicional (TABASHNIK, 1994), já que as pragas-alvo ficam expostas continuamente à ação de controle da proteína e mesmo em alguns casos quando a praga apresenta-se como polífaga como, por exemplo, S. frugiperda, há o risco de exposição a outras culturas que também apresentam o mesmo gene de Bt aumentando o risco de evolução de resistência, existindo também a necessidade de avaliações diretas de efeitos potenciais sobre organismos não-alvo (POLANCZYCK et al., 2003; PRASIFKA et al., 2005).

O cultivo de híbridos de milho geneticamente modificado resistentes a insetos, visando o controle de lagartas de $S$. frugiperda que já apresentam resistência a inseticidas, demonstra que os custos adaptativos verificados em parâmetros biológicos e fisiológicos deste inseto podem promover maior eficiência de controle, mediante a interação com outras táticas de controle já utilizadas, como controle biológico por parasitoides, já que lagartas sobreviventes em milho Bt e resistentes a um determinado inesticida poderão apresentar maior tempo de desenvolvimento e, consequentemente, maior tempo de exposição à ação de seus inimigos naturais (VENDRAMIM, 1990, SIMS; FRITZ, 1990; ODE, 2006; SANDERS et al., 2007; SHARMA et al, 2008). A possibilidade de regulação dos diferentes mecanismos que alteram a aptidão de lagartas de $S$. frugiperda sobreviventes em milho Bt e resistentes a inseticidas, como a inibição do sistema imunológico destes insetos (BARAT-HOUARI et al., 2006; GASSMANN et al., 2009), são fatores que poderão ser explorados na interação do milho Bt com o controle biológico.

Dessa forma, programas de manejo de resistência deverão ser considerados para garantir a vida útil das toxinas de Bt, bem como evitar, retardar ou reverter a evolução da resistência, considerando principalmente estudos realizados em campo que propiciam condições reais quando comparados aos de laboratório (MOAR et al, 2008; NARANJO, 2009), já que a expressão da proteína na planta pode variar de acordo com o ambiente. A utilização de novas enzimas de restrição, a expressão de alta dose das toxinas aliada à área de 
refúgio para os insetos suscetíveis e preservação dos inimigos naturais, o monitoramento de insetos resistentes, a avaliação de custo adaptativo de indivíduos resistentes (GASSMANN et al., 2009) e o uso de plantas piramidizadas, ou seja, a utilização da expressão de mais de uma toxina numa mesma cultivar (ZHAO et al. 2003; HUTCHISON; STORER, 2010), associada à utilização adequada da área de refúgio, poderá prolongar significativamente a utilização dos genes de resistência (BOKONON-GANTA et al., 2003; BATES et al., 2005; WAQUIL et al., 2008; GASSMANN et al., 2009).

Para o manejo da resistência das espécies alvo no milho $\mathrm{Bt}$, têm sido recomendadas duas táticas: a expressão de alta dose da toxina nas plantas e o cultivo de área de refúgio. No entanto, os híbridos de milho Bt (MON810 e Bt11) expressando a toxina Cry1Ab, têm sido considerados de resistência moderada para o controle de $S$. frugiperda no Brasil. Neste caso, o produtor que optar pela adoção destas cultivares de milho Bt, deverá adotar medidas de controle que possam ser integradas ao uso do milho $\mathrm{Bt}$, como o uso de inseticidas e do controle biológico. Considerando a estratégia do cultivo de uma área de refúgio para o manejo da resistência com o uso do milho Bt MON810 e Bt11, é exigida uma área de 10\% de refúgio cultivada com milho não Bt de igual ciclo e porte, preferencialmente o seu híbrido isogênico. $\mathrm{Na}$ área de refúgio, é permitido o controle das pragas alvo, desde que não seja usado bioinseticidas à base de Bt, sendo que esta não poderá estar localizada a mais de $1.500 \mathrm{~m}$ de distância da área cultivada com o milho Bt (MENDES et al., 2008; WAQUIL et al, 2008).

Além disso, esta área de refúgio servirá tanto como reservatório de indivíduos suscetíveis da praga alvo de Cry1 Ab e de inseticidas, quanto de inimigos naturais, que poderão atuar no controle de indivíduos sobreviventes a ação da toxina de Bt (MUSSER et al., 2006; ROSE; DIVELY, 2007), potencializando o controle de S. frugiperda sobrevivente em milho Bt e possibilitando a reversão de sua suscetibilidade a inimigos naturais e a inseticidas utilizados anteriormente para seu controle em milho (WU et al., 2005), além da possível contribuição na diluição de alelos da resistência em cultivos de milho Bt e não Bt. 


\subsection{Efeito do milho geneticamente modificado resistente a insetos sobre inimigos naturais}

O efeito do milho Bt sobre os predadores e parasitoides dos insetos alvo da toxina Cry1 Ab pode ser negativo ou positivo, sendo direto, mediante a alimentação de partes da planta que expressam as proteínas, como pólen e anteras (FONTES et al., 2002) ou indireto (WOLFENBARGER; PHIFER, 2000), relacionado à qualidade nutricional da presa ou hospedeiro que reflete em parâmetros biológicos, como desenvolvimento atrasado ou prolongado, redução da taxa de eclosão e de peso, redução do desempenho controlador e interferência nas interações tritróficas com a emissão de compostos químicos secundários pelas plantas danificadas (SCHULER et al., 1999a,b; POPPY; SUTHERLAND, 2004; ROMEIS et al., 2006).

Estudos realizados em laboratório com variedades de milho geneticamente modificado expressando a proteína Cry1 Ab em pólen, demonstraram que não houve efeito negativo sobre as espécies de predadores Chrysoperla carnea (Stephens) (Neuroptera: Chrysopidae), Orius majusculus (Reuter) (Hemiptera: Anthocoridae), Orius insidiosus (Say, 1832). (Hemiptera: Anthocoridae), Cycloneda munda (Say, 1835) (Coleoptera: Coccinellidae) (PILCHER et al, 1997, 2005; PONS et al., 2004) e Coleomegilla maculata (DeGeer) (Coleoptera: Coccinelidae) (DUAN et al., 2002; LUNDGREN; WIEDENMANN, 2002, 2005) quando alimentadas diretamente do pólen. Da mesma forma que no evento Bt11 (Cry1Ab), não foi verificado efeito negativo sobre parâmetros biológicos do percevejo predador $O$. majusculus quando alimentado de Anaphotrhrips obscurus (Muller, 1776) (Thysanoptera: Thripidae) (ZWAHLEN et al., 2000).

Entretanto, larvas de $C$. carnea quando alimentadas de lagartas de lepidópteros que haviam ingerido a toxina Cry1 Ab apresentaram redução no seu tempo de desenvolvimento e reprodução (HILBECK et al., 1998a), enquanto que o mesmo modelo trófico quando analisado por Lozzia et al. (1998), Hilbeck et al. (1998b), Dutton et al. (2002) e Romeis et al. (2004) não apresentou efeito negativo sobre o desenvolvimento deste predador. Esta diferença de resultados pode ser atribuída ao fato de que no primeiro estudo, a dose de toxina oferecida para as lagartas se alimentarem em dieta artificial foi maior do que aquela expressa na planta de milho em campo, explicitando a necessidade de estudos que demonstrem as condições reais de ingestão da toxina, como aquelas ocorrentes em campo (LOVËI; ARPAIA, 2005; LOVËI et al., 2009; NARANJO, 2009). 
Estudos de campo para avaliar o impacto na diversidade de insetos amostrados entre milho Bt e não-Bt têm revelado resultados divergentes. Daly; Buntin (2005) verificaram que o milho MON810 não apresentou efeitos adversos sobre fitófagos não alvos e predadores, no entanto, o gênero Nabis sp. apresentou-se menos abundante em milho-Bt do que em não-Bt. Frizzas (2003) avaliou a dinâmica populacional do predador Doru luteipes Scudder, 1836 (Dermaptera: Forficulidae) no Brasil, não observando diferenças na quantidade de insetos coletados em milho Bt (MON810) quando comparado ao convencional.

Em relação a coleópteros predadores de solo, 3 de 57 espécies foram contabilizadas em $81 \%$ de todos os espécimens capturados em armadilhas pitfall em um agroecossistema transgênico de milho-soja, sendo capturados igualmente em ambas as culturas (ESTRUCH et al., 1997). Estudos realizados por Harwood et al. (2006) em laboratório e em campo acerca da interação tritrófica milho-Bt/Deroceras leave (Müller, 1774), uma lesma, e o carabídeo predador Scarites subterraneus (Fabricius, 1775) (Coleoptera: Carabidae) rejeitaram a hipótese de que a toxina Cry1Ab se movimentasse através dos níveis tróficos, sendo verificada ausência da toxina nos predadores.

Estudos utilizando hospedeiros que se alimentaram de cultivares de milho transgênico contendo a expressão da toxina Cry1 Ab revelaram que para as espécies de parasitoide Cotesia marginiventris Cresson (Hymenoptera: Braconidae) (VOJTECH et al., 2005), Cotesia flavipes (Cameron) (Hymenoptera: Braconidae) (PRÜTZ; DETTNER, 2004) e Campoletis sonorensis (Cameron) (Hymemoptera: Ichneumonidae) (MEISSLE et al., 2004) o desenvolvimento larval foi afetado negativamente.

A densidade populacional do parasitoide Macrocentrus cingulum Brischke (Hymenoptera: Braconidae) foi significativamente afetada em milho $\mathrm{Bt}$, sendo reduzida de 29 a 60\% quando comparada em não-Bt (PILCHER et al., 2005). Para verificar efeitos da toxina Cry1Ab sobre o parasitóide $C$. marginiventris mediados pelo hospedeiro $S$. frugiperda, Ramirez-Romero et al. (2007) realizaram dois experimentos em laboratório: um com a liberação da toxina purificada via dieta artificial e outro com a liberação da toxina via tecido foliar de milho Bt. No primeiro experimento, não foram evidenciados efeitos da toxina sobre o parasitoide. Entretanto, quando Cry1 Ab foi liberada via tecido foliar foram afetados o tempo de desenvolvimento, tamanho do adulto e fecundidade do parasitoide. Adultos do parasitoide $C$. sonorensis criados em S. frugiperda alimentada com milho Bt apresentaram tamanho menor (15 a 30\%) quando comparados àqueles criados em S. frugiperda alimentada com não Bt, sendo verificada ausência de efeito negativo sobre o tempo de desenvolvimento, 
ausência de Cry1Ab nos adultos deste inimigo natural e não preferência de fêmeas de $C$. sonorensis por hospedeiros alimentados nos diferentes tratamentos.

Redução significativa de formação da pupa, emergência de adultos e prolongamento do período larval em dois dias do parasitoide Campoletis chlorideae Uchida (Hymenoptera: Ichneumonidae) foi observada utilizando-se lagartas de Helicoverpa armigera (Hübner, 1805) (Lepidoptera: Noctuidae) alimentadas em dieta artificial incorporada com Cry1 Ab antes e após o parasitismo (SANDERS et al., 2007). Entretanto, para este mesmo modelo, não foi observado efeito sobre a fecundidade de fêmeas (SHARMA et al., 2008). No Brasil, FERNANDES (2003), verificou que não houve diferença quanto a capacidade de parasitismo, porcentagem de emergência, número de parasitoides emergidos, razão sexual e longevidade do parasitoide Trichogramma atopovirilia (Oatman \& Platner) (Hymenoptera: Trichogrammatidae), quando criado em ovos de fêmeas de S. frugiperda que foram alimentadas em milho MON810 e não- Bt.

Em relação à interação do controle do milho Bt com o controle biológico, examinando o padrão espacial de parasitismo de Macrocentrus grandii Goidanich (Hymenoptera: Braconidae) em resposta a densidade de seu hospedeiro O. nubilalis, White; Andow (2005) observaram que padrões resultantes da densidade do parasitoide e parasitismo, apresentaram menores agregações com menor parasitismo somente quando não associado com amplas agregações de hospedeiros indicando que o parasitismo dependente da densidade do hospedeiro pode acelerar a evolução da resistência à toxina Cry1Ab em O. nubilalis, sugerindo que proximidade espacial entre culturas transgênicas e refúgios pode equalizar o parasitismo de $M$. grandii, aumentando a complementaridade do controle proporcionado pelo milho Bt com o controle biológico da praga em questão.

A eficiência da associação de híbridos resistentes com o controle biológico também poderá ser verificada pelo crescimento populacional de $S$. frugiperda em híbrido resistente (milho Bt) e suscetível com ou sem a presença de seus inimigos naturais, com a adoção de outras táticas de controle, como o uso de inseticidas. Neste sentido, estudos em condições de campo sobre a interação do milho $\mathrm{Bt}$ com o uso do inseticida lambda-cyhalothrin demonstraram que este inseticida teve impacto negativo sobre invertebrados não alvos de Cry1 Ab, afetando a presença de inimigos naturais em 21 a 48\%, enquanto que em milho nãoBt as aplicações reduziram em 33 a $70 \%$ a presença dos insetos benéficos, onde os grupos de predadores que apresentaram abundância mais significativamente reduzida pela aplicação do piretroide foram Orius sp., coccinelídeos, ovos de crisopídeos, aranhas e coleópteros pertencentes à família Cantharidae (DIVELY, 2005; ROSE; DIVELY, 2007). 
Em outro estudo, verificou-se em campo que a abundância de Coccinella septempunctata Linnaeus, 1758 (Coleoptera: Coccinellidae) foi significativamente maior nas parcelas tratadas com inseticidas do que no milho Bt ou nas parcelas controle (ECKERT et al., 2006). Enquanto que, em áreas de milho Bt e não Bt onde foram aplicados os inseticidas lambda-cyhalothrin e Delfin (Bt), verificou-se que não houve efeito negativo do milho $\mathrm{Bt}$ sobre predadores de solo e da parte aérea (CANDOLFI et al., 2004). No entanto, tendências de efeito negativo foram verificadas sobre alguns artrópodes voadores como os pertencentes às famílias Lonchopteridae, Mycetophilidae, Syrphidae e Ceraphronidae em comparação ao não-Bt. Estudos acerca da interação de controle químico com variedades transgênicas sobre parasitoides revelaram que populações de braconídeos e taquinídeos apresentaram-se menos suscetíveis a inseticidas aplicados em campos de milho Bt, devido às altas taxas de recrutamento para substituição de adultos dos parasitóides (ROSE; DIVELY, 2007).

\subsection{Implicações do custo adaptativo associado à resistência a inseticidas na resposta imunólogica de insetos}

A resistência a inseticidas naturais, sintéticos e biomoléculas, é provocada pelo estresse imposto por essas substâncias que atuam na variabilidade genética pré-existente de populações naturais, promovendo uma espécie de microevolução que favorece genótipos adaptados e esse novo ambiente (CROW, 1957; FFRENCH-CONSTANT et al., 2004). A resistência promove a seleção por meio da sobrevivência e reprodução diferencial de indivíduos expostos a uma pressão de seleção que resultaria na mortalidade da maioria dos indivíduos de uma mesma população (FERRÉ; VAN-RIE, 2002).

A resistência a inseticidas é muitas vezes causada por uma substituição de alelos. Estes alelos surgem ao acaso por mutação e existem em baixa freqüência na população. Ao longo do tempo os alelos passam a ocorrer com maior frequência na presença de pressão de seleção, alterando a proporção entre alelos mutantes e não mutantes. Esta substituição pode ocorrer em um ou em vários locus e é favorecida pela forte seleção que o inseticida promove na variação genotípica inicial da população (GEORGHIOU, 1972; ROUSH; McKENZIE, 1987; HECKEL, et al.,1999; DONG, 2007; HECKEL, 2009). A resistência a inseticidas pode estar associada a um custo adaptativo e, frequentemente, tem comprometido a reprodução e a sobrevivência dos indivíduos resistentes em ambientes livres de inseticidas (GEORGHIOU, 1972; ROUSH; McKENZIE, 1987; COSTAU et al., 2000; TABASHNIK, 1994; GASSMANN et al., 2009). 
Praticamente não há estudos relativos a possíveis efeitos da resistência na resposta imunológica de insetos nem da expressão de genes que possam estar envolvidos nesta resposta de defesa e no metabolismo de xenobióticos de indivíduos resistentes a inseticidas e plantas Bt (FEYREISEN et al., 1999; GASSMANN et al., 2009). Diante disso, o conhecimento da resposta imunológica celular e humoral entre indivíduos suscetíveis e resistentes a uma tática de controle, pode afetar a aptidão biológica do inseto resistente e influenciar o desenvolvimento e aplicação de táticas de manejo de resistência destes indivíduos tanto a inseticidas quanto a plantas Bt, através do maior sucesso esperado na exploração do hospedeiro pelo parasitoide, dada à redução da capacidade de resposta imunológica de lagartas de S. frugiperda resistentes, devido aos custos associados à resistência, contribuindo na diluição de alelos de resistência na população, promovendo o retardamento da evolução da resistência, até mesmo reversão de suscetibilidade ao inseticida aplicado (WU et al., 2005), e ainda alteração da suscetibilidade de lagartas resistentes a inimigos naturais (IQBAL; WRIGHT, 1996; BOIVIN et al., 2001; PATHAN et al., 2010; FOSTER et al., 2011).

O sistema imunológico em insetos é responsável por proteger o indivíduo do ataque de invasores externos, como por exemplo, inimigos naturais (endoparasitoides larvais), entomopatógenos e nematoides pela ativação de vias celulares e humorais específicas, que reconhecem e eliminam seus invasores (STRAND; PECH, 1995; STRAND et al., 1997). Diante disso, as respostas de defesa iniciais incluem barreiras físicas do tegumento ou mesêntero, respostas expressas na hemolinfa e a produção de citotóxicos celulares (NAPPI et al., 2000) no local da invasão pelo agente externo (LAVINE; STRAND, 2001). Desta forma, o sistema imunológico em insetos é dividido em componentes humorais e celulares, onde a resposta humoral é resultante da ação de proteínas que estão sempre presentes ou são induzidas, sendo geralmente associadas à infecção de microrganismos (CHAPELLE et al., 2009), e a resposta celular, que se refere às repostas mediadas por hemócitos, como a fagocitose ou encapsulação do agente invasor (SCHIMDT et al., 2001; STRAND, 2008).

O patógeno ou inimigo natural invasor é reconhecido como organismo estranho pela detecção de estímulos químicos e físicos que envolvem proteínas solúveis da hemolinfa, assim como proteínas receptoras localizadas na superfície dos hemócitos ou de outras células de defesa. O reconhecimento e os sinais secundários iniciam um processo de tradução de sinais que conduzirá à ação celular, ou seja, a adesão seguida de fagocitose, nodulação ou encapsulação pelos hemócitos, liberação de fatores sinalizadores ou a transcrição induzida de genes para produção de proteínas antimicrobianas (GILLESPIE; KANOST, 1997). 
Em relação à complexidade da resposta imune em insetos a grandes invasores, como parasitoides e nematoides, a encapsulação é uma resposta que proporciona um bom entendimento da regulação hospedeira pelo agente invasor. Neste tipo de resposta celular, ocorre o isolamento e aprisionamento do invasor dentro de uma cápsula de defesa devido à adesão de hemócitos (granulócitos e plasmatócitos) ao organismo estranho, resultando em uma cápsula lisa, com camadas celulares sobrepostas (LAVINE; STRAND, 2001). Após a formação da cápsula, o invasor exibe sinais como citólise ou melanização, culminando com a morte do mesmo (CHAPMAN, 1998; GILLESPIE; KANOST, 1997). A presença de agentes estranhos na cavidade da hemocele do hospedeiro, como parasitoides e microrganismos, resulta na deposição de melanina ao redor do tecido danificado do hospedeiro, a qual oferece proteção física, prevenindo ou retardando o crescimento do invasor. Esta produção de melanina é ativada pela enzima fenoloxidase presente na hemolinfa do inseto, constituindo outro importante componente do sistema de defesa em insetos (SÖDERHÄLL, 1982).

O conhecimento da expressão de genes que possam estar envolvidos nesta resposta de defesa e no metabolismo de indivíduos resistentes a xenobióticos (FEYEREISEN, 1999; BARAT-HOUARI et al., 2006), podem fornecer informações para estudos futuros sobre os mecanismos moleculares responsáveis pela regulação gênica de custos adaptativos associados à resistência e caracterização da resistência a piretroides em S. frugiperda (SASABE et al., 2004), já que informaçõse sobre a resistência de lepidópteros a piretroides é incipiente, sabendo-se somente que esta resistência é decorrente de mutações nos canais de sódio (DONG, 2007), e se apresenta através de mecanismos como a redução da sensibilidade do sítio-alvo de ação do inseticida ou aumento da detoxificação metabólica (SCHULER et al., 1998; HECKEL, 2009) o que pode alterar a fisiologia do inseto devido à existência de custos adaptativos, podendo resultar na alteração do padrão diferencial de expressão de genes entre suscetíveis e resistentes ao piretroide (COSTAU et al., 2000; TAYLOR; FEYEREISEN, 1996), que estejam relacionados a diferentes processos fisiológicos, os quais resultam em modificações na aptidão biológica do inseto, influenciando o desenvolvimento de programas de manejo da resistência deste inseto ao controle químico, promovendo sua interação com o controle biológico e o uso de milho Bt (NARANJO, 2009).

O custo adaptativo limita o desenvolvimento dos organismos resistentes na ausência de pressão de seleção, uma vez que este genótipo resistente pode estar sob efeito pleiotrópico, permitindo que o custo interfira no metabolismo, consequentemente deixando os indivíduos resistentes menos competitivos que os organismos suscetíveis (GOULD, 1998). Diante disso, os custos adaptativos associados à resistência podem determinar uma alocação e uso de 
recursos pelos processos fisiológicos do inseto de uma maneira diferente, afetando assim processos metabólicos e o desenvolvimento em linhagens resistentes o que prejudica sua capacidade competitiva em ambientes naturais (COUSTAU et al., 2000; DINGHA et al., 2004; GUEDES et al., 2006).

A maioria dos custos adaptativos associados à resistência de determinado inseticida ocorre sobre parâmetros biológicos e reprodutivos (GASSMANN et al., 2009; GUSTAFSON et al., 2006), sugerindo em alguns casos resistência metabólica nestes insetos (CROWDER et al., 2009), como observado em S. frugiperda resistente aos inseticidas lufenuron e deltamethrin, apresentando tempo de desenvolvimento larval mais lento e redução de peso pupal (SILVA, 2004); menor fecundidade e tempo de desenvolvimento de lagartas resistentes de Cydia pomonella (Lepidoptera: Tortricidae) aos inseticidas diflubenzuron e deltamethrin (BOIVIN et al., 2001); menor taxa de emergência de adultos em Plutella xylostella (Lepidoptera: Plutellidae) resistente a tebufenozide (Lepidoptera: Plutellidae) (GUANGCHUN; ZHAOJUN, 2006), menor sobrevivência de adultos e fecundidade (GROETERS et al., 1993); menor sobrevivência, peso de pupas e oviposição por fêmea em Spodoptera exigua (Lepidoptera: Noctuidae) resistente a tebufenozide (JIA et al., 2009); em coleópteros, como Sitophilus zeamais (Coleoptera: Curculionidae) (GUEDES et al., 2006) e em afídeos, com maior taxa de reprodução líquida em Schizaphis graminum (Hemiptera: Aphididae) (STONE et al., 2000) e com menor fecundidade, período reprodutivo e longevidade em Aphis gossypii (Hemiptera: Aphididae) (KONNO; OMOTO, 2006).

Com a adoção do milho Bt resistente a insetos, a possibilidade de ocorrência da evolução da resistência em insetos-praga ameaça a eficácia das toxinas de Bt inseridas nas plantas Bt, assim como ocorre no caso do uso de inseticidas. Neste contexto, o custo adaptativo da resistência a estas formas de controle ocorre na ausência da pressão de seleção pelo inseticida aplicado e na ausência das toxinas de $\mathrm{Bt}$, sendo mais reduzido em insetos resistentes do que em insetos suscetíveis. Devido ao fato do custo adaptativo variar com as condições ecológicas, as áreas de refúgio (não-Bt) utilizadas para aumentar a dominância ou magnitude do custo, poderão ser utilizadas para retardar a evolução da resistência da praga (GASSMANN et al., 2009), servindo como reservatório de inimigos naturais da praga e imigração de suscetíveis (GEORGHIOU; TAYLOR, 1977). Diante disso, a existência de custo adaptativo que afete a resposta imunológica poderia tornar o inseto mais suscetível aos seus inimigos naturais, entomopatógenos e entomófagos, o que certamente poderia influenciar o desenvolvimento e mesmo a aplicação de táticas de manejo de pragas em milho Bt. 


\section{Referências}

ANDOW, D.A.; HILBECK, A. Bt maize, risk assessment and the Kenya case study. In: HILBECK, A.; ANDOW, D.A.; FONTES, E.M.G. Environmental risk assessment of genetically modified organisms: methodologies for assessing Bt maize in Brazil.

Cambridge: Cabi Publ., 2006. v. 1, chap. 1, p. 1-20.

ARPAIA, S.; GOULD, F.; KENNEDY, G. Potential impact of Coleomegilla maculata predation on adaptation of Leptinotarsa decemlineata to Bt-transgenic potatoes. Entomologia Experimentalis et Applicata, Dordrecht, v. 82, p. 91-100, 1997.

ARMSTRONG, J.S.; BOMAN, R.K.; JOHNSON, P.N.; BLACKSHEAR, J. Economic evaluation of short season Bollgard ${ }^{\circledR}$ cotton cultivars on the Texas high plains. The Texas Journal of Agriculture and Natural Resources, College Station, v. 16, p. 78-85, 2003.

BARAT-HOUARI, M.; HILLIOU, F.; JOUSSET, F-X; SOFER, S.; DELEURY, E.; ROCHER, J.; RAVALLEC, M.; GALIBERT, L.; DELOBEL, P.; FEYEREISEN, R.; FOURNIER, P.; VOLKOFF, A.N. Gene expression profiling of Spodotera frugiperda hemocytes and fat body using cDNA microarray reveals polydnavirus-associated variations in lepidopteran host genes transcript levels. BMC Genomics, London, v. 7, p. 1-20, 2006.

BATES, S.L.; ZHAO, J.Z.; ROUSH, R.T.; SHELTON, A.M. Insect resistance management in GM crops: past, present and future. Nature Biotechnology, New York, v. 23, n. 1, p. 57-62, 2005.

BOKONON-GANTA, A.H.; BERNAL, J.S.; PIETRANTONIO, P.V.; SÉTAMOU, M. Survivorship and development of fall armyworm, Spodoptera frugiperda (J. E. Smith) (Lepidoptera: Noctuidae), on conventional and transgenic maize cultivars expressing Bacillus thuringiensis Cry9C and Cry1A(b) endotoxins. International Journal of Pest Management, London, v. 49, n. 2, p. 169-175, 2003.

BOIVIN, T.; D’HIÉRES, C.C.; BOUVIER, J.C.; BESLAY, D.; SAUPHANOR, B. Pleiotropic of insecticide resistance in the coldling moth, Cydia pomonella. Entomologia Experimentalis et Applicata, Dodrecht, v. 99, p. 381-386, 2001.

BUNTIN, G.D.; LEE, R.D.; WILSON, D.M.; McPHERSON, R.M. Evaluation of Yieldgard transgenic resistance for control of fall armyworm and corn earworm (Lepidoptera: Noctuidae) in corn. Florida Entomologist, Gainesville, v. 84, p. 37-42, 2001.

BUNTIN, G.D.; FLANDERS, K.L.; LYNCH, R.E. Assessment of experimental Bt events against fall armyworm and corn earworm (Lepidoptera: Noctuidae) in corn. Journal of Economic Entomology, Lanham, v. 97, p. 259-264, 2004.

BURKNESS, E.C.; HUTCHISON, H.C.; BOLIN, P.C.; BARTELS, D.W.; WARNOK, D.F.; DAVIS, D.W. Field efficacy of sweet corn hybrids expressing a Bacilllus thuringiensis for management of Ostrinia nubilalis (Lepidoptera: Crambidae) and Helicoverpa zea (Lepidoptera: Noctuidae). Journal of Economic Entomology, Lanham, v. 94, p. 197-203, 2001. 
BURKNESS, E.C.; HUTCHISON, H.C.; WEINZIERL, R.A.; WEDBERG, J.L.; WOLD, S.J.; SHAW, J.T. Efficacy and risk of sweet corn hybrids expressing a Bacilllus thuringiensis toxin for lepidopteran pest management in the Midwestern US. Crop Protection, Guildford, v. 21, p. $157-169,2002$.

CANDOLFI, M.P.; BROWN, K.; GRIMM, C.; REBER, B.; SCHMIDLI, H. A faunistic approach to assess potential side-effects of genetically modified Bt-corn on non-target arthropods under field conditions. Biocontrol Science and Technology, Oxford, v. 14, p. 129-170, 2004.

CATTANEO, M.G.; YAFUSO, C.; SCHMIDT, C.; HUANG, C.Y.; RAHMAN, M.; OLSON, C.; ELLERS-KIRK, C.; ORR, B.J.; MARSH, S.E.; ANTILLA, L.; DUTILLEUL, P.;

CARRIÈRE, Y. Farm-scale evaluation of the impacts of transgenic cotton on biodiversity, pesticide use, and yield. Proceedings of the National Academy of Sciences of the USA, Washington, v. 103, p. 7571-7576, 2006.

CHAPELLE, M.; GIRARD, A.P.; COUSSERANS, F.; VOLKOFF, A. N.; DUVIC, B. Lysozymes and lysozyme-like proteins from the fall armyworm Spodoptera frugiperda. Molecular Immunology, Elmsford, v. 47, p. 261-269, 2009.

CHAPMAN, R.F. The insects (Structure and function). In: (Ed.). Circulatory system, blood and immune systems. Cambridge: Cambridge University Press, 1998. chap. 5, p. 95-131.

CHILCUTT, C.F.; ODVODY, G.N.; CORREA, J.C.; REMMERS, J. Effects of Bacillus thuringiensis transgenic corn on corn earworm and fall armyworm (Lepidoptera: Noctuidae) densities. Journal of Economic Entomology, Lanham, v. 100, p. 327-334, 2007.

COUSTAU, C.; CHEVILLON, C.; FRENCH-CONSTANT, R. Resistance to xenobiotics and parasites: can we count the cost? Trends in Ecology and Evolution, Amsterdam, v. 15, p. 378-383, 2000.

CROW, J.F. Genetics of insect resistance to chemicals. Annual Review of Entomololgy, Stanford, v. 2, p. 227-246, 1957.

CROWDER, D.W.; ELLERS-KIRK, C.; TABASHNIK, B.E.; CARRIÈRE, Y. Lack of fitness costs associated with pyriproxyfen resistance in the B biotype of Bemisia tabaci. Pest Management Science, Sussex, v. 65, p. 235-240, 2009.

COMISSÃO TÉCNICA NACIONAL DE BIOSSEGURANÇA. Liberação comercial de milho geneticamente modificado. Brasília: Ministério da Ciência e Tecnologia, CTNBio, 2007. 19 p. (Parecer Técnico, 1100/2007).

Liberação comercial de milho geneticamente modificado. Brasília: Ministério da Ciência e Tecnologia, CTNBio, 2008. 24 p. (Parecer Técnico, 1255/2008).

DALY, T.; BUNTIN, D. Effect of Bacillus thuringiensis transgenic corn for lepidopteran control on nontarget arthropods. Environmental Entomology, College Park, v. 34, p. 12921301, 2005. 
DIEZ-RODRÍGUEZ, G.I.; OMOTO, C. Herança da resistência de Spodoptera frugiperda (J.E. Smith) (Lepidoptera: Noctuidae) a Lambda-Cialotrina. Neotropical Entomology, Londrina, v. 30, p. 311-316, 2001.

DINGHA, B.N.; MOAR, W.J.; APPEL, A.G. Effects of Bacillus thuringiensis Cry1C toxin on the metabolic rate of Cry1C resistant and susceptible Spodoptera exigua (Lepidoptera: Noctuidae). Physiological Entomology, Oxford, v. 29, p. 409-418, 2004.

DIVELY, G. P. Impact of transgenic VIP3A x Cry1 Ab lepidopteran-resistant field corn on the nontarget arthropod community. Environmental Entomology, College Park, v. 34, p. 12671291, 2005.

DONG, K. Insect sodium channels and insecticide resistance. Invertebrate Neuroscience, New York, v. 7, p. 17-30, 2007.

DUTTON, A.; KLEIN, H. ROMEIS, J.; BIGLER, F. Uptake of Bt-toxin by herbivores feeding on transgenic maize and consequences of predator Chrysoperla carnea. Ecology Entomology, Edison, v. 27, p. 441-447, 2002.

ECKERT, J.; SCHUPHAN, I.; HOTHORN, L.A.; GATHMANN, A. Arthropods on maize ears for detecting impacts of Bt maize on nontarget organisms. Environmental Entomology, College Park, v. 35, 554-560, 2006.

ESTRUCH, J.J.; CAROZZI, N.B.; DESAI, N.; DUCK, N.B.; WARREN, G.W.; KOZIEL, M.G. Transgenic plants:an emerging approach to pest control. Nature Biotechnology, New York, v. 15, p. 137-141, 1997.

FANCELLI, A.L.; DOURADO-NETO, D. Ecofisiologia e fenologia. In: FANCELLI, A.L.; DOURADO-NETO, D. Produção de milho. Guaíba: Agropecuária, 2000. cap. 1, p. 21-54.

FERNANDES, O.D. Efeito do milho geneticamente modificado (MON810) em Spodoptera Frugiperda (J. E. Smith 1797) (Lepidoptera: Noctuidae) e no parasitóide de ovos Trichogramma spp. 2003. 164 p. Tese (Doutorado em Entomologia) - Escola Superior de Agricultura "Luiz de Queiroz", Universidade de São Paulo, Piracicaba, 2003.

FERNANDES, O.D.; PARRA, J.R.P.; NETO, A.F.; PÍCOLI, R.; BORGATTO, A.F.; DEMÉTRIO, C.G.B. Efeito do milho geneticamente modificado MON810 sobre a lagarta-docartucho Spodoptera frugiperda (J.E. Smith, 1797) (Lepidoptera: Noctuidae). Revista Brasileira de Milho e Sorgo, Sete Lagoas, v. 2, p. 25-35, 2003.

FERRÉ, J.; VAN RIE J. Biochemistry and genetics of insect resistance to Bacillus thuringiensis. Annual Review of Entomology, Stanford, v. 47, p. 501-533, 2002.

FONTES, E.M.G.; PIRES, C.S.S.; SUJII, E.R.; PANIZZI, A.R. The environmental effects of genetically modified crops resistant to insects. Neotropical Entomology, Londrina, v. 31, n. 4, p. 497-513, 2002. 
FOSTER, S.P.; DENHOLM, I.; POPPY, G. M.; THOMPSON, R.; POWELL, W. Fitness trade-off in peach-potato aphids (Myzus persicae) between insecticide resistance and vulnerability to parasitoid attack at several spatial scales. Bulletin of Entomological Research, Farnham Royal, v. 101, p. 659-666, 2011.

FFRENCH-CONSTANT, R.H.; DABORN, P.J.; GAELLE, L.G. The genetics and genomics of insecticide resistance. Trends in Genetics, London, v. 20, p. 163-170, 2004.

FRIZZAS, M.R. Efeito do milho geneticamente modificado (MON810) sobre a comunidade de insetos. 2003. 192 p. Tese (Doutorado em Entomologia) - Escola Superior de Agricultura "Luiz de Queiroz", Universidade de São Paulo, Piracicaba, 2003.

GASSMANN, A.J.; CARRIÉRE, Y.; TABASHNIK, B.E. Fitness costs of insect resistance to Bacillus thuringiensis. Annual Review of Entomololgy, Stanford, v. 54, p. 147-63, 2009.

GASSMANN, A.J.; JEFFREY, A.F.; SISTERSON, M.S.; HANNON, E.R.; STOCK, P.S.; CARRIÉRE, Y.; TABASHNIK, B.E. Effects of pink bollworm resistance to Bacillus thuringiensis on phenoloxidase activity and susceptibility to entomopathogenic nematodes. Journal of Economic Entomology, Lanham, v. 102, p. 1224-1232, 2009.

GUEDES, R.N.C.; OLIVERIA, E.E.; GUEDES, N.M.P.; RIBEIRO, B.; SERRÃO, J.E. Cost and mitigation of insecticide resistance in the maize weevil, Sitophilus zeamais. Physiological Entomology, Oxford, v. 31, p. 30-38, 2006.

GEORGHIOU, G.P. The evolution of resistance to pesticide. Annual Review of Ecological System, Palo Alto, v. 3, p. 133-168, 1972.

GEORGHIOU, G.P.; TAYLOR, C.E. Genetic and biological influences in the evolution of insecticide resistance. Journal of Economic Entomology, Lanham, v. 70, p. 319-323, 1977.

GILLES, K.L.; HELLMICH, R.L.; IVERSON, C.T.; LEWIS, L.C. Effects of transgenic Bacilllus thuringiensis maize grain on B. thuringiensis susceptible Plodia interpunctella (Lepidoptera: Pyralidae). Journal of Economic Entomology, Lanham, v. 93, p. 1011-1016, 2000 .

GILLESPIE, J.P.; KANOST, M.R. Biological mediators of insect immunity. Annual Review of Entomology, Stanford, v. 42, p. 611-643, 1997.

GIOLO, F.P.; GRUTZMCHER, A.D.; GARCIA, M.S.; BUSATO, G.R. Parâmetros biológicos de Spodoptera frugiperda (J. E. Smith, 1797) (Lep.: Noctuidae) oriundas de diferentes localidades e hospedeiros. Revista Brasileira de Agrociência, Pelotas, v. 8, p. 219-224, 2002.

GIUSTOLIN, T.A. Efeito de dois genótipos de Lycopersicon spp. Associados aos entomopatógenos Bacillus thuringiensis var. kurstaki e Beauveria bassiana no desenvolvimento de Tuta absoluta (Meyrick, 1917) (Lep., Gelechiidae). 1996. 99 p. Tese (Doutorado em Entomologia) - Escola Superior de Agricultura "Luiz de Queiroz", Universidade de São Paulo, Piracicaba, 1996. 
GLARE, T.R.; O'CALLAGHAN, M. Bacillus thuringiensis: biology, ecology and safety. Chichester: John Wiley, 2000. 350 p.

GOULD, F. Sustainability of transgenic insecticidal cultivars: integrating pest genetics and ecology. Annual Review of Entomology, Stanford, v. 43, p. 701-726, 1998.

GROETERS, F.R.; TABASHNIK, B.E.; FINSON,N.; JOHNSON, M.W. Effects of resistance to Bacillus thuringiensis on mating success of the diamondback moth (Lepidoptera: Plutellidae). Journal of Economic Entomology, Lanham, v. 86, p. 1035-39, 1993.

GUANGCHUN, C.; ZHAOJUN, H. Tebufenozide resistance selected in Plutella xylostella and its cross resistance and fitness cost. Pest Management Science, Sussex, v. 62, p. 746$751,2006$.

GUSTAFSON, D.I.; HEAD, G.P.; CAPRIO, M.A. Modeling the impact of alternative hosts on Helicoverpa zea adaptation to Bollgard cotton. Journal of Economic Entomology, Lanham, v. 99, p. 2116-2124, 2006.

HARWOOD, J.D.; SAMSON, R.A.; OBRYCKI, J.J. No evidence for the uptake of Cry1Ab Bt-endotoxins by the generalist predator Scarites subterraneus (Coleoptera: Carabidae) in laboratory and field experiments. Biocontrol Science and Technology, Oxford, v. 16, n. 4, p. 377-388, 2006.

HECKEL, D.G. Molecular genetics of insecticide resistance in Lepidoptera. In. (Ed.). Molecular biology and genetics of Lepidoptera. London: CRC Publ., 2009. p. 239-269.

HECKEL, D.G.; GAHAN, L.J.; LIU, Y.B.; TABASHNIK, B.E. Genetic mapping of resistance to Bacillus thuringiensis toxins in diamondback moth using biphasic linkage analysis. Proceedings of the National Academy of Sciences USA, Washington, v. 96, p. 8373-8377, 1999.

HILBECK, A.; BAUMGARTNER, M.; FRIED, P.M.; BIGLER, F. Effects of transgenic Bacillus thuringiensis corn-fed prey on mortality and development time of immature Chrysoperla carnea (Neuroptera: Chrysopidae). Environmental Entomology, College Park, v. 27, p. 480-487, 1998a.

HILBECK, A.; MOAR, W.J.; PUSZTAI-CAREY, M.; FILIPPINI, A.; BIGLER, F. Toxicity of Bacillus thuringiensis Cry1 Ab toxin to the predator Chrysoperla carnea (Neuroptera: Chrysopidae). Environmental Entomology, College Park, v. 27, p. 1255-1263, 1998 b.

HILBECK, A.; ANDOW, D.A.; ARPAIA, S.; BIRCH, A.N.E.; FONTES, E.M.G.; LÖVEI, G.L.; SUJII, E.R.; WHEATLEY, R.E.; UNDERWOOD, E. Methodology to support nontarget and biodiversity risk assessment. In: HILBECK, A.; ANDOW, D.A.; FONTES, E.M.G. Environmental risk assessment of genetically modified organisms: methodologies for assessing Bt cotton in Brazil. Cambridge: Cabi Publ., 2006. v. 1, chap. 1, p. 1-20.

HUANG, J.; ROZELLE, S.; PRAY, C.; WANG, Q. Plant biotechonology in China. Science, Washington, v. 295, p. 674-677, 2002. 
HUANG, F.; SHI, M.; YANG, Y.; LI, J.; CHEN, X. Changes in hemocytes of Plutella xylostella after parasitism by Diadegma semiclausum. Archives of Insect Biochemistry and Physiology, New York, v.70, p. 177-187, 2009.

HUTCHISON, W.D.; STORER, N.P. Expanded use of pyramided transgenic maize hybrids expressing novel Bacillus thuringiensis toxins in the Southern U.S.: potential for areawide suppression of Helicoverpa zea (Lepidoptera: Noctuidae) in the Mississippi Delta.

Southwestern Entomologist, Weslaco, v. 35, p. 403-408, 2010.

INTERNATIONAL LIFE SCIENCES INSTITUTE. An evaluation of insect resistance management in Bt field corn: a science based framework for risk assessment and risk management. Washington, 1999. $78 \mathrm{p}$.

IQBAL, M.; WRIGHT, D. Host resistance to insecticides can confer protection to endo-larval parasitoids. Bulletin of Entomological Research, Farnham Royal, v. 86, p. 721-723, 1996.

JIA, B.; LIU, Y.; ZHU, Y.C.; LIU, X.; GAO, C.; SHEN, J. Inheritance, fitness cost and mechanism of resistance to tebufenozide in Spodoptera exigua (Hübner) (Lepidoptera: Noctuidae), Pest Management Science, Sussex, v. 65, p. 996-1002, 2009.

KONNO, R.H.; OMOTO, C. Custo adaptativo associado à resistência de Aphis gossypii Glover (Hemiptera: Aphididae) ao inseticida carbosulfam. Neotropical Entomology, Londrina, v. 35, p. 246-250, 2006.

LAVINE, M.D.; STRAND, M.R. Surface characteristics of foreign targets that elicit an encapsulation response by the moth Pseudoplusia includens. Journal of Insect Physiology, Oxford, v. 47, p. 965-974, 2001.

LYNCH, R.E.; WISEMAN, B.R.; PLAINSTED, D.; WARNIK, D. Evaluation of transgenic sweet corn hybrids expressing Cry1Ab toxin for resistance to corn earworm and fall armyworm. Journal of Economic Entomology, Lanham, v. 92, p. 246-252, 1999.

LÖVEI, G.L.; ARPAIA, S. The impact of transgenic plants on natural enemies: a critical review of laboratory studies. Entomologia Experimentalis et Applicata, Dordrecht, v. 114, p. 1-14, 2005.

LÖVEI, G.L.; ANDOW, D.A.; ARPAIA, S. Transgenic insecticidal crops and natural enemies: a detailed review of laboratory studies. Environmental Entomology, College Park, v. 38, n. 2, p. 293-306, 2009.

LOZZIA, G.C.; FURLANIS, C.; MANACHINI, B.; RIGAMONTI, I.E. Effects of $B t$ corn on Rhopalosiphum padi L. (Rhynchota: Aphididae) and on its predator Chrysoperla carnea Stephen (Neuroptera: Chrysopidae). Bollettino di Zoologia Agraria e di Bachicoltura, Milano, v. 31, p. 153-164, 1998.

LUTRELL, R.G.; WAN, L.; KNIGHTEN, K. Variation in susceptibility of noctuid (Lepidoptera) larvae attacking cotton and soybean to purified endotoxin proteins and commercial formulations of Bacillus thuringiensis. Journal of Economic Entomology, Lanham, v. 92, p. 21-32, 1999. 
MEISSLE, M.; VOJTECH, E.; POPPY, G.M. Implications for the parasitoid Campoletis sonorensis (Hymenoptera: Ichneumonidae) when developing in Bt-maize-fed Spodoptera littoralis larvae (Lepidoptera: Noctuidae). IOBC WPRS Bulletin, Dordrecht, v. 27, p. 117123, 2004.

MENDES, S.M.; MARUCCI, R. C.; MOREIRA, S.G.; WAQUIL, J.M. Milho-Bt: avaliação preliminar da resistência de híbridos comerciais à lagarta-do-cartucho, Spodoptera frugiperda (J. E. Smith, 1797). Sete Lagoas: EMBRAPA, CNPMS, 2008. 8 p. (Comunicado Técnico, 157).

MENDES, S.M.; BOREGAS, K.G.B.; LOPES, M.E.; WAQUIL, M.S.; WAQUIL, J.M. Respostas da lagarta-do-cartucho a milho geneticamente modificado expressando a toxina Cry 1A(b). Pesquisa Agropecuária Brasileira, Brasília, v.46, p. 239-244, 2011.

METCALF, C.; FLINT, W.P.J. ; METCALF, R.L. Destructive and useful insects: their habits and control. $4^{\text {th }}$ ed. New York: Mc Graw - Hill, 1962. 1087 p.

MOAR, W.; ROUSH, R.; SHELTON, A.; FERRÉ, J.; MACINTHOSH, S.; LEONARD, B.R.; ABEL, C. Field-evolved resistance to Bt toxins. Nature Biotechnology, New York, v. 26, p. 1072-1074, 2008.

MORILLO, F.; NOTZ, A. Resistencia de Spodoptera frugiperda (Smith) (Lepidoptera: Noctuidae) a lambdacihalotrina y metomil. Entomotropica, Maracay, v. 16, p. 79-87, 2001.

MUNKVOLD, G.P.; HELLMICH, R.L.; RICE, L.G. Comparison of fumonisin concentrations in kernels of transgenici Bt maize hybrids and nontransgenic hybrids. Plant Disease, Saint Paul, v. 83, p. 130-138, 1999.

MUSSER, F.R.; SHELTON, A.M. Bt sweet corn and selective insecticides: Impacts on pests and predators. Journal of Economic Entomology, Lanham, v. 96, p. 71-78, 2003.

MUSSER, F.R.; NYROP, J.P.; SHELTON, A.M. Integrating biological and chemical controls in decision making: European corn borer (Lepidoptera: Crambidae) control in sweet corn as an example. Journal of Economic Entomology, Lanham, v. 55, p. 1538-1549, 2006.

NARANJO, S. E. Impacts of Bt crops on non-target invertebrates and insecticide use patterns. CAB reviews: Perspectives in Agriculture, Veterinary Science, Nutrition and Natural Resources, Warsaw, v. 4, p. 1-23, 2009.

NAPPI, A.J.; VASS, E.; FREY, F.; CARTON, Y. Nitric oxide involvement in Drosophila immunity. Nitric-Oxide: Biology and Chemistry, Cambridge, v. 4, p. 423-430, 2000.

OBRYCKI, J.J., LOSEY, J.E.; TAYLOR, O.R.; JESSE, L.C.H. Transgenic insecticidal corn: beyond insecticidal toxicity to ecological complexity. BioScience, Washington, v. 51, 353$361,2001$.

ODE, P.J. Plant chemistry and natural enemy fitness: effects on herbivore and natural enemy interactions. Annual Review of Entomology, Stanford, v. 51, p. 163-185, 2006. 
PATHAN, A. K.; SAYYED, A. H.; ASLAM, M.; LIU, T. X.; RAZZAQ, M.; GILLANI, W. A. Resistance to pyrethroids and organophosphates increased fitness and predation potential of Chrysoperla carnae (Neuroptera: Chrysopidae). Journal of Economic Entomology, Lanham, v. 103, p. 823-834, 2010.

PRÜTZ, G.; DETTNER, K. Effect of Bt corn leaf suspension on food consumption by Chilo partellus and life history parameters of ist parasitoid Cotesia flavipes under laboratory conditions. Entomologia Experimentalis et Applicata, Dordrecht, v. 111, p. 179-187, 2004.

PILCHER, C.D.; OBRYCKI, J.J.; RICE, M.E.; LEWIS, L.C. Preimaginal development, survival, and field abundance of insect predators on transgenic Bacillus thuringiensis corn. Environmental Entomology, College Park, v. 26, p. 446-454, 1997.

PILCHER, C.D.; RICE, M.E.; OBRYCKI, J.J. Impact of transgenic Bacillus thuringiensis corn and crop phenology on five nontarget arthropods. Environmental Entomology, College Park, v. 34, p. 1302-1316, 2005.

POLANCZYK, R.A.; MARTINELLI, S.; OMOTO, C.; ALVES, S.B. Bacillus thuringiensis no manejo integrado de pragas. Biotecnologia Ciência e Desenvolvimento, Brasília, v. 31, 18-27, 2003.

PONS, X.; LUMBIERRES, B.; LOPEZ, C.; ALBAJES, R. No effects of Bt maize on the development of Orius majusculus. IOBC WPRS Bulletin, Dordrecht, v. 27, p. 131-136, 2004.

POPPY, G.M.; SUTHERLAND, J.P. Can biological control benefit from geneticallymodified crops? Tritrophic interactions on insect resistant transgenic plants. Physiological Entomology, Oxford, v. 29, p. 257-268, 2004.

PRASIFKA, J.R.; HELLMICH, R.L.; DIVELY, G.P.; LEWIS, L.C. Assessing the effects of pest management on nontarget arthropods: the influence of plot size and isolation.

Environmental Entomology, College Park, v. 34, p.1181-1192, 2005.

RAMIREZ-ROMERO, R.; BERNAL, J.S.; CHAUFAUX, J.; KAISER. L. Impact assessment of Bt-maize on a moth parasitoid, Cotesia marginiventris (Hymenoptera: Braconidae), via host exposure to purified Cry1 Ab protein or Bt-plants. Crop Protection, Guildford, v. 26, p. 953-962, 2007.

RÍOS-DÍEZ, J.D.; SALDAMANDO-BENJUMEA, C.I. Susceptibility of Spodoptera frugiperda (Lepidoptera: Noctuidae) strains from Central Colombia to two insecticides, methomyl and lambda-cyhalothrin: a study of the genetic basis of resistance. Journal of Economic Entomology, Lanham, v. 104, p. 1698-1705, 2011.

ROMEIS, J.; DUTTON, A.; BIGLER, F. Bacillus thuringiensis toxin (Cry1 Ab) has no direct effect on larvae of the green lacewing Chrysoperla carnea (Stephens) (Neuroptera: Chrysopidae). Journal of Insect Physiology, Oxford, v. 50, p. 175-183, 2004.

ROMEIS, J.; MEISSLE, M.; BIGLER, F. Transgenic crops expressing Bacillus thuringiensis toxins and biological control. Nature Biotechnology, New York, v. 24, p. 63-71, 2006. 
ROMEIS, J.; BARTSCH, D.; BIGLER, F.; CANDOLFI, M.P.; GIELKENS, M.M.C.; HARTLEY, S.E.; HELLMICH, R.L.; HUESING, J.E.; JEPSON, P.C.; LAYTON, R.; QUEMADA, H.; RAYBOULD, A.; ROSE, R.I.; SHIEMANN, J.; SEARS, M.K.; SHELTON, A.M.; SWEET, J.; VAITUZIS, Z.; WOLT, J.D. Assessment of risk of insect-resistant transgenic crops to nontarget arthropods. Nature Biotechnology, New York, v. 26, p. 203208, 2008.

ROSE, R.; DIVELY, G.P. Effects of insecticide-treated and lepidopteran-active Bt-transgenic sweet corn on the abundance and diversity of arthropods. Environmental Entomology, College Park, v. 36, p. 1254-1268, 2007.

ROUSH, R.T.; McKENZIE, J.A. Ecological genetics of insecticide and acaricide resistance. Annual Review of Entomology, Stanford, v. 32, p. 361-380, 1987.

SANDERS, C.J.; PELL, J.K.; POPPY, G.M.; RAYBOULD, A.; GARCIA-ALONSO, M.; SCHULER, T.H. Host-plant mediated effects of transgenic maize on the insect parasitoid Campoletis sonorensis (Hymenoptera: Ichneumonidae). Biological Control, Orlando, v. 40, p. 362-369, 2007.

SASABE, M.; WEN, Z.; BERENBAUM, M. R.; SCHULER, M. A. Molecular analysis of CYP321A1, a novel cytochrome P450 involved in metabolism of plant allelochemicals (furanocoumarins) and insecticides (cypermethrin) in Helicoverpa zea. Gene, Amsterdam, v. 338, p. 163-175, 2004.

SARMENTO, R.A.; AGUIAR, R.W.S.; AGUIAR, R.A.S.S.; VIEIRA, S.M.J.; OLIVEIRA, H.G.; HOLTZ, A.M. Revisão da biologia, ocorrência e controle de Spodoptera frugiperda (Lepidoptera: Noctuidae) em milho no Brasil. Bioscience Journal, Uberlândia, v. 18, p. 4148, 2002.

SCHMIDT, O.; THEOPOLD, U.; STRAND, M.R. Innate immunity and evasion by insect parasitoids. BioEssays, Cambridge, v. 23, p. 344-351, 2001.

SCHULER, T.H.; van EMDEN, H.F. Resistant cabbage cultivars change the susceptibility of Plutella xylostella to Bacillus thuringiensis. Agricultural and Foresty Entomology, Malden, v. 2, p. 33-38, 2000.

SCHULER, T.H.; POTTING, R.P.J.; DENHOLM, I.; POPPY, G.M. Parasitoid behaviour and Bt plants. Nature, London, v. 400, p. 825-826, 1999a.

SCHULER, T.H.; POPPY, G.M.; KERRY, B.R.; DENHOLM, I. Potential side effects of insect-resistant transgenic plants on arthropod natural enemies. Trends in Biotechnology, Amsterdam, v. 17, 210-216, 1999 b.

SHARMA, H.C.; DHILLON, M.K.; ARORA, R. Effects of Bacillus thuringiensis $\delta$ endotoxin-fed Helicoverpa armigera on the survival and development on the parasitoid Campoletis chlorideae. Entomologia Experimentalis et applicata, Dordrecht, v. 126, p. 1-8, 2008. 
SHELTON, A.M.; ZHAO, J.Z.; ROUSH, R.T. Economic, ecological, food safety, and social consequences of the deployment of $B t$ transgenic plants. Annual Review of Entomology, Stanford, v. 47, p. 845-881, 2002.

SILVA, R.F. Biologia de Spodoptera frugiperda (J. E., Smith, 1797) (Lepidoptera: Noctuidae) expostas a inseticidas durante a fase larval. 2004. 49 p. Dissertação (Mestrado em Agronomia) - Faculdade de Ciências Agronômicas, Universidade Estadual Paulista "Júlio de Mesquita Filho”, Botucatu, 2004.

SIMMS, E.L.; FRITZ, R.S. The ecology and evolution of host-plant resistance to insects. Trends in Ecology and Evolution, Amsterdam, v. 5, p. 356-360, 1990.

SÖDERHÄLL, K. The prophenoloxidase activating system and melanization a recognition mechanism of arthropods: a review. Developmental and Comparative Immunology, New York, v. 6, p. 601-611, 1982.

STONE, B.S.; SHUFRAN, R.A.; WILDE, G.E. Life history study of multiple clones of insecticide resistance and susceptible greenbug Schizaphis graminum (Homoptera: Aphididae). Journal of Economic Entomology, Lanham, v. 93, p. 971-974, 2000.

STRAND, M.R. Insect hemocytes and their role in immunity. In: BECKAGE, N.E. (Ed.). Insect immunology. San Diego: Academic Press; Elsevier, 2008. chap. 2, p. 25-47.

STRAND, M.R.; PECH, L.L. Immunological basis for compatibility in parasitoid-host relationships. Annual Review of Entomology, Stanford, v. 40, p. 31-56, 1995.

STRAND, M.R.; WHITERELL, R.A.; TRUDEAU, D. Two Microplitis demolitor polydnavirus mRNAs expressed in hemocytes of Pseudoplusia includens contain a common cysteine-rich domain. Journal of Virology, Washington, v. 71, p. 2146-2156, 1997.

TABASHNIK, B.E. Evolution of resistance to Bacillus thuringiensis. Annual Review of Entomology, Stanford, v. 39, p. 47-79, 1994.

TAYLOR, M.; FEYEREISEN, R. Molecular biology and evolution of resistance to toxicants. Molecular Biology and Evolution, Chicago, v. 13, p. 719-734, 1996.

VENDRAMIM, J.D. A resistência de plantas e o manejo de pragas. In: CROCOMO, W.B. Manejo integrado de pragas. São Paulo: CETESB, 1990. cap. 9, p. 177-197.

VOJTECH, E.; MEISSLE, M.; POPPY, G.M. Effects of Bt maize on the herbivore Spodoptera littoralis (Lepidoptera: Noctuidae) and the parasitoid Cotesia marginiventris (Hymenoptera: Braconidae). Transgenic Research, London, v. 14, p. 133-144, 2005.

WAQUIL, J.M.; BOREGAS, K.G.B.; MENDES, S.M. Viabilidade do uso de hospedeiros alternativos como área de refúgio para o manejo da resistência da lagarta-do-cartucho, Spodoptera frugiperda (J. E. Smith) (Lepidoptera: Noctuidae) no cultivo do milho-Bt. Sete Lagoas: EMBRAPA, CNPMS, 2008. 10 p. (Comunicado Técnico, 160). 
WHITE, J.A.; ANDOW, D.A. Host-parasitoid interactions in a transgenic landscape: spatial proximity effects of host density. Environmental Entomology, College Park, v. 34, p. 1493$1500,2005$.

WILLIAMS, W.P.; SAGERS, J.B.; HANTEN, J.A.; DAVIS, F.M.; BUCKLEY, P.M.

Transgenic corn evaluated for resistance to fall armyworm and southwestern corn borer. Crop Science, Madison, v. 37, p. 957-962, 1997.

WOLFENBARGER, L.L.; PHIFER, P.R. The ecological risks and benefits of genetically engineered plants. Science, Wahsington, v. 290, n. 5499, p. 2088-2093, 2000.

WU K, MU, W, LIANG G, GUO Y. Regional reversion of insecticide resistance in Helicoverpa armigera (Lepidoptera: Noctuidae) is associated with the use of Bt cotton in northern China. Pest Management Science, Sussex, v. 61, p. 491-498, 2005.

YU, S.J. Insecticide resistance in the fall armyworm Spodoptera frugiperda (J. E. Smith). Pesticide Biochemestry and Physiology, San Diego, v. 39, p. 91-94, 1991.

Detection and biochemical characterization of insecticide resistance in fall armyworm (Lepidoptera: Noctuidae) larvae. Journal of Economic Entomology, Lanham, v. 85, p. 675-682, 1992.

Insensitivity of acetylcolinesterase in a field strain fall armyworm, Spodoptera frugiperda (J. E. Smith). Pesticide Biochemestry and Physiology, San Diego, v. 84, p. 135$142,2006$.

YU, S.J.; NGUYEN, S.N. Inheritance of carbaryl resistance and microsomal oxidases in the fall armyworm (Lepidoptera: Noctuidae). Journal of Economic Entomology, Lanham, v. 87, p. 301-304, 1994.

YU, S.J.; NGUYEN, S.N.; ABO-ELGHAR, G.E. Biochemical characteristics of insecticide resistance in the fall armyworm Spodoptera frugiperda (J. E. Smith). Pesticide Biochemestry and Physiology, San Diego, v. 77, p. 1-11, 2003.

ZHAO, J.Z.; CAO, J.; LI, Y.; COLLINS, H.L.; ROUSH, R.T.; EARLE, E.D.; SHELTON, A.M. Transgenic plants expressing two Bacillus thuringiensis toxins delay insect resistance evolution. Nature Biotechnology, New York, v. 21, p. 1493-1497, 2003.

ZWAHLEN, C.; NENTWIG, W.; BIGLER, F.; HILBECK, A. Tritrophic interactions of transgenic Bacillus thuringiensis corn, Anaphothrips obscurus (Thysanoptera: Thripidae), and the predator Orius majusculus (Heteroptera: Anthocoridae). Biological Control, Orlando, v. 29, p. 846-850, 2000. 
3 CUSTOS ADAPTATIVOS EM Spodoptera frugiperda (J.E. Smith, 1797) (LEPIDOPTERA: NOCTUIDAE) ASSOCIADOS À RESISTÊNCIA A LAMBDACYHALOTHRIN E IMPLICAÇÕES DA INTERAÇÃO COM MILHO GENETICAMENTE MODIFICADO (MON810) NO PARASITISMO POR Campoletis aff. flavicincta (HYMENOPTERA: ICHNEUMONIDAE)

\title{
Resumo
}

A resistência a inseticidas em Spodoptera frugiperda (J.E. Smith) (Lepidoptera: Noctuidae) tem comprometido a eficiência do uso do controle químico em diversas culturas. $\mathrm{O}$ custo adaptativo associado à resistência a inseticidas pode ser explorado no restabelecimento da resistência a inseticidas. Com o uso de novas tecnologias visando o controle desta praga, como o uso de variedades de milho geneticamente modificadas, a pressão de seleção imposta por inseticidas pode ser reduzida e a suscetibilidade a inseticidas pode ser restabelecida, podendo ocorrer maior mortalidade natural da praga por agentes de controle biológico. Sendo assim, o objetivo desta pesquisa foi avaliar a existência de custo adaptativo associado com a resistência de $S$. frugiperda a lambda-cyhalothrin e sua implicação no controle desta praga pelo parasitoide Campoletis aff. flavicincta (Hymenoptera: Ichneumonidae) e as interações da resistência a inseticidas com o milho geneticamente modificado (MON810) que expressa a toxina Cry1 Ab (milho Bt) no parasitismo por Campoletis aff. flavicincta. Estudos comparativos de biologia de linhagens de $S$. frugiperda suscetível e resistente a lambda-cyhalothrin foram conduzidos para avaliar alguns parâmetros biológicos de imaturos (desenvolvimento e sobrevivência) e de adultos (reprodução e longevidade) e o parasitismo por Campoletis aff. flavicincta em ambas as linhagens de $S$. frugiperda criadas em dieta artificial ou alimentadas com milho Bt. O custo adaptativo associado à resistência de $S$. frugiperda a lambda-cyhalothrin foi detectado pelo retardamento do desenvolvimento das fases larval e pupal, redução no peso e longevidade de fêmeas, razão sexual, taxa líquida de reprodução $(R o)$, taxa intrínseca de aumento $(\mathrm{rm})$ e taxa finita de aumento $(\lambda)$. Não foram verificadas diferenças na aceitação de hospedeiros e sobrevivência de Campoletis aff. flavicincta em ambas as linhagens de $S$. frugiperda. Entretanto, foi observado maior número de ovos ovipositados por fêmea de Campoletis aff. flavicincta em lagartas resistentes a lambda-cyhalothrin. O parasitismo larval conduzido em estudos utilizando gaiolas, com plantas de milho Bt e não-Bt, foi maior tanto em lagartas de $S$. frugiperda suscetíveis quanto resistentes ao inseticida. Dessa forma, devido ao custo adaptativo associado com a resistência de $S$. frugiperda a lambda-cyhalothrin e maior parasitismo larval de lagartas resistentes por Campoletis aff. flavicincta, estratégias de controle desta praga que reduzem o uso de inseticidas podem favorecer o restabelecimento da suscetibilidade de $S$. frugiperda a lambda-cyhalothrin e a eficiência do controle biológico natural com parasitoides em milho Bt.

Palavras-chave: Controle biológico; Desvantagem adaptativa; Lagarta-do-cartucho

\begin{abstract}
The resistance of Spodoptera frugiperda (J.E. Smith) (Lepidoptera: Noctuidae) to insecticides has compromised the efficacy of chemical control in many crops. Fitness costs associated to insecticide resistance can be exploited to delay the development of resistance to insecticides. As the selection pressure imposed by insecticides is lowered with the use of new pest control technologies, such as the use of genetically modified crops, the susceptibility to insecticides could be reset and natural mortality by biological control agents could be
\end{abstract}


improved. Therefore, the objective of this research was to evaluate the existence of fitness costs associated with the resistance of $S$. frugiperda to lambda-cyhalothrin and their implications for host use by the larval parasitoid Campoletis aff. flavicincta (Hymenoptera: Ichneumonidae) and the interactions of insecticide resistance with the genetically modified maize (MON810) that expresses Cry1 Ab toxin (Bt maize) in larval parasitization by Campoletis aff. flavicincta. Comparative life history studies of susceptible and lambdacyhalothrin resistant strains of $S$. frugiperda were conducted to evaluate some biological parameters of immatures (development and survival) and adults (reproduction and longevity) and the parasitism of Campoletis aff. flavicincta in both strains of S. frugiperda reared on artificial diet or Bt maize. Fitness costs associated to resistance of $S$. frugiperda to lambdacyhalothrin were detected by the delay in larval and pupal development, reduction in the pupal weight and longevity of females, sex ratio, net reproductive rate $(R o)$, intrinsic rate of natural increase $\left(r_{m}\right)$ and the finite rate of increase $(\lambda)$. No differences were detected in host acceptance and survival of Campoletis aff. flavicincta in both strains of $S$. frugiperda. However, a higher number of eggs was deposited by Campoletis aff. flavicincta females in lambda-cyhalothrin-resistant larvae. Larval parasitization in cage studies with Bt and non-Bt plants was higher on the resistant than on the susceptible strain of $S$. frugiperda. Therefore, due to the fitness cost associated with the resistance of $S$. frugiperda to lambda-cyhalothrin and the higher larval parasitization of resistant larvae by Campoletis aff. flavicincta, pest control strategies that reduce insecticide use can favor the reset of the susceptibility of $S$. frugiperda to lambda-cyhalothrin and the efficacy of natural biological control with this parasitoid in Bt maize.

Keywords: Biological control; Fitness costs; Fall armyworm

\subsection{Introdução}

A evolução da resistência a inseticidas em Spodoptera frugiperda (J. E. Smith) (Lepidoptera: Noctuidae) ameaça a eficiência de seu controle e compromete o Manejo Integrado de Pragas (MIP) em diversas culturas, já sendo documentada a resistência ao piretroide lambda-cyhalothrin no Brasil (DIEZ-RODRÍGUEZ; OMOTO, 2001) e a inseticidas de outros grupos químicos em outros países (YU, 1991; RÍOS-DÍEZ; SALDAMANDOBENJUMEA, 2011).

A ocorrência de custos adaptativos associados à resistência a inseticidas é um dos fatores que podem auxiliar no restabelecimento da suscetibilidade do inseto em programas de manejo da resistência (GEORGHIOU, 1972; ROUSH; McKENZIE, 1987). Além disso, a existência de custos adaptativos associados à resistência também pode favorecer a atuação dos agentes de controle biológico natural, quando os custos adaptativos interferem em parâmetros biológicos que tornam o inseto mais suscetível ao parasitismo, como, por exemplo, via redução da capacidade de resposta imunológica (IQBAL; WRIGHT, 1996; FOSTER et al., 2011) ou prolongamento da fase imatura, aumentando o tempo de exposição do inseto aos inimigos naturais (VENDRAMIM, 1990; SIMS; FRITZ, 1990; ODE, 2006). 
O uso de novas tecnologias visando ao controle de $S$. frugiperda, como, por exemplo, os híbridos de milho geneticamente modificados que expressam genes da bactéria Bacillus thuringiensis Berliner (milho Bt), pode contribuir para o retardamento da evolução da resistência de insetos a inseticidas mediante a redução da pressão de seleção com inseticidas e, consequente possibilidade de reversão para a suscetibilidade, seja pela presença de custo adaptativo associado à resistência ou pela imigração de genótipos suscetíveis da praga (GEORGHIOU; TAYLOR, 1977; WU et al., 2005).

Neste contexto, a constatação de efeito moderado da proteína Cry1Ab expressa em milho Bt no retardamento do desenvolvimento larval de S. frugiperda (WILLIAMS et al., 1997; FERNANDES et al., 2003; MENDES et al., 2011) pode proporcionar maior exposição da lagarta à ação de seus inimigos naturais, os quais poderão utilizar-se da redução de vigor, mobilidade e desenvolvimento (MUSSER et al., 2006; ROSE; DIVELY, 2007) da praga, ou mesmo de alterações em condições fisiológicas, como a inibição do sistema imunológico (GASSMANN et al., 2009), potencializando o controle de $S$. frugiperda em milho Bt, diante da possibilidade de alteração de suscetibilidade ao agente de controle natural (RAMIREZROMERO et al., 2007; SHARMA et al, 2008). Em casos em que a exploração do hospedeiro por inimigos naturais é beneficiada pela existência de custos adaptativos (FOSTER et al., 2011), o controle biológico natural pode contribuir para diluição dos alelos de resistência na população e, consequentemente, para o retardamento da evolução da resistência (GASSMANN et al., 2009).

Assim, este estudo teve por objetivo verificar a existência de custos adaptativos associados à resistência de $S$. frugiperda ao inseticida lambda-cyhalothrin e suas implicações na interação com milho Bt no desenvolvimento e eficiência de parasitismo por Campoletis aff. flavicincta (Hymenoptera: Ichneumonidae).

\subsection{Material e Métodos}

\subsubsection{Linhagens de $S$. frugiperda suscetível e resistente a lambda-cyhalothrin}

A linhagem suscetível de referência (SUS) foi obtida junto à EMBRAPA Milho e Sorgo, em Sete Lagoas, MG, Brasil, tendo sido comprovada a sua suscetibilidade pela realização de bioensaios de aplicação tópica do inseticida lambda-cyhalothrin. Esta linhagem foi mantida em laboratório na ausência de pressão de seleção do inseticida. A linhagem resistente a lambda-cyhalothrin foi obtida do Laboratório de Resistência de Artrópodes a 
Táticas de Controle, ESALQ/USP, Piracicaba, SP, Brasil, mediante constante pressão de seleção com este inseticida, conforme método descrito por Díez-Rodriguez e Omoto (2001).

Para manutenção da criação de cada linhagem em laboratório foi adotado procedimento de criação em dieta artificial à base de feijão, caseína, germe de trigo, proteína de soja e levedura de cerveja, conforme Parra (1991).

\subsubsection{Obtenção e estabelecimento da criação de Campoletis aff. flavicincta}

A criação do parasitoide larval Campoletis aff. flavicincta foi iniciada mediante coletas de $S$. frugiperda de $2^{\circ}$ ou $3^{\circ}$ ínstar em cultivo de algodão e milho na região de Luís Eduardo Magalhães-BA, em 2009. Estas lagartas foram mantidas em placas contendo uma porção de dieta artificial para a sua manutenção e coleta de parasitoides emergentes.

Casais do parasitoide foram individualizados em tubos de vidro contendo uma gota de mel para sua alimentação. Cerca de seis a 10 lagartas de $3^{\circ}$ ínstar de $S$. frugiperda eram oferecidas para parasitismo por $24 \mathrm{~h}$ em condições controladas $\left(25 \pm 1^{\circ} \mathrm{C} ; 70 \pm 10 \% \mathrm{UR}\right.$; fotofase de $14 \mathrm{~h}$ ), conforme método adaptado de Huang et al. (2009). Após este período, as lagartas foram individualizadas em placas plásticas preenchidas com uma porção de dieta artificial e mantidas nas mesmas condições descritas anteriormente $\left(25 \pm 1^{\circ} \mathrm{C} ; 70 \pm 10 \% \mathrm{UR}\right.$; fotofase de 14 horas) para o desenvolvimento e emergência dos parasitoides.

\subsubsection{Biologia de $S$. frugiperda suscetível e resistente a lambda-cyhalothrin}

\subsubsection{Fase imatura}

Foram utilizadas as primeiras posturas da criação de manutenção de laboratório para realização dos estudos de biologia das linhagens de $S$. frugiperda suscetível e resistente a lambda-cyhalothrin. As posturas de cada linhagem foram coletadas aleatoriamente e acondicionadas em recipientes plásticos em câmara climatizada $\left(21 \pm 1^{\circ} \mathrm{C} ; 70 \pm 10 \%\right.$ UR; fotofase de $14 \mathrm{~h}$ ).

As lagartas recém-eclodidas (0-24 h) foram individualizadas em tubos de vidro $(2,5$ $\mathrm{cm}$ de diâmetro $\times 8,5 \mathrm{~cm}$ de altura) contendo dieta artificial e mantidas em condições controladas $\left(25 \pm 1{ }^{\circ} \mathrm{C} ; 70 \pm 10 \% \mathrm{UR}\right.$; fotofase de $\left.14 \mathrm{~h}\right)$. Foram individualizadas 50 lagartas/linhagem $(1$ lagarta $=1$ repetição) para verificação de custos adaptativos ligados à resistência a lambda-cyhalothrin, avaliando-se os parâmetros: número de ínstares, duração do 


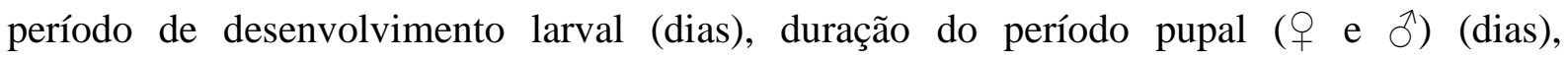

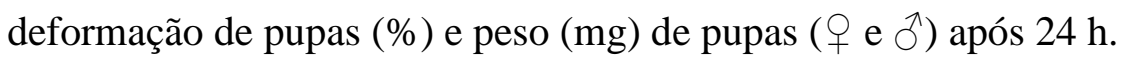

A determinação do número de ínstares foi baseada na medição diária da cápsula cefálica de 30 lagartas/linhagem em ocular graduada com precisão de 0,05 mm acoplada a microscópio estereoscópico. O número de ínstares foi determinado utilizando-se a curva multimodal de frequiências para cápsulas cefálicas para a formulação de hipóteses a serem testadas matricialmente pelo método dos quadrados mínimos. Estes testes resultaram no coeficiente de determinação $\left(\mathrm{R}^{2}\right)$, bem como os valores de razão média de crescimento $(\mathrm{K})$, permitindo, assim, a verificação do ajuste dos dados baseada na regra de Dyar (PARRA; HADDAD, 1989).

Os valores médios obtidos para os parâmetros avaliados foram submetidos ao teste de normalidade de Shapiro-Wilk a 5\%, sendo, caso necessário, realizada a transformação em $\sqrt{x+0.5}$ para os parâmetros avaliados e de $\operatorname{arcsen}\left(\frac{\sqrt{2(\%)}}{100}\right)$ para \% porcentagem de deformação de pupas, sendo posteriormente, as médias comparadas pelo teste t de Student a $5 \%$ de probabilidade (SAS INSTITUTE, 2002).

\subsubsection{Fase adulta}

Para a verificação de custos adaptativos relacionados à resistência a lambdacyhalothrin na fase adulta de S. frugiperda, 20 casais/linhagem foram individualizados em tubos de PVC (10 cm de diâmetro $\times 20 \mathrm{~cm}$ de altura), conforme descrito por Parra (1991), e mantidos em condições controladas $\left(25 \pm 1^{\circ} \mathrm{C} ; 70 \pm 10 \% \mathrm{UR}\right.$; fotofase de $\left.14 \mathrm{~h}\right)$ para a avaliação do período de preoviposição (dias), período de oviposição (dias), número de posturas por fêmea, fecundidade (número de ovos/fêmea), e longevidade (dias) de machos e fêmeas. As fêmeas foram armazenadas em $60 \%$ etanol imediatamente após a morte e dissecadas para observação do número de espermatóforos presentes na bolsa copuladora, como estimativa do número de cópulas realizadas por cada casal ( 1 espermatóforo = 1 cópula) (BROWN; DEWHURST, 1975). A razão sexual também foi avaliada para ambas as linhagens de $S$. frugiperda.

As massas de ovos depositadas foram recolhidas diariamente e acondicionadas em recipientes plásticos contendo papel filtro umedecido em água destilada. A quantidade de ovos foi avaliada conforme Leuck e Perkins (1972), sendo a viabilidade calculada com base 
na eclosão obtida em massas de ovos provenientes da $2^{\text {a }}$ postura de ambas as linhagens de $S$. frugiperda.

Os valores médios obtidos para os parâmetros avaliados na fase adulta foram submetidos ao teste de normalidade de Shapiro-Wilk a 5\%, sendo, caso necessário, realizada a transformação em $\sqrt{x+0.5}$ para posterior comparação de médias pelo teste t de Student a $5 \%$ de probabilidade (SAS INSTITUTE, 2002). A razão sexual foi comparada pelo teste de chiquadrado, determinada através da fórmula: $q / q+\overbrace{}^{\Uparrow}$ (SILVEIRA NETO et al., 1976).

\subsubsection{Tabela de vida de fertilidade}

A partir dos dados de sobreviência e oviposição de cada fêmea, foram construídas tabelas de vida de fertilidade utilizando-se de 20 casais para cada linhagem de S. frugiperda, sendo $x$ = ponto médio de cada idade das fêmeas parentais; $l x=$ expectativa de vida até a idade $x ; m x=$ fertilidade específica ou número de descendentes por fêmea produzidos na idade $x$ e que originarão fêmeas; $l x \cdot m x=$ número total de fêmeas nascidas na idade $x$.

Baseando-se nas informações da tabela de vida, foram estimados os seguintes parâmetros para cada linhagem de $S$. frugiperda: $R_{o}$ (taxa líquida de reprodução, ou seja, a taxa de aumento populacional a cada geração, mediante o número total de fêmeas produzidas por uma única fêmea por geração), $T$ (tempo médio de uma geração, ou seja, tempo gasto entre o nascimento dos pais e o nascimento dos filhos), $r_{m}$ (taxa intrínseca de crescimento, ou seja, taxa de aumento populacional por unidade de tempo), $\lambda$ (taxa finita de aumento, ou seja, número de fêmeas adicionadas à população por fêmea por unidade de tempo), TRB (taxa bruta de reprodução = número de fêmeas produzidas por uma única fêmea durante toda a sua vida, não sendo considerada a sobrevivência das formas imaturas) e TD (tempo necessário para a população duplicar). Em seguida, estes valores foram utilizados para obtenção da taxa intrínseca de crescimento " $r_{m}$ " e do intervalo de gerações " $T$ " pelo método interativo (SOUTHWOOD, 1995).

Os parâmetros da tabela de vida de fertilidade foram estimados pelo método de "Jacknife" (MEYER et al., 1986) e as médias comparadas pelo teste t unilateral, $(\mathrm{P} \leq 0,05)$, utilizando o software "Lifetable.sas" (MAIA et al., 2000). 


\subsubsection{Biologia e parasistimo de Campoletis aff. flavicincta em linhagens de $S$. frugiperda suscetível e resistente a lambda-cyhalothrin}

\subsubsection{Desenvolvimento e morfologia dos imaturos}

O acompanhamento do desenvolvimento e morfologia da fase larval e dos estádios imaturos do parasitoide Campoletis aff. flavicincta foi realizado a partir do parasitismo até o abandono do hospedeiro pela larva do parasitoide para a sua transformação em pupa. Assim, lagartas de $3^{\circ}$ ínstar de $S$. frugiperda suscetíveis e resistentes a lambda-cyhalothrin foram individualmente submetidas ao parasitismo assistido em sala climatizada $\left(25 \pm 1^{\circ} \mathrm{C} ; 70 \pm 10 \%\right.$ UR; fotofase de 14 h), sendo utilizadas fêmeas de Campoletis aff. flavicincta de 4 dias de idade, previamente acasaladas. Após o parasitismo, as lagartas eram transferidas individualmente para placas contendo dieta artificial e mantidas em condições controladas até a sua dissecação. Para a observação do imaturo do parasitoide em desenvolvimento, cinco lagartas parasitadas de cada linhagem (1 lagarta = 1 repetição) foram dissecadas diariamente. As lagartas eram esterilizadas superficialmente em 70\% etanol, lavadas em água destilada e secas em papel filtro. Posteriormente, foram dissecadas em tampão anticoagulante (98 mM $\mathrm{NaOH}, 150 \mathrm{mM} \mathrm{NaCl}$ e 1,7 mM EDTA, pH 4,5) (STRAND et al., 1997) para a coleta das fases imaturas do parasitoide. Os ovos ou a(s) larva(s) do parasitoide assim obtidos eram transferidos com o auxílio de uma micropipeta para lâminas de vidro em pequena quantidade de tampão anticoagulante para registro de imagens em microscópio óptico (Axiostar Plus, Zeiss) acoplado a sistema de captura e análise de imagens Motic Image Advanced 2.0 (Motic China Group, CO., Ltd). A duração da fase de pupa do parasitoide também foi observada.

\subsubsection{Aceitação de $S$. frugiperda por Campoletis aff. flavicincta}

A aceitação de $S$. frugiperda por Campoletis aff. flavicincta foi avaliada 24 h após o parasitismo assistido de 20 lagartas/linhagem de S. frugiperda, onde uma fêmea do parasitoide com 4 dias de idade, previamente acasalada, foi colocada em contato com uma lagarta de $S$. frugiperda de $3^{\circ}$ ínstar em tubo de vidro para o parasitismo. Após a verificação da introdução do ovipositor da fêmea do parasitoide, as lagartas eram resgatadas e mantidas individualmente em placas plásticas contendo dieta artificial. Após $24 \mathrm{~h}$ do parasitismo assistido, as lagartas parasitadas foram dissecadas como descrito no item 3.2.4.1, para 
confirmação do parasitismo e contagem do número de ovos depositados pela fêmea do parasitoide por lagarta de S. frugiperda.

Os valores médios obtidos foram submetidos ao teste de normalidade de Shapiro-Wilk a $5 \%$, sendo, caso necessário, realizada a transformação para $\sqrt{x+0.5}$ para posterior comparação de médias pelo teste $\mathrm{t}$ de Student a $5 \%$ de probabilidade (SAS INSTITUTE, 2002).

3.2.4.3 Parasitismo por Campoletis aff. flavicincta após interação de $S$. frugiperda com milho Bt

Para verificar o parasitismo por Campoletis aff. flavicincta em lagartas de $S$. frugiperda suscetíveis e resistentes a lambda-cyhalothrin sobreviventes à alimentação com milho Bt (híbrido DKB240YG ${ }^{\circledR}$ ) ou não-Bt (híbrido DKB240), foi realizado experimento em condições de gaiola em casa de vegetação.

Inicialmente, lagartas recém-eclodidas das linhagens de $S$. frugiperda suscetível e resistente a lambda-cyhalothrin foram submetidas à alimentação com os híbridos de milho, sendo individualizadas em tubos de vidro $(2,5 \mathrm{~cm}$ de diâmetro $\times 8,5 \mathrm{~cm}$ de altura) contendo papel filtro umedecido em água destilada e pedaços de folhas de $5 \mathrm{~cm}$ de comprimento, retiradas do cartucho de plantas de milho Bt ou não-Bt no estádio fenológico V6 a V8 (plantas com seis a oito folhas). Os tubos foram acondicionados em câmara climatizada a $25 \pm 1^{\circ} \mathrm{C} ; 70$ $\pm 10 \% \mathrm{UR}$; fotofase de $14 \mathrm{~h}$ e as folhas de milho trocadas diariamente até que as lagartas atingissem o início do $3^{\circ}$ ínstar (comprimento de aproximadamente $1 \mathrm{~cm}$ ) para avaliar a eficiência de parasitismo por Campoletis aff. flavicincta, conforme método adaptado de Sanders et al. (2007).

Após a inoculação das lagartas nas plantas, cada vaso foi recoberto com uma gaiola ( $80 \mathrm{~cm}$ de diâmetro $\times 1 \mathrm{~m}$ de altura) confeccionada com tecido tipo voil. Após 24 h do contato das lagartas com as plantas de milho Bt ou não-Bt, uma fêmea previamente copulada de Campoletis aff. flavicincta de 4 dias de idade foi liberada dentro de cada gaiola, a qual permaneceu $24 \mathrm{~h}$ em confinamento com as lagartas para o parasitismo. Após esse período, as fêmeas do parasitoide foram resgatadas e cada planta foi cortada na região próxima ao colo, sendo retirada e acondicionada em sacos plásticos para o resgate das lagartas no laboratório. As lagartas foram individualizadas em tubos de vidro $(2,5 \mathrm{~cm}$ de diâmetro $\times 8,5 \mathrm{~cm}$ de altura) 
contendo pedaços de folhas dos respectivos tratamentos com milho Bt ou não-Bt, sendo o alimento renovado diariamente até a formação de pupas do hospedeiro ou do parasitoide.

$\mathrm{O}$ experimento obedeceu o delineamento inteiramente casualizado num esquema fatorial $2 \times 2$. Os tratamentos foram repetidos quatro vezes, sendo cada repetição representada por um vaso contendo duas plantas de milho Bt ou não-Bt, totalizando 32 plantas por tratamento. Foram inoculadas cinco lagartas de $3^{\circ}$ ínstar/planta/vaso oriundas de criação em folhas dos respectivos tratamentos, totalizando 40 lagartas por repetição.

Para análise estatística, o número de lagartas parasitadas em cada planta foi contabilizado, sendo obtido o número médio de lagartas parasitadas por tratamento (milho Bt ou não-Bt). Posteriormente, os valores de porcentagem de parasitismo foram calculados e transformados em $\operatorname{arcsen}\left(\frac{\sqrt{P(\%)}}{100}\right)$, para fins de homogeneização da variância e normalização. O percentual médio de parasitismo foi comparado entre o tipo de alimentação (milho Bt e não-Bt) para cada linhagem, e entre linhagens para cada condição de alimentação, utilizando teste de Tukey a 5\% de probabilidade (SAS INSTITUTE, 2002).

\subsection{Resultados}

\subsubsection{Biologia de $S$. frugiperda suscetível e resistente a lambda-cyhalothrin}

Ambas as linhagens de $S$. frugiperda analisadas apresentam seis ínstares durante o desenvolvimento larval (suscetível: $\mathrm{R}^{2}=99,17 \% ; \mathrm{k}=1,54$; resistente: $\mathrm{R}^{2}=98,60 \% ; \mathrm{k}=1,54$ ). A largura da cápsula cefálica das lagartas apresentou razão média de crescimento de 1,55, com variação de 1,47 a 1,64 em suscetíveis e de 1,41 a 1,80 em resistentes (Tabelas 3.1 e 3.2; Figura 3.1). 
Tabela 3.1 - Média da largura $(\mathrm{mm})$, intervalo de variação e razão de crescimento da cápsula cefálica de lagartas de $S$. frugiperda suscetível a lambda-cyhalothrin, considerando a hipótese de seis ínstares, mantidas em dieta artificial à base de feijão $\left(25 \pm 1^{\circ} \mathrm{C} ; 70 \pm 10 \% \mathrm{UR}\right.$; fotofase de $\left.14 \mathrm{~h}\right)$

\begin{tabular}{lccc}
\hline Instar & $\begin{array}{c}\text { Cápsula cefálica } \\
(\mathrm{mm})\end{array}$ & $\begin{array}{c}\text { Intervalo de variação } \\
\text { I }\end{array}$ Razão de crescimento \\
II & $0,31 \pm 0,00$ & $0,28-0,34$ & \\
III & $0,48 \pm 0,01$ & $0,40-0,59$ & 1,55 \\
IV & $0,79 \pm 0,01$ & $0,60-0,95$ & 1,64 \\
V & $1,24 \pm 0,01$ & $1,10-1,38$ & 1,57 \\
VI & $1,87 \pm 0,02$ & $1,66-2,07$ & 1,51 \\
\hline
\end{tabular}

Tabela 3.2 - Média da largura $(\mathrm{mm})$, intervalo de variação e razão de crescimento da cápsula cefálica de lagartas de $S$. frugiperda resistente a lambda-cyhalothrin, considerando a hipótese de seis ínstares, mantidas em dieta artificial à base de feijão $\left(25 \pm 1^{\circ} \mathrm{C} ; 70 \pm 10 \% \mathrm{UR}\right.$; fotofase de $\left.14 \mathrm{~h}\right)$

\begin{tabular}{lccc}
\hline Instar & $\begin{array}{c}\text { Cápsula cefálica } \\
(\mathrm{mm})\end{array}$ & Intervalo de variação & Razão de crescimento \\
\hline I & $0,30 \pm 0,00$ & $0,27-0,33$ & \\
II & $0,46 \pm 0,00$ & $0,42-0,50$ & 1,53 \\
III & $0,83 \pm 0,01$ & $0,70-0,95$ & 1,80 \\
IV & $1,31 \pm 0,01$ & $1,14-1,49$ & 1,58 \\
V & $1,85 \pm 0,01$ & $1,70-2,05$ & 1,41 \\
VI & $2,66 \pm 0,01$ & $2,50-2,82$ & 1,44 \\
\hline
\end{tabular}



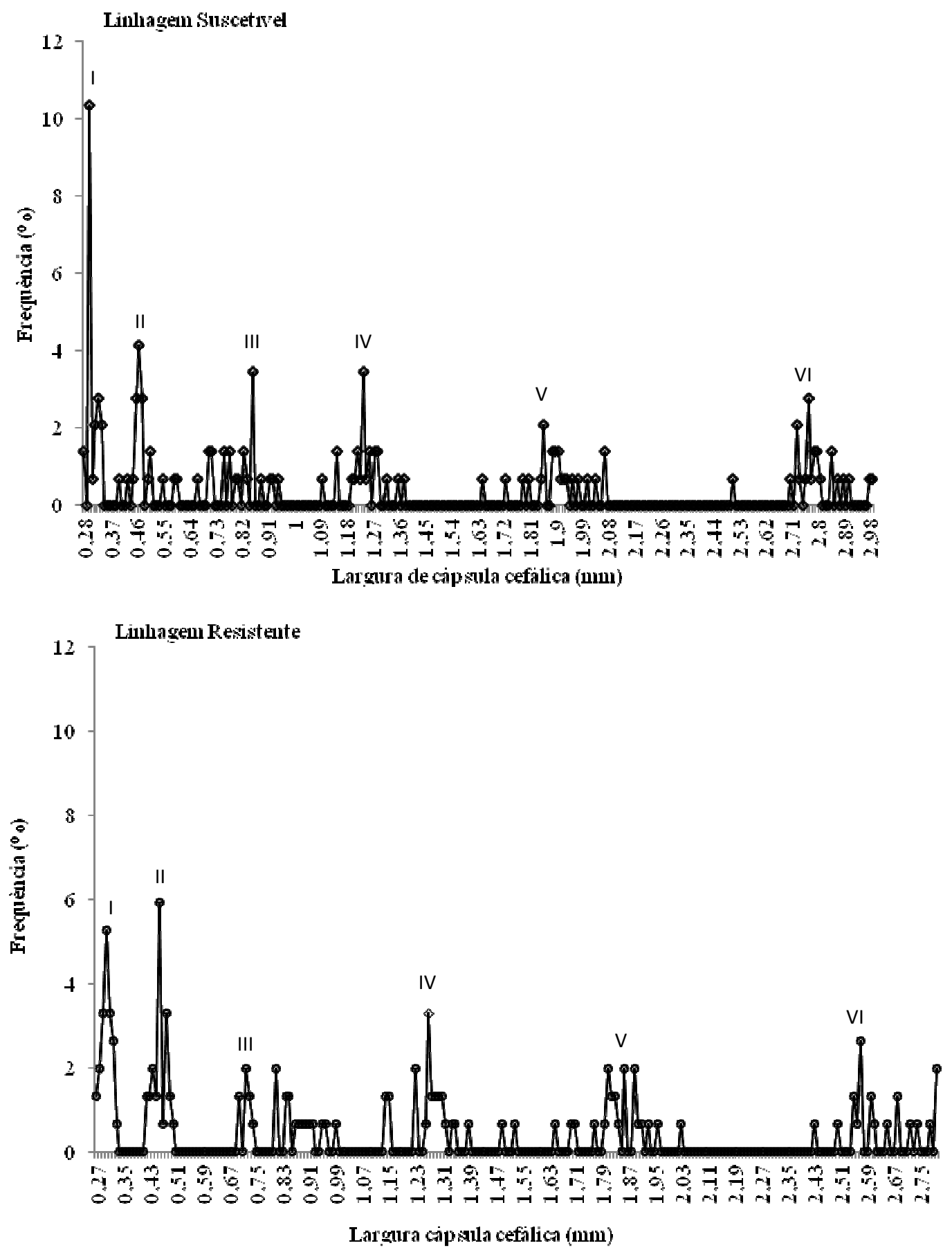

Figura 3.1 - Frequência de medidas da largura $(\mathrm{mm})$ da cápsula cefálica de lagartas de $S$. frugiperda suscetíveis e resistentes a lambda-cyhalothrin, mantidas em dieta artificial à base de feijão $\left(25 \pm 1^{\circ} \mathrm{C} ; 70 \pm 10 \% \mathrm{UR}\right.$; fotofase de $\left.14 \mathrm{~h}\right)$ 
Foi verificada diferença significativa na duração média da fase de desenvolvimento larval entre as linhagens ( $t=6,91$; g.l. $=1,54 ; P=0,0111)$, sendo o desenvolvimento de lagartas resistentes muito mais lento do que o de suscetíveis (Tabela 3.3). A duração média da fase pupal foi maior na linhagem resistente do que na suscetível, para ambos os sexos, $(t=29,22$; g.l. $=1,19 ; P=<.0001)$ em fêmeas e $(t=22,34 ;$ g.l. $=1,19 ; P=0,0002)$ em machos. Interessantemente, pupas macho da linhagem resistente apresentaram peso muito superior àquele obtido na linhagem suscetível $(t=7,79 ;$ g.l. $=1,19 ; P=0,0125)$, sendo o valor nominal superior até mesmo ao peso obtido para fêmeas (Tabela 3.3). Embora numericamente a porcentagem de pupas deformadas observada tenha sido maior para a linhagem resistente, não foi verificada diferença significativa entre as linhagens (Tabela 3.3).

Tabela 3.3 - Parâmetros biológicos de S. frugiperda suscetíveis e resistentes a lambdacyhalothrin, mantidas em dieta artificial à base de feijão $\left(25 \pm 1^{\circ} \mathrm{C} ; 70 \pm 10 \%\right.$ UR; fotofase de $14 \mathrm{~h}$ ).

\begin{tabular}{|c|c|c|}
\hline Parâmetros biológicos ${ }^{1}$ & Suscetível & Resistente \\
\hline Duração desenvolvimento larval (dias) & $13,9 \pm 0,95 \mathrm{~b}$ & $17,1 \pm 1,02 \mathrm{a}$ \\
\hline Duração pupa $\widehat{o}$ (dias) & $10,7 \pm 0,18 b$ & $12,2 \pm 0,20 \mathrm{a}$ \\
\hline Duração pupa $q$ (dias) & $10,5 \pm 0,14 b$ & $12,1 \pm 0,29$ a \\
\hline Peso pupa $\widehat{\sigma}(\mathrm{mg})$ & $254,4 \pm 3,28 b$ & $275,8 \pm 5,46$ a \\
\hline Peso pupa $q(\mathrm{mg})$ & $261,9 \pm 4,41 \mathrm{a}$ & $264,6 \pm 10,08 \mathrm{a}$ \\
\hline Deformação de pupas (\%) & $12,0 \pm 4,91 \mathrm{a}$ & $20,0 \pm 5,01 \mathrm{a}$ \\
\hline
\end{tabular}

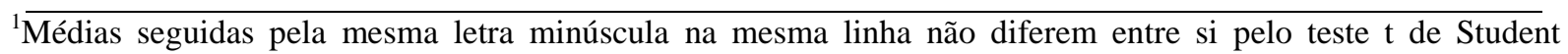
( $\mathrm{P}>0,05)$.

Foram verificadas razão sexual e longevidade de fêmeas $(t=15,39 ;$ g.l. $=1,19$; $P=0,0234)$ menores para a linhagem de $S$. frugiperda resistente a lambda-cyhalothrin em relação à linhagem suscetível (Tabela 3.4). 
Tabela 3.4 - Variáveis biológicas de S. frugiperda suscetíveis e resistentes a lambdacyhalothrin, mantidas em dieta artificial à base de feijão $\left(25 \pm 1^{\circ} \mathrm{C} ; 70 \pm 10 \%\right.$ UR; fotofase de $14 \mathrm{~h}$ ).

\begin{tabular}{|c|c|c|}
\hline Variáveis biológicas & Suscetível & Resistente \\
\hline Período de preoviposição (dias) $^{1}$ & $4,6 \pm 0,54 \mathrm{a}$ & $4,8 \pm 0,24 \mathrm{a}$ \\
\hline Período de oviposição (dias) ${ }^{1}$ & $6,0 \pm 1,15$ a & $6,3 \pm 1,01 \mathrm{a}$ \\
\hline Ovos/fêmea $\left(n^{o}\right)^{1}$ & $1113,3 \pm 252,26 \mathrm{a}$ & $985,4 \pm 146,70 \mathrm{a}$ \\
\hline Posturas/fêmea $\left(n^{o}\right)^{1}$ & $9,6 \pm 1,15$ a & $8,7 \pm 1,19$ a \\
\hline Espermatóforos/fêmea $\left(\mathrm{n}^{\mathrm{o}}\right)^{1}$ & $1,8 \pm 0,22 \mathrm{a}$ & $1,3 \pm 0,05 \mathrm{a}$ \\
\hline Longevidade de machos (dias) $^{1}$ & $11,9 \pm 1,20 \mathrm{a}$ & $10,8 \pm 1,00 \mathrm{a}$ \\
\hline Longevidade de fêmeas (dias) ${ }^{1}$ & $14,3 \pm 0,81 \mathrm{a}$ & $9,8 \pm 1,34 \mathrm{~b}$ \\
\hline Razão sexual $^{2}$ & $0,65 *$ & $0,40 *$ \\
\hline
\end{tabular}

${ }^{1}$ Médias seguidas pela mesma letra minúscula na mesma linha não diferem entre si pelo teste $\mathrm{t}$ de Student $(\mathrm{P}>0,05),{ }^{2}$ Valores diferem pelo teste de $\chi^{2}$.

\subsubsection{Tabela de vida de fertilidade de linhagens de $S$. frugiperda suscetível e resistente a lambda-cyhalothrin}

Baseada na confecção da tabela de vida e de fertilidade, foi verificada diferença significativa para a taxa líquida de reprodução $\left(\mathrm{R}_{0}\right)$, taxa intrínseca de aumento $\left(r_{m}\right)$ e taxa finita de aumento $(\lambda)$, com a linhagem suscetível apresentando maiores valores do que a resistente (Tabela 3.5). A taxa líquida de reprodução $\left(\mathrm{R}_{0}\right)$ de 393,42 na linhagem suscetível indica uma estimativa de produção de aproximadamente 393 fêmeas da linhagem suscetível resultantes de cada fêmea em fase reprodutiva em um período de 23 dias (T). Portanto, a taxa líquida de reprodução $\left(\mathrm{R}_{0}\right)$ foi mais de 1,6 vezes superior na linhagem suscetível do que na resistente, demonstrando que a linhagem resistente apresenta desvantagem reprodutiva em relação a suscetível na ausência da pressão de seleção do inseticida. 
Tabela 3.5 - Parâmetros de tabela de vida e de fertilidade de linhagens de S. frugiperda suscetível e resistente a lambda-cyhalothrin, mantidas em dieta artificial à base de feijão $\left(25 \pm 1^{\circ} \mathrm{C} ; 70 \pm 10 \% \mathrm{UR}\right.$; fotofase de $\left.14 \mathrm{~h}\right)$.

\begin{tabular}{lcc}
\hline Parâmetros* & Suscetível & Resistente \\
\hline Taxa líquida de reprodução $\left(\mathrm{R}_{0}\right)$ & $393,42 \pm 72,55 \mathrm{a}$ & $243,34 \pm 37,23 \mathrm{~b}$ \\
Tempo de geração $(T)$ (dias) & $23,21 \pm 0,18 \mathrm{a}$ & $27,73 \pm 0,11 \mathrm{a}$ \\
Tempo para duplicação populacional $(T D)($ dias $)$ & $2,69 \pm 0,09 \mathrm{a}$ & $3,48 \pm 0,10 \mathrm{a}$ \\
Taxa intrínseca de aumento $\left(r_{m}\right)$ & $0,257 \pm 0,009 \mathrm{a}$ & $0,199 \pm 0,005 \mathrm{~b}$ \\
Taxa finita de aumento $(\lambda)$ & $1,29 \pm 0,01 \mathrm{a}$ & $1,22 \pm 0,00 \mathrm{~b}$
\end{tabular}

*Médias seguidas da mesma letra minúscula na linha não diferem significativamente entre si pelo teste $t$ de Student unilateral $(\mathrm{P}>0,05)$.

A fecundidade das linhagens de S. frugiperda avaliadas foi dependente da idade, sendo que a maior deposição de ovos/fêmea ocorreu na primeira postura, independentemente da linhagem. Em relação à fertilidade, fêmeas suscetíveis apresentaram maior fertilidade nos primeiros dias de oviposição, entre $4^{\circ}$ e $5^{\circ}$ dia $(m x=268,74)$, enquanto que fêmeas resistentes apresentaram maior fertilidade entre o $5^{\circ}$ e $6^{\circ}$ dia $(m x=96,74)$ (Figura 3.2). Também foram verificadas altas taxas de sobrevivência $(l x)$ para os primeiros dias de vida reprodutiva de ambas as linhagens, sendo a curva de decréscimo da sobrevivência de adultos resistentes um pouco mais acentuada do que a curva dos suscetíveis (Figura 3.2).

Na linhagem de $S$. frugiperda resistente a lambda-cyhalothrin foi observado menor valor de $m x$ (natalidade) durante toda a fase reprodutiva em relação às suscetíveis (Figura 3.2). Adultos resistentes apresentaram mortalidade logo após o $5^{\circ}$ dia de vida reprodutiva, enquanto que lagartas suscetíveis apresentaram mortalidade após o $7^{\circ}$ dia de vida reprodutiva (Figura 3.2). 




Figura 3.2 - Sobrevivência $(l x)$ e natalidade $(m x)$ em linhagens de $S$. frugiperda suscetível e resistente lambda-cyhalothrin mantidas em dieta artificial à base de feijão $\left(25 \pm 1{ }^{\circ} \mathrm{C} ; 70 \pm 10 \% \mathrm{UR}\right.$; fotofase de $\left.14 \mathrm{~h}\right)$

3.3.3 Biologia e parasitismo por Campoletis aff. flavicincta em linhagens de $S$. frugiperda suscetível e resistente a lambda-cyhalothrin

\subsubsection{Desenvolvimento e morfologia das fases imaturas}

Não foram observadas diferenças dos estágios de desenvolvimento embrionário, larval e pupal do parasitoide Campoletis aff. flavicincta em linhagens de S. frugiperda suscetível e resistente a lambda-cyhalothrin. A duração da fase embrionária foi de 4 dias e da fase larval de 5 dias, em ambas as linhagens do hospedeiro. 
Após 24 h do parasitismo por Campoletis aff. flavicincta, os ovos do parasitoide foram encontrados nos últimos segmentos abdominais do hospedeiro em ambas as linhagens, localizados próximos ao "falso pulmão" (“tokus lungs”) (LOCKE, 1997; RAO et al., 2009).

Em relação à morfologia, os ovos do parasitoide apresentaram cerca de $0,1 \mathrm{~mm}$ de largura e 0,2 mm de comprimento, sendo alongados e de coloração marrom clara. Em relação ao desenvolvimento embrionário (Figura 3.3), a maioria dos ovos observados no início apresentavam células em divisão (Figura 3.3a). Com dois e três dias de desenvolvimento foi observado o embrião do parasitoide, respectivamente, em fase de histogênese ou completamente desenvolvido (Figuras 3.3b e 3.3c). Aos quatro dias após o parasitismo, foi registrada a eclosão de larvas do parasitoide em ambas as linhagens de hospedeiros utilizadas.
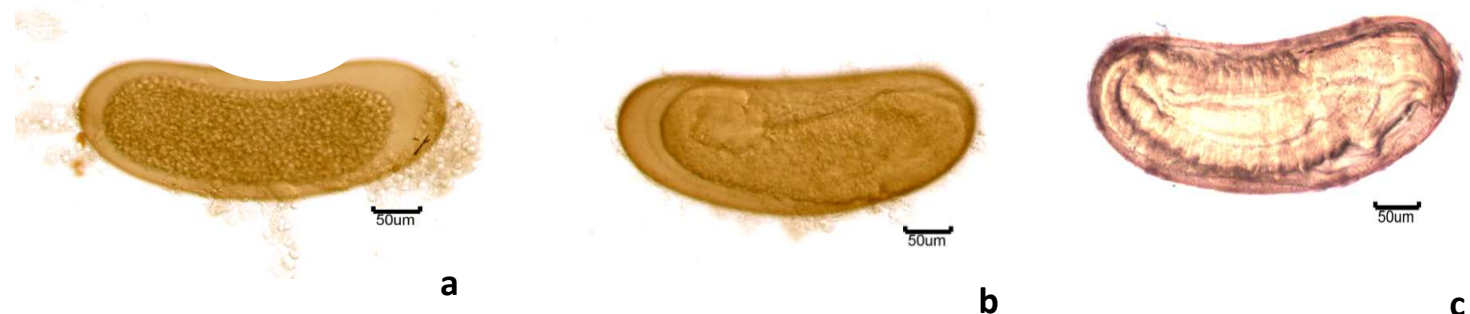

b

c

Figura 3.3 - Desenvolvimento embrionário de Campoletis aff. flavicincta em lagartas de Spodoptera frugiperda suscetível ou resistente a lambda-cyhalothrin aos 1 (a), 2 (b) e 3 (c) dias após o parasitismo (DAP). $\left(25 \pm 1^{\circ} \mathrm{C} ; 70 \pm 10 \%\right.$ UR; fotofase de $14 \mathrm{~h})$

Em relação ao desenvolvimento larval do parasitoide, larvas de 0-24 h (cinco dias após o parasitismo) de idade de Campoletis aff. flavicincta apresentaram cauda e mandíbulas bem desenvolvidas, cabeça larga e esclerotizada e corpo de coloração hialina. Aos seis dias após o parasitismo, foi observada regressão da cauda das larvas, sendo as larvas encontradas na porção superior do hospedeiro e próximas aos túbulos de Malpighi. Já aos sete dias após o parasitismo, as larvas apresentaram regressão total da cauda e formação da cápsula anal, mantendo a localização no hospedeiro anteriormente descrita. Neste período de desenvolvimento, as larvas apresentavam $3 \mathrm{~mm}$ de comprimento por $0,5 \mathrm{~mm}$ de largura. $\mathrm{Um}$ fato importante foi a observação de somente uma larva por hospedeiro, evidenciando a eliminação de concorrentes que estiveram presentes até o sexto dia de desenvolvimento. 
Entre os dias oito e nove, as larvas apresentavam ganho de peso corporal e tamanho quase que completo do corpo do hospedeiro. Foi observado que o tecido adiposo do hospedeiro estava totalmente consumido e, aos nove dias, as larvas se encontravam mais próximas à cabeça do hospedeiro. Entre nove e 10 dias após o parasitismo, a maioria das larvas já haviam rompido o tegumento do hospedeiro. As larvas apresentavam coloração rósea, com mandíbulas bem desenvolvidas em forma de foice, com tamanho de seu corpo igual ou até mesmo maior do que o corpo do hospedeiro. Também foi observado que as larvas do parasitoide se movimentaram até o ponto mais alto da placa em que se encontravam acondicionadas para iniciar a transformação em pupa.

As pupas formadas em ambas as linhagens, entre 10 e 12 dias após o parasitismo, apresentavam inicialmente coloração branca com pontuações negras, oriundas possivelmente da deposição de mecônio do hospedeiro. A duração média da fase pupal foi de nove a 10 dias para cada linhagem.

\subsubsection{Aceitação de $S$. frugiperda por Campoletis aff. flavicincta}

Dentre as 20 lagartas de $S$. frugiperda de ambas as linhagens submetidas ao parasitismo por Campoletis aff. flavicincta, observou-se que o número médio de ovos de Campoletis aff. flavicincta depositados por oviposição/fêmea em lagartas resistentes foi maior do que em suscetíveis ( $t=2,50 ;$ g.l. $=19 ; P=0,0507)$. No entanto, não foi observada diferença estatística significativa na porcentagem de aceitação de lagartas suscetíveis e resistentes por Campoletis aff. flavicincta $(t=1,00 ;$ g.l.= 19; $P=1,000)$ (Tabela 3.6).

Tabela 3.6 - Número médio de ovos por lagarta parasitada e porcentagem de aceitação de lagartas de Spodoptera frugiperda suscetíveis e resistentes a lambda-cyhalothrin por Campoletis aff. flavicincta $\left(25 \pm 1{ }^{\circ} \mathrm{C} ; 70 \pm 10 \% \mathrm{UR}\right.$; fotofase de $\left.14 \mathrm{~h}\right)$.

\begin{tabular}{lcc}
\hline Linhagem & ovos/lagarta parasitada* & \% de aceitação* \\
\hline Suscetível & $2,0 \pm 0,28 \mathrm{~B}$ & $85,0 \pm 8,00 \mathrm{~A}$ \\
Resistente & $3,0 \pm 0,44 \mathrm{~A}$ & $85,0 \pm 8,00 \mathrm{~A}$ \\
\hline
\end{tabular}

*Médias seguidas pela mesma letra maiúscula na coluna não diferem entre si pelo teste t de Student $(\mathrm{P}>0,05)$. 


\subsubsection{Interação do milho geneticamente modificado (MON810) e do parasitoide} Campoletis aff. flavicincta

Os fatores "linhagem do hospedeiro" (resistente ou suscetível a lambda-cyhalothrin) e "híbrido de milho" (milho Bt e não-Bt) não interagiram para influenciar o parasitismo de larvas de $S$. frugiperda pelo parasitoide Campoletis aff. flavicincta $(F=1,01 ;$ g.l. $=1,15 ; P=$ 0,3347). No entanto, a linhagem do hospedeiro foi o único fator a influenciar o parasitismo de lagartas de S. frugiperda pelo parasitoide $(F=7,50 ;$ g.l. $=1,15 ; P=0,0180)$, sendo o parasitismo de lagartas resistentes a lambda-cyhalothrin superior ao de lagartas suscetíveis (Tabela 3.7). O tipo de híbrido de milho utilizado pelo hospedeiro não se mostrou como um fator que influenciou o parasitismo de lagartas de S. frugiperda por Campoletis aff. flavicincta $(F=1,01 ;$ g.l. $=1,15 ; P=0,3347)$, sendo observado parasitismo médio de 13,7 e 16,2, respectivamente para os híbridos não-Bt e Bt.

Tabela 3.7 - Percentual médio de parasitismo por Campoletis aff. flavicincta em S. frugiperda suscetível (SUS) e resistente (RES) a lambda-cyhalothrin, sobreviventes em milho Bt (DKB240YG ${ }^{\circledR}$ ) e não-Bt (DKB240).

\begin{tabular}{lccc}
\hline Linhagem & \multicolumn{3}{c}{ Híbrido de milho } \\
\hline \multirow{2}{*}{ SUS } & $\mathrm{Bt}$ & Não-Bt & Média $^{1}$ \\
RES & $12,5 \pm 2,50$ & $7,50 \pm 2,50$ & $10,0 \pm 1,88 \mathrm{~B}$ \\
& $20,0 \pm 4,08$ & $20,0 \pm 4,08$ & $20,0 \pm 2,67 \mathrm{~A}$
\end{tabular}

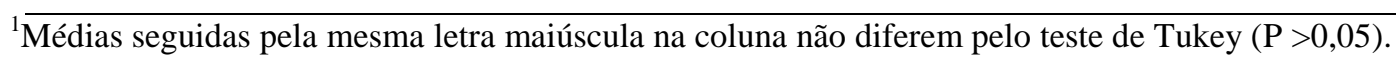

\subsection{Discussão}

A resistência de insetos a xenobióticos define a mudança da frequência fenotípica de uma população com a exposição ao fator de pressão de seleção (COSTAU et al., 2000; OAKESHOTT et al., 2003), mas a mesma nem sempre está associada à ocorrência de custos adaptativos (FOURNIER et al., 1988; ARNAUD et al., 2002; PIMENTEL et al., 2007; CROWDER et al., 2009). A ausência de custo adaptativo relacionado à resistência, em alguns casos, pode acelerar o desenvolvimento de resistência em populações de insetos (BIELZA et al., 2008).

Custos adaptativos resultantes da alteração fenotípica em uma população dada a seleção de indivíduos resistentes podem ocorrer devido a mutações essenciais que levam ao 
processo de contrasseleção na ausência do fator de seleção (GEORGHIOU, 1972; ROUSH; McKENZIE, 1987; FFRENCH-CONSTANT et al., 2004). Assim, é evidente que a existência de custos adaptativos associados à resistência é dependente do mecanismo molecular envolvido nesse processo (CROW, 1957; SCHULER et al., 1998; HECKEL, 2009), sendo a superprodução constitutiva de moléculas que levam à degradação do xenobiótico (FEYEREISEN, 1999) aquela que normalmente resulta na alocação diferencial de nutrientes e, consequentemente, em custos fisiológicos (COSTAU et al., 2000; TAYLOR; FEYEREISEN, 1996).

Há vários relatos de custos adaptativos associados à resistência de insetos a piretroides (PARK; TAYLOR, 1997; PARK et al., 2000; ZHAO et al., 2000; HARDSTONE et al., 2009; CORRÊA et al., 2011), apesar da possível redução dos mesmos devido à seleção de alelos modificadores dos custos associados à resistência (COSTAU et al., 2000; ARAÚJO et al., 2008).

As análises biológicas comparativas realizadas entre linhagens de $S$. frugiperda suscetível e resistente a lamba-cyhalothrin demonstraram a existência de alterações na biologia do inseto que apontam nitidamente a existência de custos fisiológicos associados à resistência a esse xenobiótico. Insetos da linhagem resistente a lambda-cyhalothrin apresentaram prolongamento da duração da fase larval, redução na longevidade de fêmeas e, principalmente, redução na capacidade de aumento populacional, alterações essas ligadas à redução da aptidão biológica do inseto (BIGLER, 1989; BALE et al, 2008; MIYATAKE, 2011).

As alterações na biologia de $S$. frugiperda decorrentes dos custos fisiológicos da resistência desse inseto a lambda-cyhalothrin podem ter implicações diretas no manejo de populações resistentes. O prolongamento da fase larval de desenvolvimento do inseto resistente aumenta os riscos de exposição desse estágio imaturo do inseto aos fatores naturais de mortalidade, como, por exemplo, os inimigos naturais (TREACY et al., 1985; IQBAL; WRIGHT, 1996; BOIVIN et al., 2001; PATHAN et al., 2010; FOSTER et al., 2011). No entanto, inimigos naturais se beneficiariam dos custos fisiológicos associados à resistência do hospedeiro ao xenobiótico desde que os mesmos não implicassem em redução da qualidade do hospedeiro ao seu inimigo natural (UMORU; POWELL, 2002; LIU et al., 2003; ODE, 2006; HODGE et al., 2011). Ainda, benefícios aos inimigos naturais em sistemas tradicionais de cultivo só poderiam ser obtidos se o produto em questão apresentasse seletividade ao inimigo natural (FERNANDES et al., 2010). Porém, lambda-cyhalothrin, assim como outros piretroides, devido ao seu modo de ação, apresenta espectro de ação bastante amplo, atingindo 
indiscriminadamente organismos não-alvos (PROVOST et al., 2003; DESNEUX et al., 2004; WANG et al., 2012).

No entanto, em sistemas de cultivo em que novas tecnologias são utilizadas, como o cultivo de plantas geneticamente modificadas, espera-se que a existência de custos associados à resistência a xenobióticos auxiliem no restabelecimento da suscetibilidade devido à remoção do fator de pressão de seleção (MUSSER et al., 2006). Assim, dado que o parasitoide Campoletis aff. flavicincta não apresentou qualquer efeito negativo ao se desenvolver em lagartas de $S$. frugiperda resistentes a lambda-cyhalothrin, é possível que esse inimigo natural exerça maior pressão de seleção sobre as lagartas resistentes dada à redução da aptidão biológica das mesmas se comparada às suscetíveis, auxiliando, assim, o restabelecimento da suscetibilidade de populações de $S$. frugiperda ao inseticida lambda-cyhalothrin.

Apesar da inexistência de efeitos negativos de hospedeiros resistentes ao desenvolvimento de inimigos naturais ser relatado em outros sistemas (SCHULER et al., 2004) e, em alguns casos, hospedeiros resistentes protegerem o imaturo do inimigo natural da ação do xenobiótico (FURLONG; WRIGHT, 1993), não é possível descartar por completo a possível existência de efeitos nocivos a Campoletis aff. flavicincta dada à utilização de lagartas de S. frugiperda resistentes a lambda-cyhalothrin, visto a possibilidade de efeito sobre aspectos iniciais do processo de seleção hospedeira (FOSTER et al., 2005), os quais não foram avaliados para esse parasitoide de S. frugiperda. A ausência de efeito negativo no desenvolvimento e morfologia de imaturos do parasitoide Campoletis aff. flavicincta, quando parasitando lagartas resistentes a lambda-cyhalothrin, pode ser devida ao fato de que os custos da resistência não interferem em aspectos da fisiologia do hospedeiro relevantes à nutrição do parasitoide ou que seja devido à capacidade de manipulação do hospedeiro pelo parasitoide. Parasitoides cenobiontes como Campoletis aff. flavicincta são capazes de manipular a fisiologia do hospedeiro (VINSON et al., 2001; CÔNSOLI; VINSON, 2009), tornando-os nutricionalmente adequados ao seu próprio desenvolvimento (BRODEUR; BOIVIN, 2004), influenciando a aquisição e utilização de nutrientes pelos hospedeiros (JERVIS et al., 2008; LE LANN et al., 2011).

Apesar dos ensaios de casa-de-vegetação em condições de gaiola não terem demonstrado qualquer efeito aditivo do uso de plantas Bt no parasitismo de lagartas de $S$. frugiperda resistentes a lambda-cyhalothrin quando comparadas a lagartas suscetiveis, é esperado que, em condições naturais, o prolongamento do período de desenvolvimento larval de $S$. frugiperda resistente a lambda-cyhalothrin seja potencializado, dado o efeito nocivo de toxinas Bt no desenvolvimento desse inseto (SANDERS et al., 2007; RAMIREZ-ROMERO 
et al., 2007, SHARMA et al., 2008), fazendo com lagartas resistentes permaneçam disponíveis ao parasitismo (ou a outras fontes de mortalidade natural) por períodos muito mais longos do que as lagartas suscetíveis. Porém, esta questão só poderá ser definitivamente esclarecida após a condução de ensaios a campo (NARANJO, 2009).

Sendo assim, o controle biológico pode funcionar como mecanismo auxiliar no processo de alteração e restabelecimento da suscetibilidade a inseticidas quando em associação com outras táticas de controle (GOULD, 1998; ROMEIS et al., 2006), como, por exemplo, o uso de híbridos de milho geneticamente modificados resistentes a insetos (ROSE; DIVELY, 2007). A maior pressão de seleção sobre lagartas resistentes a lambda-cyhalothrin, dada pelo parasitismo em cultivos de milho Bt, na ausência do inseticida, tende a contribuir para a diluição da frequência de alelos de resistência (TABASHNIK, 1994; GUSTAFSON et al., 2006) e, assim, para o restabelecimento da suscetibilidade a inseticidas (WU et al., 2005).

Ainda, a observação de sobreviventes de S. frugiperda, sejam elas suscetíveis ou resistentes a lambda-cyhalothrin, fortalece a necessidade de uso de áreas de cultivo com milho não-Bt como área de refúgio para o manejo da resistência de $S$. frugiperda às toxinas $\mathrm{Bt}$ expressas nessa planta (WAQUIL et al., 2008; GASSMANN et al., 2009). Neste caso, esperase que os efeitos subletais induzidos pela toxina Cry1Ab em lagartas de S. frugiperda resultem em maior pressão de parasitismo nessas lagartas do que naquelas em desenvolvimento na área de refúgio, o que tende a produzir o efeito de diluição do alelo resistente na população, retardando a evolução da resistência desse inseto a esta tecnologia de controle de pragas.

\subsection{Conclusões}

- A resistência a lambda-cyhalothrin em Spodoptera frugiperda resulta em custos adaptativos ao inseto;

- A linhagem de S. frugiperda resistente a lambda-cyhalothrin apresenta maior duração das fases larval e pupal, redução no peso de pupas e longevidade de fêmeas;

- As taxas líquida de reprodução $(R o)$, íntrinseca de aumento $(\mathrm{rm})$ e finita de aumento $(\lambda)$ são reduzidas em $S$. frugiperda resistente a lambda-cyhalothrin;

- O custo adaptativo associado à resistência de $S$. frugiperda a lambda-cyhalothrin não afeta o desenvolvimento do parasitoide Campoletis aff. flavicincta; 
- Lagartas de S. frugiperda resistentes a lambda-cyhalothrin são mais sujeitas ao parasitismo por Campoletis aff. flavicincta do que as lagartas suscetíveis, em testes de gaiolas em condições de casa de vegetação;

- O parasitismo de lagartas de $S$. frugiperda, suscetíveis ou resistentes a lambdacyhalothrin, pelo parasitoide larval Campoletis aff. flavicincta não foi influenciado pela planta hospedeira (milho Bt vs. não-Bt) em testes de gaiolas em condições de casa de vegetação;

- Na ausência do fator de seleção (lambda-cyhalothrin), o parasitoide Campoletis aff. flavicincta pode acelerar o restabelecimento da suscetibilidade de $S$. frugiperda a este produto.

\section{Referências}

ARAÚJO, R.A.; GUEDES, R.N.C.; OLIVEIRA, M.G.A.; FERREIRA, G.H. Enhanced activity of carbohydrate- and lipid-metabolizing enzymes in insecticide-resistant populations of the maize weevil, Sitophilus zeamais. Bulletin of Entomological Research, Farnham Royal, v. 98, p. 417-424, 2008.

ARNAUD, L.; BROSTAUX, Y.; ASSIE, L.K.; GASPAR, C.; HAUBRUGE, E. Increased fecundity of malathion-specific resistant beetles in absence of insecticide pressure. Heredity, London, v. 89, p. 425-429, 2002.

BALE, J.S.; VAN LENTEREN, J.C.; BIGLER, F. Biological control and sustainable food production. Philosophical transactions of the Royal of Society B: Biological Sciences, London, v. 363, p. 761-776, 2008.

BIELZA, P.; QUINTO, V.; GRÁVADOS, C.; ABELLÁN, J.; FERNÁNDEZ, E. Lack of fitness costs of insecticide resistance in the western flower thrips (Thysanoptera: Thripidae). Journal of Economic Entomology, Lanham, v. 101, p. 499-503, 2008.

BIGLER, F. Quality assessment and control in entomophagous insects used for biological control. Journal of Applied Entomology, Berlin, v. 108, p. 390-400, 1989.

BOIVIN, T.; D’HIÉRES, C.C.; BOUVIER, J.C.; BESLAY, D.; SAUPHANOR, B. Pleiotropic of insecticide resistance in the codling moth, Cydia pomonella. Entomologia Experimentalis et Applicata, Dodrecht, v. 99, p. 381-386, 2001.

BRODEUR, J.; BOIVIN, G. Functional ecology of immature parasitoids. Annual Review of Entomology, Stanford, v. 49, p. 27-49, 2004.

BROWN, E.S.; DEWHURST, C.F. The genus Spodoptera (Lepidoptera, Noctuidae) in Africa and the Near East. Bulletin of Entomological Research, Farnham Royal, v. 65, p. 221-262, 1975. 
CÔNSOLI, F.L.; VINSON, S.B. Parasitoides (Hymenoptera). In. PANIZI, A.R.; PARRA, J.R.P. (Ed.). Bioecologia e nutrição de insetos. Londrina: Embrapa, 2009. cap. 20, p. 837874.

CORRÊA, A.S.; PEREIRA, E.J.G.; CORDEIRO, E.M.G.; BRAGA, L.S.; GUEDES, R.N.C. Insecticide resistance, mixture potentiation and fitness in populations of the maize weevil (Sitophilus zeamais). Crop Protection, Guildford, v. 30, p. 1655-1666, 2011.

COUSTAU, C.; CHEVILLON, C.; FRENCH-CONSTANT, R. Resistance to xenobiotics and parasites: can we count the cost? Trends in Ecology and Evolution, Amsterdam, v. 15, p. 378-383, 2000.

CROW, J.F. Genetics of insect resistance to chemicals. Annual Review of Entomology, Stanford, v. 2, p. 227-246, 1957.

CROWDER, D.W.; ELLERS-KIRK, C.; TABASHNIK, B.E.; CARRIÈRE, Y. Lack of fitness costs associated with pyriproxyfen resistance in the B biotype of Bemisia tabaci. Pest Management Science, Sussex, v. 65, p. 235-240, 2009.

DESNEUX, N.; PHAM-DELÈGUE, M.H.; KAISER, L. Effects of sub-lethal and lethal doses of lambda-cyhalothrin on oviposition experience and host-searching behaviour of a parasitic wasp, Aphidius ervi. Pest Management Science, Sussex, v. 60, p. 381-389, 2004.

DÍEZ-RODRIGUEZ, G.I.; OMOTO, C. Herança da resistência de Spodoptera frugiperda (J.E. Smith) (Lepidoptera: Noctuidae) a Lambda-Cialotrina. Neotropical Entomology, Londrina, v. 30, p. 311-316, 2001.

FERNANDES, O.D.; PARRA, J.R.P.; NETO, A.F.; PÍCOLI, R.; BORGATTO, A.F.; DEMÉTRIO, C.G.B. Efeito do milho geneticamente modificado MON810 sobre a lagarta-docartucho Spodoptera frugiperda (J.E. Smith, 1797) (Lepidoptera: Noctuidae). Revista Brasileira de Milho e Sorgo, Sete Lagoas, v. 2, p. 25-35, 2003.

FERNANDES, F.L.; BACCI, L.; FERNANDES, M.S. Impact and selectivity of insecticides to predators and parasitoids. EntomoBrasilis, Londrina, v. 3, p. 1-10, 2010.

FEYEREISEN, R. Insect P450 enzymes. Annual Review of Entomology, Stanford, v. 44, p. 507-533, 1999.

FRRENCH-CONSTANT, R.H.; DABORN, P.; LE GOFF, G. The genetics and genomics of insecticide resistance. Trends inGenetics, London, v. 20, p. 163-170, 2004.

FOSTER, S.P.; DENHOLM, I.; POPPY, G.M.; THOMPSON, R.; POWELL, W. Fitness trade-off in peach-potato aphids (Myzus persicae) between insecticide resistance and vulnerability to parasitoid attack at several spatial scales. Bulletin of Entomological Research, Farnham Royal, v. 101, p. 659-666, 2011.

FOSTER, S.P.; DENHOLM, I.; THOMPSON, R.; POPPY, G.M.; POWELL, W. Reduced response of insecticide resistant aphids and attraction of parasitoids to aphid alarm pheromone; a potential fitness trade-off. Bulletin of Entomological Research, Farnham Royal, v. 95, p. 37-46, 2005. 
FOURNIER, D.; PRALAVORIO, M.; COULON, J.; BERGE, J.B. Fitness comparison in Phytoseiulus persimilis strains resistant and susceptible to methidathion. Experimental and Applied Acarology, Amsterdam, v. 5, p. 55-64, 1988.

FURLONG, M.J.; WRIGHT, D.J. Effect of the acylurea insect growth regulator teflubenzuron on the endo-larval stages of the hymenopteran parasitoids Cotesia plutellae and Diadegma semiclausum in a susceptible and an acylurea-resistant strain. Pesticide Science, Oxford, v. 39, p. 305-312, 1993.

GASSMANN, A.J.; CARRIÉRE, Y.; TABASHNIK, B.E. Fitness costs of insect resistance to Bacillus thuringiensis. Annual Review of Entomololgy, Stanford, v. 54, p. 147-163, 2009.

GASSMANN, A.J.; JEFFREY, A.F.; SISTERSON, M.S.; HANNON, E.R.; STOCK, P.S.; CARRIÉRE, Y.; TABASHNIK, B.E. Effects of pink bollworm resistance to Bacillus thuringiensis on phenoloxidase activity and susceptibility to entomopathogenic nematodes. Journal of Economic Entomology, Lanham, v. 102, p. 1224-1232, 2009.

GEORGHIOU, G.P. The evolution of resistance to pesticide. Annual Review of Ecological System, Stanford, v. 3, p. 133-168, 1972.

GEORGHIOU, G.P.; TAYLOR, C.E. Genetic and biological influences in the evolution of insecticide resistance. Journal of Economic Entomology, Lanham, v. 70, p. 319-323, 1977.

GOULD, F. Sustainability of transgenic insecticidal cultivars: integrating pest genetics and ecology. Annual Review of Entomology, Stanford, v. 43, p. 701-726, 1998.

GUSTAFSON, D.I.; HEAD, G.P.; CAPRIO, M.A. Modeling the impact of alternative hosts on Helicoverpa zea adaptation to Bollgard cotton. Journal of Economic Entomology, Lanham, v. 99, p. 2116-2124, 2006.

HARDSTONE, M.C.; LAZZARO, B.P.; SCOTT, J.G. The effect of three environmental conditions on the fitness of cytochrome $\mathrm{P} 450$ monooxygenase-mediated permethrin resistance in Culex pipiens quinquefasciatus. BMC Evolutionary Biology, London, v. 2, p. 9-42, 2009.

HECKEL, D.G. Molecular genetics of insecticide resistance in Lepidoptera. In. (Ed.). Molecular biology and genetics of Lepidoptera. London: CRC Publ., 2009. p. 239-269.

HODGE, S.; WARD, J.L.; GALSTER, A.M.; BEALE, M.H.; POWELL, G. The effects of a plant defence priming compound, $\beta$-aminobutyric acid, on multitrophic interactions with an insect herbivore and a hymenopterous parasitoid. Biological Control, Orlando, v. 56, p. 699$711,2011$.

HUANG, F.; SHI, M.; YANG, Y.; LI, J.; CHEN, X. Changes in hemocytes of Plutella xylostella after parasitism by Diadegma semiclausum. Archives of Insect Biochemistry and Physiology, New York, v. 70, p. 177-187, 2009.

IQBAL, M.; WRIGHT, D. Host resistance to insecticides can confer protection to endo-larval parasitoids. Bulletin of Entomological Research, Farnham Royal, v. 86, p. 721-723, 1996. 
JERVIS, M.A.; ELLERS, J.; HARVEY, J.A. Resource acquisition, allocation, and utilization in parasitoid reproductive strategies. Annual Review of Entomology, Stanford, v. 53, p. 361$385,2008$.

LE LANN, C.; VISSER, B.; VAN BAAREN, J.; VAN ALPHEN, J.J.M.; ELLERS, J. Comparing resource exploitation and allocation of two closely related aphid parasitoids sharing the same host. Evolutionary Ecology, London, v. 26, p. 79-94, 2011.

LEUCK, D.B.; PERKINS, W.D. A method of estimating fall armyworm progeny reduction when evaluating control achieved host-plant resistance. Journal of Economic Entomology, Lanham, v. 65, p. 482-483, 1972.

LOCKE, M. Caterpillars have evolved lungs for hemocyte gas exchange. Journal of Insect Physiology, Oxford, v. 44, p. 1-20, 1997.

LIU, S.S.; LI, Y.X.; ZHEN, H.T. Host resistance to an insecticide favors selection of resistance in the parasitoid Cotesia plutellae. Biological Control, Orlando, v. 28, p. 137-143, 2003.

MAIA, H.N.; LUIZ, M.A.J.B.; CAMPANHOLA, C. Statistical inference on associated fertility life table parameters using jackknife technique: computational aspects. Journal of Economic Entomology, Lanham, v. 93, p. 511-518, 2000.

MENDES, S.M.; BOREGAS, K.G.B.; LOPES, M.E.; WAQUIL, M.S.; WAQUIL, J.M. Respostas da lagarta-do-cartucho a milho geneticamente modificado expressando a toxina Cry 1A(b). Pesquisa Agropecuária Brasileira, Brasília, v. 46, p. 239-244, 2011.

MEYER, J.S.; INGERSOLL, C.G.; MCDONALD, L.L.; BOYCE, M.S. Estimating uncertainty in population growth rates: jackknife vs. Bootstrap techniques. Ecology, Washington, v. 67, p. 1156-1166, 1986.

MIYATAKE, T. Insect quality control: synchronized sex, mating system, and biological rhythm. Applied and Entomological Zoology, Tokyo, v.46, p. 3-14, 2011.

MUSSER, F.R.; NYROP, J.P.; SHELTON, A.M. Integrating biological and chemical controls in decision making: European corn borer (Lepidoptera: Crambidae) control in sweet corn as an example. Journal of Economic Entomology, Lanham, v. 55, p. 1538-1549, 2006.

NARANJO, S.E. Impacts of Bt crops on non-target invertebrates and insecticide use patterns. CAB reviews: Perspectives in Agriculture, Veterinary Science, Nutrition and Natural Resources, Warsaw, v. 4, p. 1-23, 2009.

OAKESHOTT, J.G.; HORNE, I.; SUTHERLAND, T.D.; RUSSELL, R.J. The genomics of insecticide resistance. Genome Biology, London, v. 4, p. 202, 2003.

ODE, P.J. Plant chemistry and natural enemy fitness: effects on herbivore and natural enemy interactions. Annual Review of Entomology, Stanford, v. 51, p. 163-185, 2006. 
PARK, Y.; TAYLOR, M.F.J. A novel mutation L1029H in sodium channel gene hscp associated with pyrethroid resistance for Heliothis virescens (Lepidoptera: Noctuidae). Insect Biochemestry and Molecular Biology, New York, v. 27, p. 9-13, 1997.

PARK, Y.; LEE, D.W.; TYALOR, M.F.J. A mutation Leu1029 to His in Heliothis virescens F.: hscp sodium channel gene associated with a nerve-insensitivity mechanism of resistance to pyrethroid insecticides. Pesticide Biochemistry, New York, v.66, p. 1-8, 2000.

PARRA, J.R.P. Consumo e utilização de alimentos por insetos. In: PANIZZI, A.R.; PARRA, J.R.P. (Ed.). Ecologia nutricional de insetos e suas implicações no manejo de pragas. São Paulo: Manole, 1991. p. 9-65.

PARRA, J.R.P.; HADDAD, M.L. Determinação do número de ínstares de insetos. Piracicaba: FEALQ, 1989. 49 p.

PATHAN, A.K.; SAYYED, A.H.; ASLAM, M.; LIU, T.X.; RAZZAQ, M.; GILLANI, W.A. Resistance to pyrethroids and organophosphates increased fitness and predation potential of Chrysoperla carnae (Neuroptera: Chrysopidae). Journal of Economic Entomology, Lanham, v. 103, p. 823-834, 2010.

PIMENTEL, M.A.G.; FARONI, L.R.D.; TÓTOLA, M.R.; GUEDES, R.N.C. Phosphine resistance, respiration rate and fitness consequences in stored-product insects. Pest Management Science, Sussex, v. 63, p. 876-881, 2007.

PROVOST, C.; CODERRE, D.; LUCAS, E.; NOUBAR, J.B. Impact of lambda-cyhalothrin on intraguild predation among three mite predators. Environmental Entomology, College Park, v. 32, p. 256-263, 2003.

RAMIREZ-ROMERO, R.; BERNAL, J.S.; CHAUFAUX, J.; KAISER. L. Impact assessment of Bt-maize on a moth parasitoid, Cotesia marginiventris (Hymenoptera: Braconidae), via host exposure to purified Cry1 Ab protein or Bt-plants. Crop Protection, Guildford, v. 26, p. 953-962, 2007.

RAO, A.; HENDERSON, R.E.; VINSON, S.B. The probable significance of tracheal tufts in the $8^{\text {th }}$ abdominal segment of Heliothis virescens (F.) on the development of its parasitoid, Toxoneuron nigriceps (Viereck). Journal of Insect Physiology, Oxford, v. 55, p. 769-773, 2009.

RÍOS-DÍEZ, J.D.; SALDAMANDO-BENJUMEA, C.I. Susceptibility of Spodoptera frugiperda (Lepidoptera: Noctuidae) strains from Central Colombia to two insecticides, methomyl and lambda-cyhalothrin: a study of the genetic base of resistance. Journal of Economic Entomology, Lanham, v. 104, p. 1698-1705, 2011.

ROMEIS, J.; MEISSLE, M.; BIGLER, F. Transgenic crops expressing Bacillus thuringiensis toxins and biological control. Nature Biotechnology, New York, v. 24, p. 63-71, 2006.

ROSE, R.; DIVELY, G.P. Effects of insecticide-treated and lepidopteran-active Bt-transgenic sweet corn on the abundance and diversity of arthropods. Environmental Entomology, College Park, v. 36, p. 1254-1268, 2007. 
ROUSH, R.T.; McKENZIE, J.A. Ecological genetics of insecticide and acaricide resistance. Annual Review of Entomololgy, Stanford, v. 32, p. 361-380, 1987.

SANDERS, C.J.; PELL, J.K.; POPPY, G.M.; RAYBOULD, A.; GARCIA-ALONSO, M.; SCHULER, T.H. Host-plant mediated effects of transgenic maize on the insect parasitoid Campoletis sonorensis (Hymenoptera: Ichneumonidae). Biological Control, Orlando, v. 40, p. 362-369, 2007.

SAS INSTITUTE. SAS/STAT: user's guide. Version 8: Cary, 2002.

SCHULER, T.H.; MARTINES-TORRES, D.; THOMPSON, A.J. Toxicological, electrophysiological, and molecular characterization of knockdown resistance to pyrethroid insecticides in the diamondback moth, Plutella xylostella (L.). Pesticide Biochemistry, New York, v. 59, p. 169-182, 1998.

SCHULER, T.H., DENHOLM, I.; CLARKE, S.J.; STEWART, C.N.; POPPY, G.M. Effects of Bt plants on the development and survival of Cotesia plutellae in susceptible and Btresistant larvae of Plutella xylostella. Journal of Insect Physiology, Oxford, v. 50, p. 435443, 2004.

SHARMA, H.C.; DHILLON, M.K.; ARORA, R. Effects of Bacillus thuringiensis $\delta$ endotoxin-fed Helicoverpa armigera on the survival and development on the parasitoid Campoletis chlorideae. Entomologia Experimentalis et applicata, Dordrecht, v. 126, p. 1-8, 2008.

SILVEIRA NETO, S.; NAKANO, O. BARBIN, D.; VILLA NOVA, N.D. Manual de ecologia dos insetos. São Paulo: Ceres, 1976. 419 p.

SIMMS, E.L.; FRITZ, R.S. The ecology and evolution of host-plant resistance to insects. Trends in Ecology and Evolution, Amsterdam, v. 5, p. 356-360, 1990.

SOUTHWOOD, T.R.E. Ecological methods. London: Chapmam \& Hall, 1995. 524 p.

STRAND, M.R.; WHITERELL, R.A.; TRUDEAU, D. Two Microplitis demolitor polydnavirus mRNAs expressed in hemocytes of Pseudoplusia includens contain a common cysteine-rich domain. Journal of Virology, Washington, v. 71, p. 2146-2156, 1997.

TABASHNIK, B.E. Evolution of resistance to Bacillus thuringiensis. Annual Review of Entomology, Stanford, v. 39, p. 47-79, 1994.

TAYLOR, M.; FEYEREISEN, R. Molecular biology and evolution of resistance to toxicants. Molecular Biology and Evolution, Chicago, v. 13, p. 719-734, 1996.

TREACY, M.F.; ZUMMO, G.R.; BENEDICT, J.H. Interactions of host-plant resistance in cotton with predators and parasites. Agriculture, Ecosystems and Environment, Amsterdam, v. 13, p. 151-157, 1985.

UMORU, P.A.; POWELL, W. Sub-lethal effects of the insecticide pirimicarb and dimethoate on the aphid parasitoid Diaeretiella rapae when attacking and developing in insecticideresistant hosts. Biocontrol Science and Technology, Oxoford, v. 12, p. 605-614, 2002. 
VENDRAMIM, J.D. A resistência de plantas e o manejo de pragas. In: CROCOMO, W.B. Manejo integrado de pragas. São Paulo: CETESB, 1990. cap. 9, p. 177-197.

VINSON, S.B.; PENNACCHIO, F.; CÔNSOLI, F.L. The parasitoid-host endocrine interaction from a nutritional perspective. In: EDWARD, J.P.; WEAVER, R.J. (Ed.). Endocrine interactions of insect parasites and pathogens. Oxford: Bios Scientific, 2001. p. 187-206.

WANG, Y.; YU, R.; ZHAO, X.; CHEN, L.; WU, C.; CANG, T.; WANG, Q. Susceptibility of adult Trichogramma nubilale (Hymenoptera: Trichogrammatidae) to selected insecticides with different modes of action. Crop Protection, Guildford, v. 34, p. 76-82, 2012.

WAQUIL, J.M.; BOREGAS, K.G.B.; MENDES, S.M. Viabilidade do uso de hospedeiros alternativos como área de refúgio para o manejo da resistência da lagarta-do-cartucho, Spodoptera frugiperda (J. E. Smith) (Lepidoptera: Noctuidae) no cultivo do milho-Bt. Sete Lagoas: EMBRAPA, CNPMS, 2008. 10 p. (Comunicado Técnico, 160).

WILLIAMS, W.P.; SAGERS, J.B.; HANTEN, J.A.; DAVIS, F.M.; BUCKLEY, P.M. Transgenic corn evaluated for resistance to fall armyworm and southwestern corn borer. Crop Science, Madison, v. 37, p. 957-962, 1997.

WU, K.; MU, W.; LIANG, G.; GUO, Y. Regional reversion of insecticide resistance in Helicoverpa armigera (Lepidoptera: Noctuidae) is associated with the use of Bt cotton in northern China. Pest Management Science, Sussex, v. 61, p. 491-498, 2005.

YU, S.J. Insecticide resistance in the fall armyworm Spodoptera frugiperda (J. E. Smith). Pesticide Biochemestry and Physiology, New York, v. 39, p. 91-94, 1991.

ZHAO, Y.; PARK, Y.S.; ADAMS, M.E. Functional and evolutionary consequences of pyrethroid resistance mutations in $\mathrm{S} 6$ transmembrane segments of a voltage-gated sodium channel. Biochemical and Biophysical Research Communications, Orlando, v. 278, p. 516$521,2000$. 
4 EFEITO DA RESISTÊNCIA DE Spodoptera frugiperda (J. E. Smith, 1797) (LEPIDOPTERA: NOCTUIDAE) A LAMBDA-CYHALOTHRIN NA EXPRESSÃO DE GENES RELACIONADOS AO METABOLISMO E RESPOSTA IMUNOLÓGICA AO PARASITISMO POR Campoletis aff. flavicincta (HYMENOPTERA: ICHNEUMONIDAE)

\section{Resumo}

A resistência de lepidópteros a piretroides pode decorrer da redução da sensibilidade do sítio-alvo de ação do inseticida via mutações nos canais de sódio ou do aumento da detoxificação metabólica, os quais podem alterar a fisiologia do inseto devido à existência de custos adaptativos, levando a alterações no padrão de expressão de genes relacionados a diferentes processos fisiológicos do inseto. A intensidade com que alterações no padrão normal de desenvolvimento são detectadas é influenciada por fontes de estresse, que tendem a potencializar os efeitos induzidos pela presença de custos adaptativos associados à resistência. Neste trabalho, objetivou-se verificar a existência de custos adaptativos associados à resistência de Spodoptera frugiperda (J. E. Smith, 1797) (Lepidoptera: Noctuidae) ao inseticida lambda-cyhalothrin avaliando-se a expressão diferencial de genes associados ao metabolismo (proteína rica em metionina), resposta imunológica (calreticulina, lisozima, colágeno-IV-2, hemócito protease-3, serina protease, imunolectina, "scavenger receptor" classe C) e detoxificação de xenobióticos (glutationa-S-transferase 145 e as monoxigenases P450 Cyp9A31 e Cyp333B2) expressos em diferentes tecidos (tecido adiposo, hemócitos e/ou mesêntero), na ausência e presença de fonte de estresse (parasitismo por Campoletis aff. flavicincta). A expressão dos genes mencionados em lagartas de $S$. frugiperda suscetíveis e resistentes a lambda-cyhalothrin foi comparada, via PCR em tempo real, em diferentes períodos de desenvolvimento ou parasitismo (1, 3, 5 e 7 dias). As análises indicaram que, no geral, independentemente do período de avaliação e da presença ou não da fonte de estresse, a expressão gênica em lagartas suscetíveis foi superior àquela de lagartas resistentes. Genes como colágeno IV-2 e proteína rica em metionina mantiveram níveis de expressão superiores em lagartas suscetíveis, independentemente do período de avaliação e da presença ou não de fonte de estresse. Em alguns casos, como os dos genes da protease-3 em hemócitos e das monoxigenases $\mathrm{P} 450$ no mesêntero, a grande diferença de expressão observada entre lagartas resistentes e suscetíveis na ausência do parasitismo, foi drasticamente reduzida quando as lagartas foram submetidas ao parasitismo. Na ausência do parasitismo foi observada maior expressão do gene da serina protease em lagartas suscetíveis, enquanto que em lagartas parasitadas, a expressão foi superior nas resistentes se comparadas às suscetíveis nos primeiros períodos de avaliação. Houve ainda casos em que alterações na expressão gênica foram observadas apenas em determinados períodos do desenvolvimento, como para os genes da calreticulina, imunolectina e do "scavenger receptor", com níveis de expressão muito superiores nos hemócitos de lagartas suscetíveis do que em resistentes não-parasitadas com 5 dias de desenvolvimento, mas praticamente sem diferenças quando parasitadas. Poucos foram os genes em que a expressão foi predominantemente alta em lagartas resistentes, como o gene da calreticulina, que, no tecido adiposo, apresentou expressão superior em comparação às suscetíveis, tanto na condição não-parasitada quanto parasitada, aos 1, 5 e 7 DAP. Assim, apesar das variações observadas, os resultados apresentados demonstraram a redução na atividade de transcrição gênica em lagartas resistentes quando comparada às suscetíveis, provavelmente como resultado da existência de custo adaptativo associado à resistência ao piretroide lambda-cyhalothrin. 
Palavras-chave: Resistência a inseticidas; Lepidoptera; Parasitoide; Expressão gênica; Resposta imunológica; Mecanismo de resistência

\section{Abstract}

The resistance in Lepidoptera to pyrethroids occur by mutation on the sodium channels, accross mechanisms as sensibility reduction on target site of insecticide action or increase on the metabolic detoxification can alter the insect physiology, by existance of fitness costs, resulting in the alteration of genes expression involved to different physiological proccess, wich result on modifications in biological adaptation of the insect. The intensity with the alterations on the normal standard of development are detected is influenced by stress resources, wich can potencialize the effects ocurred by fitness costs presence. The objective of this research was to verify the existance of fitness costs associated with Spodoptera frugiperda (Lepidoptera: Noctuidae) resistance to lambda-cyhalothrin, evaluating the differential genes expression associated to metabolism (methionine rich protein), immunological response (calreticulin, lysozime, collagen-IV-2, protease- 3 hemocyte, serine protease, immunolectin, scavenger-receptor class $\mathrm{C}$ ) and xenobiotic detoxification (glutathione-S-transferase 145 and monooxigenases P450 Cyp9A31 and Cyp333B2) expressed in different tissues (fat body, hemocytes and/or midgut), in the absence and presence (parasitism by Campoletis aff. flavicincta) as stress resource. The gene expression in S. frugiperda susceptible and resistants larvaes to lambda-cyhalothrin was evaluated by realtime PCR, in different periods of development or parasitism (1, 3, 5 and 7 days). The gene expression was independent of evaluation period and presence or not of parasitoid and it was generally higher in susceptible larvae those resistants, as colágeno IV-2 and methionine rich protein genes. The protease-3 in hemocytes and monoxigenases P450 in midgut, showed difference in expression between the lines of $S$. frugiperda in absence of parasitism, and was reducted with parasitism. In absence of parasitism was observed higher expression of serine protease in suscetible. With the parasitism, the expression of this gene, after 1 and 3 DAP, was inverted, being higher in resistant larvae. Was verified in determined periods of development, alterations on expression of calreticulin, imunolectin and scavenger receptor genes, with higher levels in susceptible hemocytes larvae than resitants non-parasitized in 5 days, but, was not observed differences when parasitized. Fewer genes showed higher expression in resistant larvaes, as calreticulin in fat body, in both parasitism conditions in 1, 5 and 7 days. Thus, despite the variations observed, the results showed the reduction on the metabolic activity in resistants larvae when compared to susceptible, probably, as result of existance of fitness costs associated to lambda-cyhalothrin resistance.

Keywords: Insecticide resistance; Lepidoptera; Parasitoid; Genic expression; Immune response; Resistance mechanism

\subsection{Introdução}

A constatação da resistência de Spodoptera frugiperda (J. E. Smith, 1797) (Lepidoptera: Noctuidae) a diversas classes de inseticidas (YU, 1991), como o piretroide lambda-cyhalothrin (DIEZ-RODRIGUES; OMOTO, 2001; RÍOS-DÍEZ; SALDAMANDOBENJUMEA, 2011), pode estar associada a custos adaptativos que podem refletir em alterações sobre parâmetros biológicos e fisiológicos de lagartas resistentes, mesmo na ausência da pressão de seleção pelo produto aplicado (GASSMANN et al, 2009). 
A existência de custo adaptativo associado à resistência pode contribuir para a alteração da suscetibilidade de indivíduos resistentes a outros agentes de controle, como, por exemplo, parasitoides (MUSSER et al., 2006; ODE, 2006; ROSE; DIVELY, 2007), os quais poderão se beneficiar da existência de custo adaptativo quando as alterações biológicas refletirem em mudanças da aptidão biológica do hospedeiro, como redução no tempo de desenvolvimento, tornando o hospedeiro acessível ao parasitismo por período prolongado, e/ou redução na capacidade de defesa do sistema imunológico, facilitando, assim, a colonização do hospedeiro ou a exploração de hospedeiros em estádios mais avançados de desenvolvimento. Nestes casos, alterações na aptidão biológica que resultem no maior sucesso de exploração de hospedeiros resistentes em relação aos suscetíveis podem contribuir para o retardamento da evolução da resistência mediante a redução da frequência de alelos de resistência na população devido a maior pressão de parasitismo sobre o genótipo do hospedeiro resistente (UMORU; POWELL, 2002; FOSTER et al., 2005).

A resistência a piretroides pelo aumento da detoxificação metabólica pode ocorrer mediante expressão diferencial de genes que levam à tradução de níveis distintos de proteínas (enzimas) importantes no processamento e metabolização da molécula tóxica (GUNNING et al., 1991; FEYEREISEN, 1999). A resistência também pode ocorrer devido a mutações de genes dos canais de sódio, como o $k d r$, geralmente nos segmentos 4 a 6 do domínio II, sendo a substituição de uma leucina por fenilalanina, histidina ou serina, no segmento 6 do domínio II (IIS6), a mais comum (PARK; TAYLOR, 1997; HECKEL, 2009), caracterizando a resistência no inseto pela redução da sensibilidade do sítio-alvo de ação do inseticida (GAMMON, 1980; SCHULER et al., 1998; PARK et al., 2000). As alterações que levam à seleção de genótipos resistentes a inseticidas podem induzir alterações substanciais no funcionamento do organismo, resultando em custos adaptativos que podem afetar sua aptidão biológica (BOIVIN et al., 2001; ARAÚJO et al., 2008; CORRÊA et al., 2011).

Neste contexto, a intensidade com que alterações no padrão normal de desenvolvimento são detectadas pode ser influenciada por fontes de estresse (TREACY et al., 1985; IQBAL; WRIGHT, 1996; FOSTER et al., 2001), como por exemplo, por parasitoides, que podem potencializar os efeitos induzidos pela presença de custos adaptativos em indivíduos resistentes. Assim, insetos resistentes poderiam apresentar menor capacidade de defesa ao ataque por parasitoides, transformando-se em hospedeiros mais sujeitos ao parasitismo do que indivíduos suscetíveis quando na ausência da pressão de seleção exercida pelo inseticida. O maior parasitismo de indivíduos resistentes poderia, dessa forma, auxiliar no manejo da resistência de insetos a inseticidas pela diluição dos alelos da resistência na 
população (GEORGHIOU; TAYLOR, 1977; FFRENCH-CONSTANT et al., 2004) e possível reversão da resistência ao produto selecionado (WU et al., 2005).

Diante disso, este trabalho teve por objetivo avaliar o efeito da resistência a lambdacyhalothrin no padrão de expressão de genes candidatos envolvidos na resposta imunológica e metabolismo de $S$. frugiperda, na ausência e presença de uma fonte de estresse, via análise comparativa de vários genes candidatos em diferentes tecidos e tempo de desenvolvimento de linhagens suscetível e resistente a este produto. O parasitoide Campoletis aff. flavicincta (Hymenoptera: Ichneumonidae) foi utilizado como fonte de estresse às lagartas de $S$. frugiperda, dada a reconhecida capacidade de parasitoides cenobiontes atuarem na regulação da transcrição gênica do hospedeiro.

\subsection{Material e Métodos}

\subsubsection{Linhagens e criação de $S$. frugiperda e de Campoletis aff. flavicincta}

Foram utilizadas as linhagens de $S$. frugiperda suscetível e resistente ao inseticida lambda-cyhalothrin e do parasitoide larval Campoletis aff. flavicincta, as quais tiveram suas criações mantidas em laboratório, conforme descrito no Capítulo 3.

\subsubsection{Coleta das amostras para extração de RNA}

Lagartas de $S$. frugiperda pertencentes às linhagens suscetível e resistente ao inseticida lambda-cyhalothrin e às diferentes condições de parasitismo (parasitadas e não-parasitadas por Campoletis aff. flavicincta) nos diferentes intervalos de tempo avaliados (1, 3, 5 e 7 dias), foram esterilizadas superficialmente em $70 \%$ etanol, lavadas com água destilada e secas em papel filtro. Em seguida, foram coletados $20 \mu \mathrm{l}$ de hemolinfa via excisão de uma das falsas pernas para a amostragem de hemócitos. A hemolinfa coletada foi submetida à centrifugação ( $200 \mathrm{~g}$ a $4^{\circ} \mathrm{C}$ por $1 \mathrm{~min}$ ) e o sedimento de células ressuspenso em tampão de lise de RNA, utilizando-se do kit SV total RNA Isolation System (Promega ${ }^{\circledR}$ ), sendo em seguida armazenado a $-80^{\circ} \mathrm{C}$ para posterior extração de RNA.

A mesma lagarta foi imediatamente dissecada em tampão anticoagulante refrigerado (98 mM NaOH, $150 \mathrm{mM} \mathrm{NaCl}, 1,7 \mathrm{mM}$ EDTA, pH 4,5) (STRAND et al., 1997), em condições assépticas, para a coleta do tecido adiposo e mesêntero. As amostras de tecido 
adiposo e de mesêntero foram imediatamente transferidas para tampão de lise de RNA $\left(\right.$ Promega $^{\circledR}$ ) e armazenadas a $-80^{\circ} \mathrm{C}$ para posterior extração do RNA.

\subsubsection{Extração de RNA}

O RNA total foi extraído utilizando-se do sistema comercial de extração RNAeasy $\left(\right.$ Promega $^{\circledR}$ ), seguindo as instruções do fabricante. Resumidamente, cada amostra foi submetida à lise celular com o tampão de lise, seguida pela precipitação do RNA. O sedimento obtido foi lavado sucessivas vezes e transferido para filtros de extração, para a remoção de contaminantes e recuperação do RNA extraído. O RNA foi submetido a novas lavagens com tampões apropriados, sendo finalmente eluído da matriz do filtro via centrifugação. Uma alíquota de $5 \mu 1$ do RNA total obtido foi misturada a $15 \mu 1$ de água estéril livre de nucleases para quantificação da concentração de RNA em espectrofotômetro. Posteriormente, o RNA extraído de cada amostra foi armazenado em alíquotas de $95 \mu \mathrm{l}$ a $80^{\circ} \mathrm{C}$.

\subsubsection{Transcrição reversa}

A reação de transcrição reversa para obtenção do cDNA de fita simples foi realizada

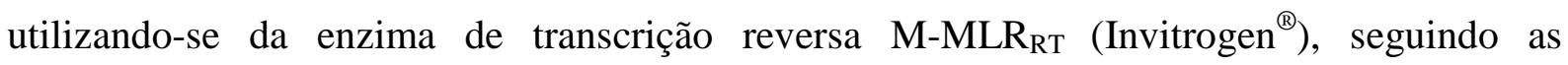
recomendações do fabricante. Para isso, cada amostra apresentou volume final de reação de $12 \mu \mathrm{l}$, constituídos por $0,56 \mu \mathrm{l}$ de $10 \mathrm{mM}$ OligoDT (900 ng/mL); $1 \mu \mathrm{l}$ da mistura de $10 \mathrm{mM}$ dNTPs, e um volume variável $(\mu 1)$ de RNA de acordo com cada amostra, de modo a se utilizar 100 ng de RNA/reação de transcrição reversa e água MiliQ. Cada amostra foi acondicionada em termociclador a $65^{\circ} \mathrm{C}$ por $5 \mathrm{~min}$ e, em seguida, refrigerada a $4^{\circ} \mathrm{C}$ por $2 \mathrm{~min}$. Após o resfriamento das amostras, foram adicionados os seguintes reagentes às mesmas, $4 \mu 1$ do tampão 5x da reação, $2 \mu 1100 \mathrm{mM}$ DTT e $1 \mu 1$ de Rnase OUT. A amostra foi aquecida a $37^{\circ} \mathrm{C}$ por $2 \mathrm{~min}$, sendo então adicionado $1 \mu \mathrm{l}$ da transcriptase reversa $M-M_{\mathrm{R}} \mathrm{R}_{\mathrm{RT}}$ para nova incubação a $37^{\circ} \mathrm{C}$ por 50 min, seguida de incubação a $70^{\circ} \mathrm{C}$ por 15 min para obtenção do cDNA de fita simples. 


\subsubsection{Quantificação de transcritos por PCR em tempo real}

A comparação do nível de expressão dos genes candidatos envolvidos no metabolismo e na resposta imunológica de $S$. frugiperda nas diferentes condições em estudo foi realizada por PCR em tempo real (qPCR). Para isso, foram utilizados iniciadores (primers) e condições de qPCR já utilizados em estudo prévio da resposta imunólogica de $S$. frugiperda ao parasitoide larval Hyposoter didymator (Hymenoptera: Ichneumonidae) (BARAT-HOUARI et al., 2006), do qual genes expressos diferencialmente em resposta ao parasitismo foram selecionados. Assim, foram quantificados cinco genes no tecido adiposo (GST-145 glutationa-S-transferase, CRT - calreticulina, LYS - lisozima, COL - Colágeno-IV-2 e METH-R - proteína rica em metionina) e seis genes nos hemócitos ( HP3 - protease 3 do hemócito, LYS - lisozima, CRT - calreticulina, SR-C - receptor "scavenger" classe-C, PPAE - enzima ativadora da profenoloxidase (PPAE) e LPS - imunolectina). Também foram quantificados dois genes de monoxigenases do citocromo P450, Cyp9A31 e Cyp333B2, em amostras de mesêntero de $S$. frugiperda, os quais são relacionados à metabolização de xenobióticos e são pertencentes às famílias 9 e 333. Para as amostras de tecido adiposo e de mesêntero foram utilizados como controle endógeno os genes da ATP-sintase (ATP) e ubiquitina-E2 (UE2), enquanto que para as amostras de hemócitos foram utilizados os genes da ATP-sintase e RNA polimerase II (Tabela 4.1). 
Tabela 4.1 - Primers utilizados e descrição das condições nas reações de RT-PCR nos diferentes tecidos $($ Ad = adiposo; He = hemócitos; Me = mesêntero) de $S$. frugiperda suscetíveis e resistentes a lambda-cyhalothrin.

\begin{tabular}{|c|c|c|c|c|}
\hline Alvo & Tecido & Spodobase & Sequência (5'- 3') & $\begin{array}{l}\text { Anelamento } \\
\quad\left(\mathrm{T}^{\circ} \mathrm{C}\right)\end{array}$ \\
\hline GST-145 & Ad & Sf9L06774 & $\begin{array}{l}\text { 5'- GGAGAAATTGAGCGCCATCTT - 3' } \\
\text { 3'- CCTAAAGCAACATGGCCGTT - 5' }\end{array}$ & $60^{\circ} \mathrm{C}$ \\
\hline Calreticulina & $\mathrm{Ad}, \mathrm{He}$ & Sf9L00974 & $\begin{array}{l}\text { 5'- TTGATGATGAGGCCGGTGA - 3', } \\
\text { 3'- ACAGCTCATCGTGGTCCTCC - 5' }\end{array}$ & $60^{\circ} \mathrm{C}$ \\
\hline Colágeno IV-2 & Ad & Sf1H00310-5-1 & $\begin{array}{c}\text { 5' - CATAGGTGGACGATGCAATGA - 3' } \\
\text { 3'- CCTTTCTGTCCGGGTCCTC - 5' }\end{array}$ & $60^{\circ} \mathrm{C}$ \\
\hline $\begin{array}{l}\text { Proteína rica em } \\
\text { metionina }\end{array}$ & Ad & Sf1F03479-3-1 & $\begin{array}{l}5 \text { '- CGGCATGATCAGCAAGACTG - 3' } \\
\text { 3'- CGGGTCTTGTACCACCAGCT - 5' }\end{array}$ & $62^{\circ} \mathrm{C}$ \\
\hline Hemócito Protease-3 & $\mathrm{He}$ & Sf1H02799-5-1 & $\begin{array}{l}\text { 5'- TCGCTGAATGCTACTGGGTG - 3' } \\
\text { 3'- TGATATCTTGCCTTCGGGCT - 5' }\end{array}$ & $60^{\circ} \mathrm{C}$ \\
\hline Serina protease & $\mathrm{He}$ & Sf1H00566-5-1 & $\begin{array}{l}\text { 5'- AGACAACCGAGCACGTTTGG - 3', } \\
\text { 3'- CAACCGGCGACATATACATCG - 5' }\end{array}$ & $60^{\circ} \mathrm{C}$ \\
\hline $\begin{array}{l}\text { Receptor "Scavenger" } \\
\text { (classe C) }\end{array}$ & $\mathrm{He}$ & Sf1H00106-5-1 & $\begin{array}{c}\text { 5'- CGCAGCAACGTTCGGTCTA - 3' } \\
\text { 3'- CGCGATCTAGTCAGAACAATGG - 5' }\end{array}$ & $60^{\circ} \mathrm{C}$ \\
\hline
\end{tabular}


Conclusão.Tabela 4.1 - Primers utilizados e descrição das condições nas reações de RT-PCR nos diferentes tecidos $($ Ad = adiposo; He = hemócitos; $\mathrm{Me}=$ mesêntero) de $S$. frugiperda suscetíveis e resistentes a lambda-cyhalothrin.

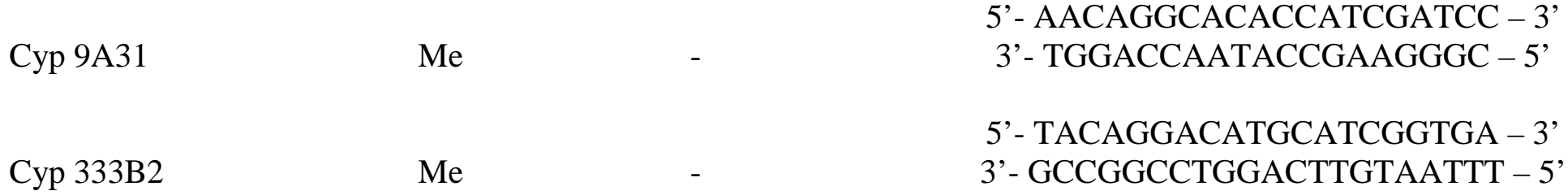

Cyp 333B2

$\mathrm{Ad}, \mathrm{He}, \mathrm{Me}$

Sf9L00262

Ubiquitina E2 ligase

Ad, Me

Sf9L03548

RNA polimerase II
$\mathrm{He}$

Sf9L00930
5'- GCTGGTTCGTTCCTTGAGCA - 3'

3'- GCCTTAACGAGTTGGCTTGC - 5'

5'- GGATCGGCACAATAAATGGG - 3'

3'- ACTTGTGGCCCGCATACACT - 5'

5' - TGCCATCGGGAAAATGAAAT - 3' 3' - TTCTCTGCACCTTATTGGGTCTC - 5' $55^{\circ} \mathrm{C}$

$62^{\circ} \mathrm{C}$

$62^{\circ} \mathrm{C}$

$62^{\circ} \mathrm{C}$ 
O cDNA obtido de cada amostra foi diluído cerca de 5 a 10 vezes dependendo da amostra, após determinação dos valores de Ct ("threshold cycle”) apresentado para os genes candidatos na reação para determinação da curva padrão. Assim, para o tecido adiposo e para os hemócitos foram utilizados $0,5 \mathrm{ng} / \mu \mathrm{l}$ de cDNA por reação, enquanto que para o mesêntero foram utilizados $0,8 \mathrm{ng} / \mu 1$ por reação. A detecção do produto de amplificação foi realizada utilizando o reagente $\mathrm{SYBR}^{\circledR}$ Green I Dye (Applied Biosystems) em reações realizadas em termociclador LightCycler ${ }^{\circledR} 480$ System (Applied Biosystems). As reações de amplificação foram conduzidas em volume final de $10 \mu 1$, sendo constituídas de $5 \mu 1$ de $\mathrm{SYBR}^{\circledR}$ Green mix $2 \mathrm{x} ; 1 \mu \mathrm{l}$ de cada iniciador $(10 \mu \mathrm{M})$, constituído por $0,5 \mu \mathrm{l}$ da sequência senso e $0,5 \mu \mathrm{l}$ da sequência antisenso, $1 \mu 1$ de cDNA (diluído nas concentrações anteriormente mencionadas) e $3 \mu 1$ de água para PCR-RT LightCycler ${ }^{\circledR} 480$ System.

Cada amostra avaliada foi representada por três repetições biológicas, as quais foram individualmente realizadas em triplicata técnica. A qualidade da amplificação foi analisada pela curva de dissociação.

A quantificação dos transcritos de interesse foi calculada a partir da diferença dos valores de $C t$ em relação àqueles dos genes que serviram como controle endógeno, de acordo com as instruções do LightCycler ${ }^{\circledR} 480$ System. Primeiramente, foram realizadas as médias dos $C t$ das leituras de cada amostra, tanto do gene de interesse quanto dos controles endógenos, para posterior normalização das leituras de $C t$ dos genes de interesse. Esta normalização foi realizada pela subtração do valor de $C t$ obtido para o gene de interesse daquele obtido para os genes controle utilizados $(\Delta C t)$.

Para a comparação da expressão gênica em indivíduos de $S$. frugiperda suscetíveis ou resistentes a lambda-cyhalothrin, dentro de cada condição de parasitismo (parasitado e nãoparasitado), os valores de $\Delta C t$ obtidos para cada gene foram utilizados para o cálculo da expressão relativa, seguindo a fórmula $\left(\Delta C t_{\mathrm{SUS}} / \Delta C t_{\mathrm{RES}}\right)-1$, onde $\Delta C t_{\mathrm{SUS}}=$ valor de $C t$ normalizado para lagartas suscetíveis e $\Delta C t_{\mathrm{RES}}=$ valor de $C t$ normalizado para lagartas resistentes. Assim, valores iguais a zero indicam níveis de transcrição idênticos em lagartas suscetíveis e resistentes. Já os valores superiores a zero indicam maior transcrição em lagartas suscetíveis, enquanto que aqueles menores que zero indicam maior transcrição em lagartas resistentes. 


\subsection{Resultados}

\subsubsection{Efeito da resistência a lambda-cyhalothrin na expressão de genes relacionados ao metabolismo e resposta imunológica de $S$. frugiperda na ausência e presença de parasitismo por Campoletis aff. flavicincta}

\subsubsection{Tecido adiposo}

Os níveis de transcrição dos genes candidatos selecionados para o tecido adiposo variaram consideravelmente com o estágio de desenvolvimento da lagarta, independentemente do parasitismo, sendo a expressão, geralmente, muito superior em lagartas suscetíveis em relação às resistentes (Figuras 4.1 e 4.2).

A resposta dos genes calreticulina e lisozima, ambos relacionados à resposta imunológica, avaliados no tecido adiposo de lagartas suscetíveis e resistentes a lambdacyhalothrin foi bastante variável ao longo do desenvolvimento da lagarta, ora sendo maior no inseto suscetível, ora no resistente, independentemente da condição de parasitismo (Figura 4.1). Na ausência do parasitismo, a calreticulina só não apresentou maior expressão no inseto resistente aos 3 dias, enquanto a lisozima foi expressa em maior quantidade nos insetos suscetíveis do dia 3 ao dia 7 de desenvolvimento (Figura 4.1A, C). Entretanto, interessantemente, a expressão do gene da lisozima em lagartas suscetíveis aos 3 dias foi cerca de 10 vezes superior daquela em resistentes (Figura 4.1C). O padrão de expressão destes genes na condição de parasitismo foi mantido praticamente o mesmo, com exceção de reversão da maior expressão do gene da lisozima a 1 DAP das lagartas resistentes para as suscetíveis (Figuras 4.1B, D). Também se destaca a maior expressão relativa do gene da calreticulina nas lagartas suscetíveis em relação às resistentes aos 3 DAP, quando comparada a expressão relativa obtida na ausência do parasitismo (Figuras 4.1A, B).

Ainda no tecido adiposo, também foi avaliado o padrão de expressão do gene responsável pela síntese da proteína colágeno IV-2, proteína fundamental na manutenção da estrutura da membrana basal e do arcabouço celular (HEINO, 2007). Novamente, lagartas suscetíveis, parasitadas ou não, apresentaram níveis de expressão deste gene sempre superiores ao de lagartas resistentes, com exceção do dia 5 de desenvolvimento em lagartas parasitadas (Figura 4.1E-F). As diferenças na expressão relativa do gene da proteína colágeno IV-2 entre lagartas suscetíveis e resistentes foi crescente com o desenvolvimento da lagarta na ausência do parasitismo, atingindo diferença de cerca de $3 \mathrm{x}$ aos 7 dias de desenvolvimento 
(Figura 4.1E). Assim como observado para o gene da glutationa-S-transferase, o parasitismo influenciou a expressão relativa deste gene em lagartas suscetíveis e resistentes de $S$. frugiperda, aumentando a diferença entre lagartas suscetíveis e resistentes de pouco mais de 1x para mais de $3 \mathrm{x}$ aos 3 DAP (Figuras 4.1E-F). Ainda, a expressão do gene da proteína colágeno IV-2 aos 5 DAP foi mais de 2x superior em lagartas resistentes parasitadas do que nas suscetíveis (Figura 4.1F).
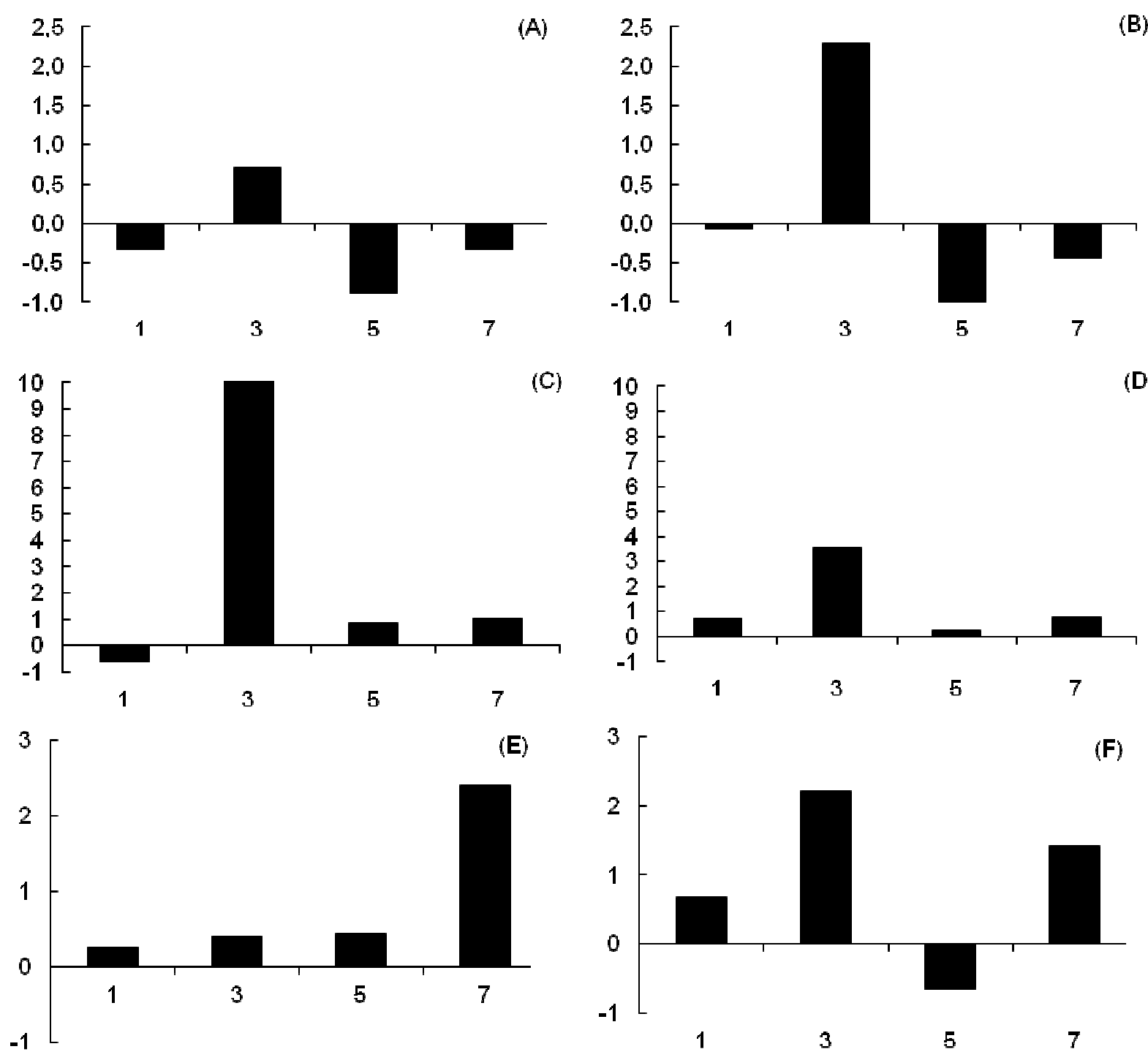

Figura 4.1 - Transcrição relativa (suscetível/resistente) de genes candidatos do tecido adiposo relacionados à resposta imunológica de lagartas de $S$. frugiperda aos 1, 3, 5 e 7 dias de desenvolvimento, submetidas (B, D, F) ou não (A, C, E ) ao parasitismo por Campoletis aff. flavicincta. A-B) Calreticulina, C-D) Lisozima e E-F) Colágeno-IV-2 
Dois genes relacionados ao metabolismo também foram avaliados no tecido adiposo, o gene de uma proteína de armazenamento, a proteína rica em metionina, ligado ao desenvolvimento e metamorfose de insetos (TELFER; KUNKEL, 1991; WHEELER; BUCK, 1995), e o gene de uma glutationa-S-transferase, enzima ligada ao metabolismo de xenobióticos (HECKEL, 2009). O padrão de expressão destes dois genes foi bastante distinto, mostrando padrão temporal de expressão bastante peculiar, seja na presença ou não de parasitismo, predominando, porém, a maior expressão em lagartas suscetíveis (Figuras 4.2AD). A expressão do gene da proteína rica em metionina em insetos não-parasitados foi substancialmente maior (cerca de 15x) em lagartas suscetíveis do que em lagartas resistentes aos 5 DAP, havendo a inversão da abundância deste transcrito aos 7 DAP, quando lagartas resistentes apresentaram expressão cerca de 2x superior àquela de lagartas suscetíveis (Figura 4.2A). O parasitismo alterou o padrão de expressão deste gene, sendo a mesma sempre superior em lagartas suscetíveis, independentemente do período de desenvolvimento avaliado (Figura 4.2B). Também foi observado que o parasitismo influenciou a expressão relativa do gene da proteína rica em metionina, ora reduzindo (5 DAP $-\sim 15 \mathrm{x}$ em lagartas não-parasitadas vs. $\sim 5 \mathrm{x}$ em lagartas parasitadas), ora aumentando a diferença nos níveis de expressão desse gene (3 DAP e 7 DAP) entre as lagartas suscetíveis e resistentes (Figuras 4.2A-B).

O padrão de expressão do gene da glutationa-S-transferase também foi influenciado pelo período de desenvolvimento do inseto em ambas as condições de parasitismo (Figuras 4.2C-D). Na ausência de parasitismo, lagartas suscetíveis apresentaram níveis de expressão quase sempre superiores ao de lagartas resistentes, com exceção do dia 5, quando a expressão em lagartas resistentes foi cerca de 10x superior àquela de lagartas suscetíveis (Figura 4.2C). Quando parasitadas, lagartas suscetíveis mantiveram níveis de expressão superiores aos das resistentes apenas no início e no final do desenvolvimento do parasitoide (Figura 4.2D). No período de maior atividade de desenvolvimento da larva do parasitoide (3 e 5 DAP), a expressão do gene da glutationa-S-transferase foi cerca de 1,4x a 2,5x superior em lagartas resistentes em relação a de suscetíveis (Figura 4.2D). 

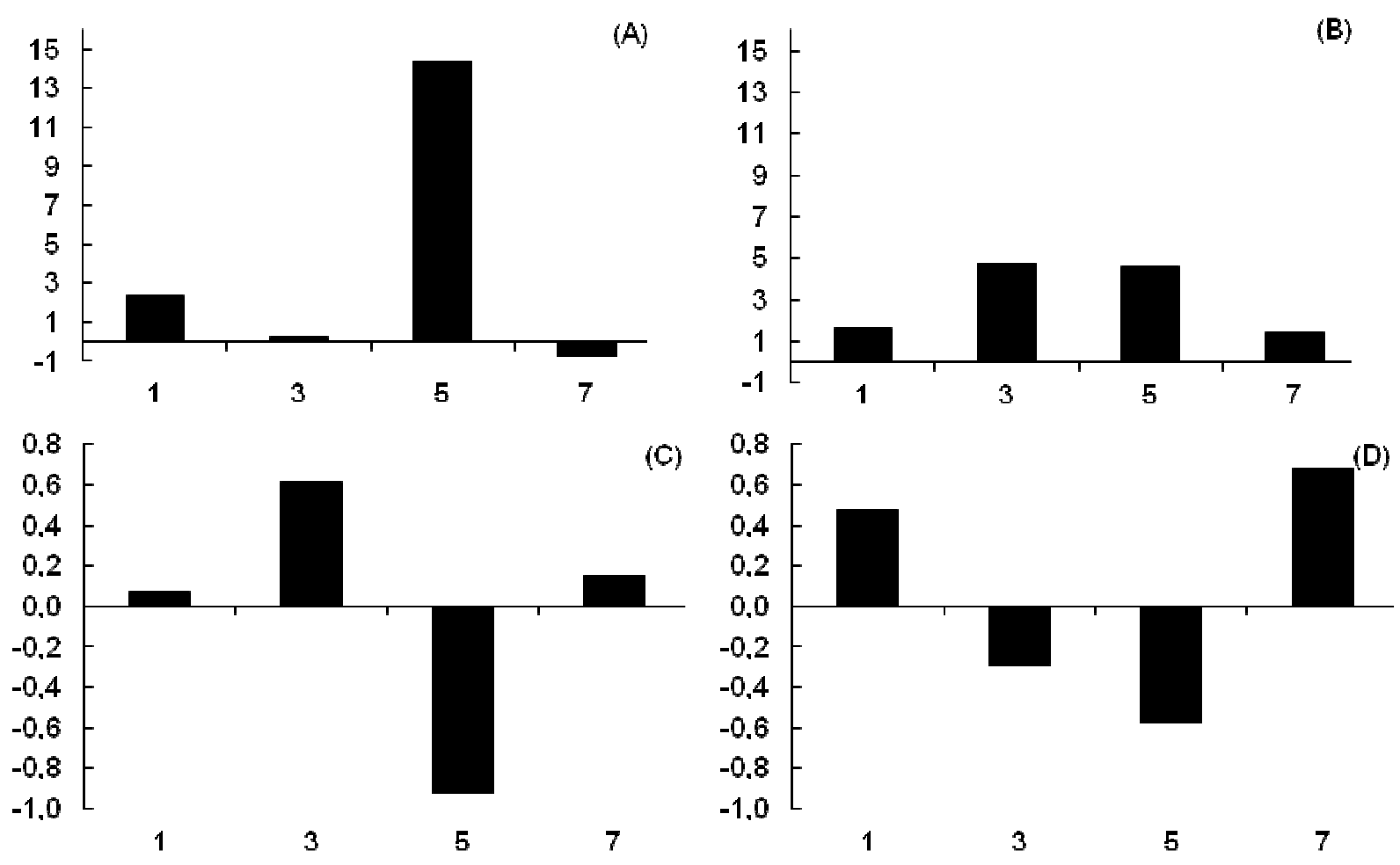

Figura 4.2 - Transcrição relativa (suscetível/resistente) de genes candidatos do tecido adiposo relacionados ao metabolismo de lagartas de $S$. frugiperda aos 1, 3, 5 e 7 dias de desenvolvimento, submetidas (B, D) ou não (A, C ) ao parasitismo por Campoletis aff. flavicincta. A-B) proteína rica em metionina e C-D) glutationaS-transferase

\subsubsection{Hemócitos}

O padrão de expressão gênica relativa observado para a protease 3 dos hemócitos, lisozima e serina protease em hemócitos de lagartas de $S$. frugiperda suscetíveis e resistentes a lambda-cyhalothrin, na ausência de parasitismo, foi praticamente o mesmo. Em todos os casos a diferença na expressão desses genes entre lagartas suscetíveis e resistentes aumentou progressivamente com o desenvolvimento do inseto do dia 1 ao dia 5 de desenvolvimento, ocorrendo uma queda brusca aos 7 dias, passando, inclusive, a ser detectada maior expressão em lagartas resistentes do em suscetíveis, assim como observado para os genes lisozima e serina protease (Figuras 4.3A, C, E).

A observação de expressão relativa muitas vezes superior em lagartas suscetíveis (cerca de 30x), como observado para o gene da protease 3 dos hemócitos, na ausência do parasitismo (Figura 4.3A), foi drasticamente reduzida quando lagartas parasitadas foram avaliadas (Figuras 4.3B, D, F). Quando parasitadas, lagartas resistentes passaram a apresentar 
níveis de expressão superiores ao de lagartas suscetíveis em momentos específicos do desenvolvimento do parasitoide, dependendo do gene em questão (Figuras 4.3B, D, F). Protease 3 dos hemócitos e lisozima apresentaram maior expressão em lagartas resistentes nos dia 1 e 5 após o parasitismo, enquanto o gene da serina protease foi mais expresso em lagartas resistentes nos dias 1 e 3 após o parasitismo (Figuras 4.3B, D, F). Também foi verificada a inversão do padrão de expressão relativa observado para os genes da lisozima e serina protease aos 7 DAP. Na ausência de parasitismo, estes genes foram mais expressos em lagartas resistentes (Figuras 4.3C-E), enquanto que na condição de parasitismo, a expressão foi maior em lagartas suscetíveis ao lambda-cyhalothrin (Figuras 4.3D-F).
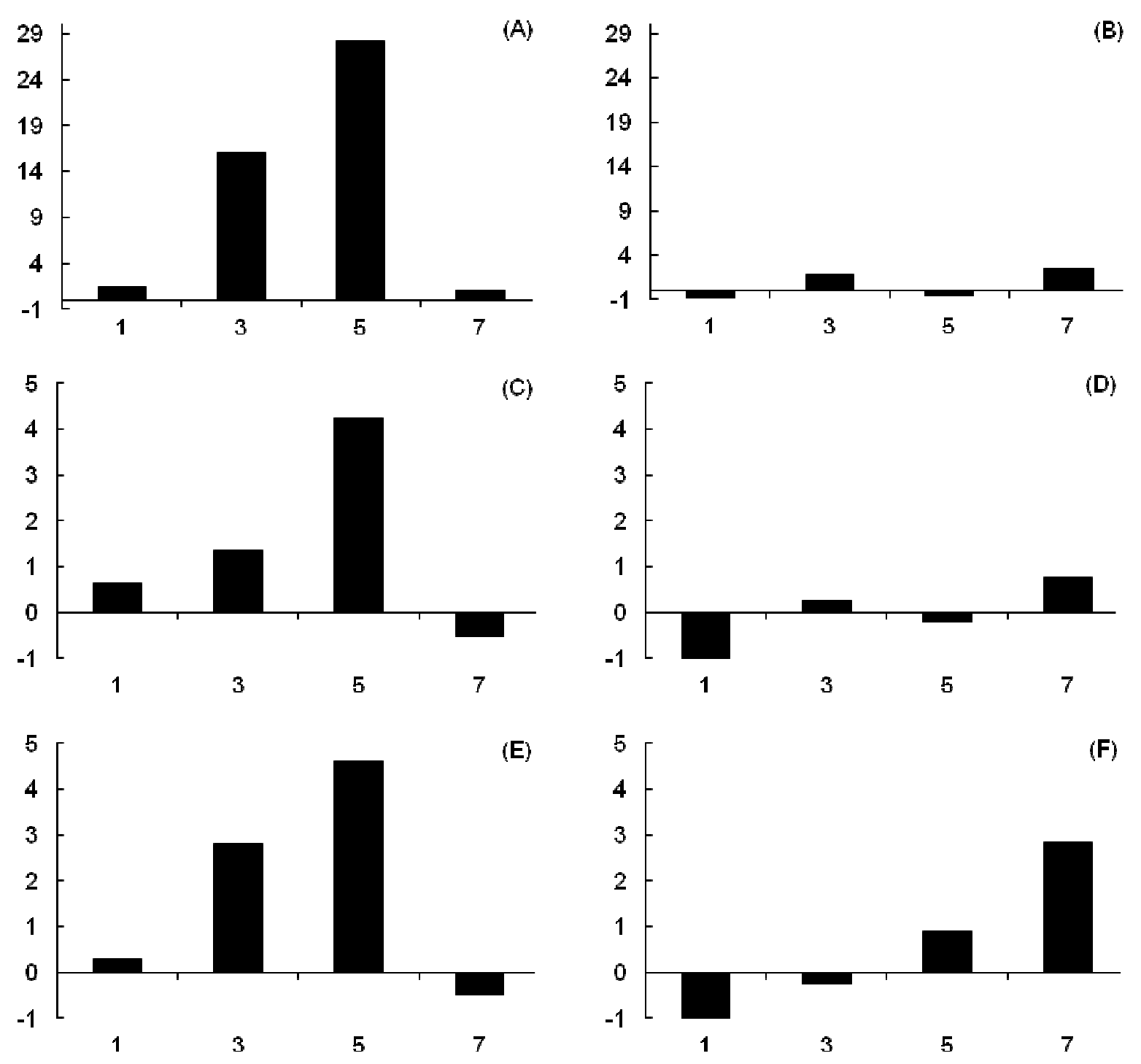

Figura 4.3 - Transcrição relativa (suscetível/resistente) de genes candidatos de hemócitos relacionados à resposta imunológica de lagartas de $S$. frugiperda aos $1,3,5$ e 7 dias de desenvolvimento, submetidas (B, D, F) ou não (A, C, E ) ao parasitismo por Campoletis aff. flavicincta. A-B) hemócito-protease-3, C-D) lisozima e EF) serina protease 
Para os demais genes avaliados nos hemócitos, calreticulina, imunolectina e receptor "scavenger", vale destacar a diferença no padrão de expressão entre lagartas suscetíveis e resistentes não-parasitadas no dia 5 de desenvolvimento, quando diferenças superiores a $10 \mathrm{x}$ na expressão em lagartas suscetíveis foram observadas (Figuras 4.4A, C, E). As diferenças nos níveis de expressão entre lagartas suscetíveis e resistentes observadas na ausência de parasitismo para o gene da calreticulina (>75x em lagartas suscetíveis do que em resistentes), praticamente desapareceram quando as lagartas foram parasitadas (Figuras 4.4A-B). O mesmo foi observado para os genes da imunolectina e do receptor "scavenger", chegando até a ocorrer inversão na expressão relativa, de maior em lagartas suscetíveis para maiores níveis em lagartas resistentes (Figuras 4.4D-F).
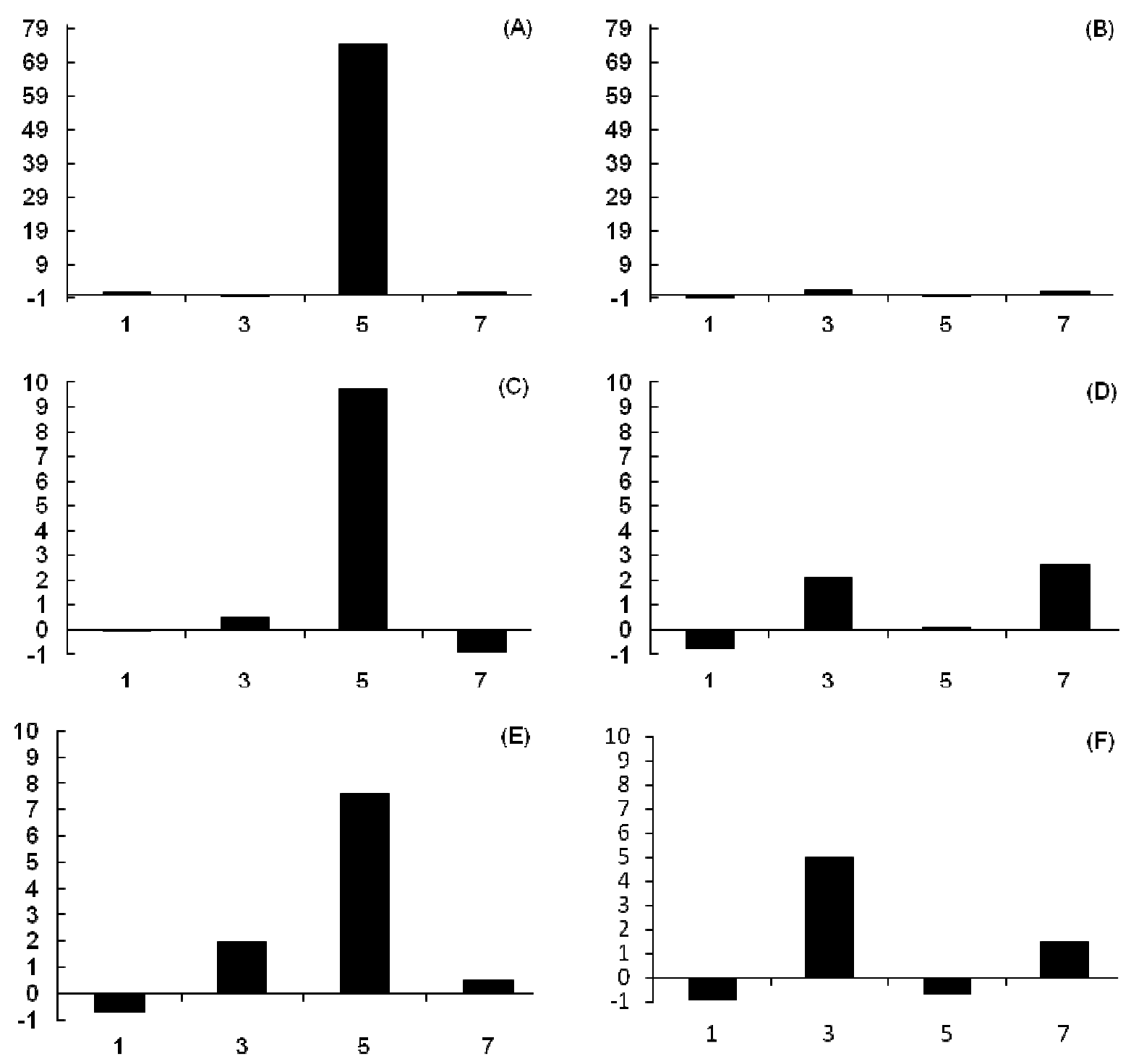

Figura 4.4 - Transcrição relativa (suscetível/resistente) de genes candidatos de hemócitos relacionados à resposta imunológica de lagartas de S. frugiperda aos 1, 3, 5 e 7 dias de desenvolvimento, submetidas (B, D, F) ou não (A, C, E ) ao parasitismo por Campoletis aff. flavicincta. A-B) Calreticulina, C-D) Imunolectina e E-F) Receptor "scavenger" (classe C) 


\subsubsection{Mesêntero}

O padrão de expressão de genes codificadores das enzimas detoxificadoras de xenobióticos (citocromo P450) foi bastante variável em relação ao tempo de desenvolvimento de lagartas suscetíveis e resistentes a lambda-cyhalothrin, em ambas as condições de parasitismo (Figura 4.5). Lagartas suscetíveis, principalmente na ausência do parasitismo, apresentaram expressão do gene Cyp9A31 mais de 35x superior àquela observada em lagartas resistentes no dia 1 de desenvolvimento, enquanto que nos dias 3 e 5 de desenvolvimento, a expressão foi ligeiramente superior em lagartas resistentes, voltando a ser maior nas lagartas suscetíveis aos 7 dias de desenvolvimento (Figura 4.5A). Quando parasitadas, o padrão geral de expressão relativa entre lagartas suscetíveis e resistentes foi mantido. Porém, a diferença nos níveis de expressão foi drasticamente reduzida, principalmente com 1 DAP (Figura 4.5B).

A expressão relativa do gene Cyp333B2 sofreu alterações maiores ao longo do desenvolvimento do inseto, principalmente na ausência do parasitismo. Lagartas suscetíveis apresentaram maior expressão aos 1 e 3 dias de desenvolvimento, sendo que, no dia 5, a expressão foi muito superior em lagartas resistentes. A diferença na expressão deste gene aos 7 dias de desenvolvimento foi praticamente inexistente (Figura 4.5C). Em lagartas parasitadas, o padrão de expressão relativa do gene Cyp333B2 entre lagartas suscetíveis e resistentes foi bastante alterado, sendo observados valores distintos de expressão aos 3 e 7 DAP. Aos 3 DAP a expressão foi cerca de 2x superior em lagartas suscetíveis, enquanto que aos 7 DAP foi de 1,25x superior em lagartas resistentes (Figura 4.5D). 



Figura 4.5 - Transcrição relativa (suscetível/resistente) de genes candidatos do mesêntero relacionados à detoxificação de xenobióticos em lagartas de $S$. frugiperda aos 1 , 3,5 e 7 dias de desenvolvimento, submetidas $(B, D)$ ou não $(A, C)$ ao parasitismo por Campoletis aff. flavicincta. A-B) Cyp9A31 e C-D) Cyp333B2

\subsection{Discussão}

Os níveis de expressão da maioria dos genes avaliados dos diferentes tecidos de $S$. frugiperda foram drasticamente inferiores em lagartas resistentes a lambda-cyhalothrin quando comparados àqueles de lagartas suscetíveis, indicando que a resistência ao produto em questão pode resultar em alterações metabólicas importantes no inseto resistente. Também foi observado que as diferenças de expressão encontradas foram dependentes do desenvolvimento do inseto e da ocorrência ou não do parasitismo por Campoletis aff. flavincicta.

Dessa forma, é possível que a menor expressão gênica observada em insetos resistentes conduza, por exemplo, à produção de níveis reduzidos de compostos relacionados à defesa imunológica da larva desse inseto. Alterações na capacidade de expressão de genes relacionados à defesa imunológica podem reduzir a aptidão biológica do inseto frente a adversidades biológicas, como a infecção por entomopatógenos ou o parasitismo por 
entomófagos, e ser decorrente de custos adaptativos associados à resistência ou ainda da seleção de indivíduos que apresentam sistema imunológico modificado pela exposição contínua a fontes de produtos químicos.

O processo de defesa imunológica representa um custo metabólico extremamente elevado, mesmo em organismos em que a resposta imunológica não é construída ao longo da existência do organismo e não dependa das experiências que o mesmo apresenta (SHELDON; VERHULST, 1996; LITTLE; KRAAIJEVELD, 2003; SCHMID-HEMPEL, 2003; SCHMIDHEMPEL; EBERT, 2003). São vários os relatos de que a capacidade de resposta imunológica pode ser dependente do investimento feito pelo organismo em outras características biológicas, como tempo de desenvolvimento, capacidade competitiva, tamanho do corpo e capacidade reprodutiva (FELLOWES et al., 1999; RANTALA; ROFF, 2005; KRAMS et al., 2011), sendo o investimento realizado no desenvolvimento do sistema imunológico do organismo extremamente influenciado por variáveis ambientais (SANDLAND; MINCHELLA, 2003). Assim, a redução observada na expressão de genes associados à resposta imunológica em lagartas resistentes de $S$. frugiperda pode estar associada aos altos custos energéticos envolvidos neste processo (FREITAK et al., 2003, 2007).

$\mathrm{O}$ efeito de xenobióticos na capacidade de resposta do sistema imunológico e na indução de respostas autoimune em vertebrados é bastante conhecido (LADICS; WOOLHISER, 2007; UETRECHT, 2007), sendo seu efeito relatado em diferentes mecanismos do sistema de defesa imunológica de invertebrados (GALLOWAY; GOVEN, 2007; JAMES; XU, 2012). A descrição de estudos sobre o fato de que insetos expostos a inseticidas pertencentes a diferentes grupos químicos apresentam alteração na resposta imunológica é bastante relatada, mas majoritariamente voltada aos microrganismos (AZAMBUJA et al., 1991; DELPUECH et al., 1996; ALAUX et al., 2010; ZIBAEE; BANDANI, 2010; VIDAU et al., 2011; PETTIS et al., 2012). A concentração de estudos voltada à interação hospedeiro-patógeno é devida ao interesse inicial em se verificar o efeito de inseticidas na eficiência de produtos microbianos e/ou o efeito de doses subletais em organismos não-alvo na suscetibilidade dos mesmos a doenças. Assim, apesar de se ter conhecimento de que pesticidas alteram os mecanismos de resposta imunológica em insetos, estudos comparativos do efeito da resistência a pesticidas são praticamente inexistentes (COSSIO-BAYUGAR et al., 2002; GONG et al., 2005; YANG et al., 2008).

Porém, sabe-se ainda que os diferentes produtos parecem atuar em vias distintas do sistema de defesa imunológica de insetos, com os piretroides afetando, preferencialmente, as vias de defesa envolvidas na ativação da cascata de fenoloxidase (GONG et al., 2005; YANG 
et al., 2008). Evidência esta contrária ao observado na linhagem de $S$. frugiperda resistente ao piretroide lambda-cyhalothrin neste trabalho, em que níveis de transcrição da serina protease foram muito superiores na linhagem suscetível do que na resistente, provavelmente relacionado à ausência de diferença na atividade das fenoloxidases entre suscetíveis e resistentes quando submetidas a ambas condições de parasitismo. Já populações do mosquito Culex pipiens pallens resistentes ao piretroide deltamethrin apresentam níveis de transcrição de serina protease muito superior ao de insetos suscetíveis (GONG et al., 2005). Essas serina proteases foram relacionadas à metabolização de deltamethrin em linhagens resistentes, sendo ainda sugerida a participação das mesmas na resposta imunológica do inseto (YANG et al., 2008).

Porém, as diferenças observadas na expressão gênica nos diferentes tecidos de lagartas suscetíveis e resistentes a lambda-cyhalothrin foram drasticamente influenciadas pela idade do inseto, dificultando discussões sobre os possíveis mecanismos de regulação envolvidos, já que se conhece muito pouco a respeito do desenvolvimento do sistema imunológico de insetos durante o seu crescimento e desenvolvimento (ROLFF; SIVA-JOTHY, 2003). Alguns aspectos da resposta imunológica de insetos têm sido demonstrados, como a ocorrência de alterações ao longo do seu desenvolvimento ontogenético, incluindo alterações significativas nos níveis de expressão de genes ligados à resposta imunológica (EVANS, 2004). sendo que os estágios mais tardios de desenvolvimento apresentam o sistema imunológico mais vigoroso. Alguns dos processos de resposta imunológica, como a encapsulação, não diferem entre os diferentes estágios de desenvolvimento, apesar do número muito maior de células de defesa nos insetos mais jovens (WILSON-RICH et al., 2008; LAUGHTON et al., 2011; SRYGLEY, 2012). Estudos que comparam alterações entre os diferentes estádios de desenvolvimento de imaturos levam às mesmas conclusões, mostrando o fortalecimento do sistema imunológico à medida que o inseto cresce (EVANS, 2004; SRYGLEY, 2012).

As dificuldades de interpretação das alterações no padrão de expressão dos genes selecionados se tornam ainda maiores quando consideramos as alterações biológicas induzidas em $S$. frugiperda resistentes a lambda-cyhalothrin, como, por exemplo, o prolongamento do ciclo larval de desenvolvimento (ver capítulo 3). O efeito do desenvolvimento mais lento das larvas de $S$. frugiperda resistentes a lambda-cyhalothrin quando comparadas às larvas suscetíveis no padrão de expressão gênica pode ser facilmente ilustrado pelos dados obtidos com a análise do gene da proteína rica em metionina. Este gene é reconhecido como sendo expresso tardiamente na fase larval à medida que o inseto se aproxima do início do processo de metamorfose (PALLI; LOCKE, 1988; TELFER; 
KUNKEL; 1991; LOURENÇO et al., 2009; ARRESE; SOULAGES, 2010). Assim, lagartas com desenvolvimento mais rápido iniciam a expressão desse gene anteriormente àquelas lagartas de desenvolvimento mais lento, que, no caso em estudo, levou à observação de maior expressão em lagartas suscetíveis no dia 5 de desenvolvimento, enquanto que no dia 7 de desenvolvimento a expressão foi maior em lagartas resistentes. Vários outros genes podem ter sido influenciados por esta pequena alteração no tempo de desenvolvimento das lagartas de $S$. frugiperda em decorrência da resistência a lambda-cyhalothrin, como observado na maior expressão do gene serina protease no início do desenvolvimento de $S$. frugiperda (ZHU et al., 2011).

O padrão de expressão gênica observado em lagartas de $S$. frugiperda submetidas ao parasitismo foi, em vários casos, bastante distinto daquele observado para lagartas nãoparasitadas. Vários dos genes selecionados são regulados por parasitoides, visto a necessidade de colonização do hospedeiro (via inativação da resposta imunológica) e adequação nutricional do hospedeiro ao desenvolvimento do imaturo do inimigo natural (VINSON et al., 2001; BRODEUR; BOIVIN, 2004; CÔNSOLI; VINSON, 2009). Assim, muitos desses genes podem sofrer alterações não apenas no seu nível de expressão, mas também modificações temporais, ora sendo expressos precocemente, ora tardiamente (GAGOU et al., 2002; BONVIN et al., 2004). Assim, alterações no padrão de transcrição relativa entre insetos controle e parasitados podem surgir devido às exigências de desenvolvimento do inimigo natural (PENNACCHIO; STRAND, 2006), e serem significativamente influenciadas pelas diferenças de desenvolvimento entre hospedeiros suscetíveis e resistentes, como pode ser verificado em algumas das respostas imunológicas avaliadas em insetos, como o aumento da atividade da enzima lisozima e redução da atividade antimicrobiana ao longo do período de desenvolvimento, sendo estas respostas imunológicas mais tardias.

No entanto, é interessante notar que para a maioria dos genes ligados à resposta imunológica do inseto, os valores de transcrição relativa obtidos em insetos parasitados são bem inferiores aos de insetos suscetíveis, apesar de, na maioria dos casos, permanecer mais elevada no inseto suscetível quando comparado ao inseto resistente. Essa observação demonstra que os mecanismos de regulação do sistema imunológico do hospedeiro empregados pelo parasitoide foram capazes de reduzir a transcrição gênica nos insetos suscetíveis a níveis próximos ao dos insetos resistentes, conseguindo modificar o hospedeiro para atender às suas exigências.

Porém, ainda chama a atenção o fato de que alguns dos genes observados passam a apresentar expressão relativa superior nas lagartas resistentes quando o inseto é submetido ao 
parasitismo, como ocorre, por exemplo, com os genes da lisozima e da serina protease no dia 1 após o parasitismo. Infelizmente, no momento, não é possível o desenvolvimento de hipóteses que venham a explicar essas alterações no padrão de expressão gênica relativa de lagartas suscetíveis e resistentes a lambda-cyhalothrin quando submetidas ou não ao parasitismo por Campoletis aff. flavincicta.

No tecido adiposo, a transcrição do gene glutationa-S-transferase-145, assim como no mesêntero dos genes Cyp9A31 e Cyp333B2, codificadores das enzimas citocromo-P450, apresentou-se maior em lagartas resistentes em relação às suscetíveis após o parasitismo por Campoletis aff. flavicincta, o que pode estar relacionado a plena atividade de desenvolvimento do parasitoide, que pode estar interferindo no nível de expressão destes genes, já que neste estudo, a expressão de genes envolvidos na detoxificação metabólica de inseticidas (DONG, 2007; HECKEL, 2009), foi verificada de forma constitutiva, sem exposição das lagartas de $S$. frugiperda ao inseticida testado, evidenciando que a resposta de insetos resistentes a xenobióticos muitas vezes é dependente de fatores que promovem a indução da expressão dos genes ligados a detoxificação metabólica (LE GOFF et al., 2006).

Diante dos resultados obtidos, apesar das variações no padrão de expressão da maioria dos genes candidatos entre lagartas suscetíveis e resistentes ao longo do tempo de desenvolvimento, os resultados apresentados demonstraram que a redução na atividade metabólica de lagartas resistentes quando comparada às suscetíveis, provavelmente como resultado da existência de custo adaptativo associado à resistência ao piretroide lambdacyhalothrin, pode facilitar os mecanismos de regulação hospedeira pelo parasitoide Campoletis aff. flavicincta.

\subsection{Conclusão}

- A expressão gênica em lagartas suscetíveis foi, no geral, superior àquela de lagartas resistentes a lambda-cyhalothrin, independente do período de desenvolvimento, do tecido avaliado e da presença ou não do parasitismo por Campoletis aff. flavicincta.

\section{Referências}

ALAUX, C.; BRUNET, J.L.; DUSSAUBAT, C.; MONDET, F.; TCHAMITCHAN, S.; COUSIN, M.; BRILLARD, J.; BALDY, A.; BELZUNCES, L.P.; LE CONTE, Y. Interactions between Nosema microspores and a neonicotinoid weaken honeybees (Apis mellifera).

Environmental Microbiology, Oxford, v. 12, p. 774-782, 2010. 
ARAÚJO, R.A.; GUEDES, R.N.C.; OLIVEIRA, M.G.A.; FERREIRA, G.H. Enhanced activity of carbohydrate- and lipid-metabolizing enzymes in insecticide-resistant populations of the maize weevil, Sitophilus zeamais. Bulletin of Entomological Research, Farnham Royal, v. 98, p. 417-424, 2008.

ARRESE; E.L.; SOULAGES, J.L. Insect fat body: energy, metabolism and regulation. Annual review of Entomology, Stanford, v. 55, p. 207-225, 2010.

AZAMBUJA, P.; GARCIA, E.S.; RATCLIFFE, N.A.; WARTHEN, J.R. Immune-depression in Rhodnius prolixus induced by the growth inhibitor, azadirachtin. Journal of Insect Physiology, Oxford, v. 37, p. 771-777, 1991.

BARAT-HOUARI, M.; HILLIOU, F.; JOUSSET, F-X; SOFER, S.; DELEURY, E.; ROCHER, J.; RAVALLEC, M.; GALIBERT, L.; DELOBEL, P.; FEYEREISEN, R.; FOURNIER, P.; VOLKOFF, A. N. Gene expression profiling of Spodotera frugiperda hemocytes and fat body using cDNA microarray reveals polydnavirus-associated variations in lepidopteran host genes transcript levels. BMC Genomics, London, v. 7, p. 1-20, 2006.

BOIVIN, T.; D’HIÉRES, C.C.; BOUVIER, J.C.; BESLAY, D.; SAUPHANOR, B. Pleiotropic of insecticide resistance in the codling moth, Cydia pomonella. Entomologia Experimentalis et Applicata, Dodrecht, v. 99, p. 381-386, 2001.

BONVIN, M.; KOJIC, D.; BLANK, F.; ANNAHEIM, M.; WEHRLE, I.; WYDER, S.; KAESLIN, M.; LANZREIN, B. Stage-dependent expression of Chelonus inanitus polydnavirus genes in the host and the parasitoid. Journal of Insect Physiology, Oxford, v. 50, p. 1015-1026, 2004.

BRODEUR, J.; BOIVIN, G. Functional ecology of immature parasitoids. Annual Review of Entomology, Stanford, v. 49, p. 27-49, 2004.

CÔNSOLI, F.L.; VINSON, S.B. Parasitoides (Hymenoptera). In: PANIZI, A.R.; PARRA, J.R.P. (Ed.). Bioecologia e nutrição de insetos. Londrina: Embrapa, 2009. cap. 20, p. 837874.

CORREAA, A.S.; PEREIRA, E.J.G.; CORDEIRO, E.M.G.; BRAGA, L.S.; GUEDES, R.N.C. Insecticide resistance, mixture potentiation and fitness in populations of the maize weevil (Sitophilus zeamais). Crop Protection, Guildford, v. 30, p. 1655-1666, 2011.

COSSIO-BAYUGAR, R.; BARHOUMI, R.; BURGHARDT, R.C.; WAGNER, G.G.; HOLMAN, P.J. Basal cellular alterations of esterase, glutathione, glutathione S-transferase, intracellular calcium, and membrane potentials in coumaphos-resistant Boophilus microplus (Acari: Ixodidae) cell lines. Pesticide Biochemistry and Physiology, San Diego, v. 72, p. 19, 2002.

DELPUECH, J.M.; FREY, F.; CARTON, Y. Action of insecticides on the cellular immune reaction of Leptopilina boulardi. Environmental Toxicology \& Chemistry, New York, v. 15, p. 2267-2271, 1996. 
DIEZ-RODRÍGUEZ, G.I.; OMOTO, C. Herança da resistência de Spodoptera frugiperda (J.E. Smith) (Lepidoptera: Noctuidae) a Lambda-Cialotrina. Neotropical Entomology, Londrina, v. 30, p. 311-316, 2001.

DONG, K. Insect sodium channels and insecticide resistance. Invertebrate Neuroscience, New York, v. 7, p. 17-30, 2007.

EVANS, J.D. Transcriptional immune responses by honey bee larvae during invasion by the bacterial pathogen, Paenibacillus larvae. Journal of Invertebrate Pathology, San Diego, v. 85, p. 105-111, 2004.

FELLOWES, M.D.E.; KRAAIJEVELD, A.R.; GODFRAY, H.C.J. The relative fitness of Drosophila melanogaster (Diptera, Drosophilidae) that have successfully defended themselves against the parasitoid Asobara tabida (Hymenoptera, Braconidae). Journal of Evolutionary Biology, Basel, v. 12, p. 123-128, 1999.

FEYEREISEN, R. Insect P450 enzymes. Annual Review of Entomology, Stanford, v. 44, p. 507-533, 1999.

FOSTER, S.P.; DENHOLM, I.; POPPY, G.M.; THOMPSON, R.; POWELL, W. Fitness trade-off in peach-potato aphids (Myzus persicae) between insecticide resistance and vulnerability to parasitoid attack at several spatial scales. Bulletin of Entomological Research, Farnham Royal, v. 101, p. 659-666, 2011.

FOSTER, S.P.; DENHOLM, I.; THOMPSON, R.; POPPY, G.M.; POWELL, W. Reduced response of insecticide resistant aphids and attraction of parasitoids to aphid alarm pheromone; a potential fitness trade-off. Bulletin of Entomological Research, Farnham Royal, v. 95, p. 37-46, 2005.

FREITAK D.; OTS, I.; VANATOA, A.; HORAK, P. Immune response is energetically costly in white cabbage butterfly pupae. Proceedings of the Royal Society of London B:

Biological Sciences, London, v. 270, p. 220-222, 2003.

FREITAK, D.; WHEAT, W.C.; HECKEL, D.G.; VOGEL, H. Immune system responses and fitness costs associated with consuptiom of bacteria larvae of Trichoplusia ni. BMC Biology, London, v. 5, p. 1-13, 2007.

FFRENCH-CONSTANT, R.H.; DABORN, P.J.; GAELLE, L.G. The genetics and genomics of insecticide resistance. Trends in Genetics, London, v.20, p. 163-170, 2004.

GAGOU, M.E.; KAPSETAKI, M.; TURBERG, A.; KAFETZOPOULOS, D. Stage-specific expression of the chitin synthase DmeChSA and DmeChSBgenes during the onset of Drosophila metamorphosis. Insect Biochemestry and Molecular Biology, New York, v. 32, p. 141-146, 2002.

GALLOWAY, T.S.; GOVEN, A.J. Invertebrate immunotoxicology. In: LUEBKE, R.; HOUSE, R.; KIMBER, I. (Ed.). Immunotoxicology and Immunopharmacology. Boca Raton: CRP Press, 2007. p. 365-384. 
GAMMON, D.W. Pyrethroid resistance in a strain of Spodoptera littoralis is correlated with decreased sensitivity of the CNS in vitro. Pesticide Biochemistry Physiology, San Diego, v. 13, p. 53-62, 1980.

GASSMANN, A.J.; CARRIÉRE, Y.; TABASHNIK, B.E. Fitness costs of insect resistance to Bacillus thuringiensis. Annual Review of Entomololgy, Stanford, v. 54, p. 147-63, 2009.

GEORGHIOU, G.P.; TAYLOR, C.E. Genetic and biological influences in the evolution of insecticide resistance. Journal of Economic Entomology, Lanham, v. 70, p. 319-323, 1977.

GONG, M.; SHEN, B.; GU, Y.; TIAN, H.; MA, L.; LI, X.; YANG, M.; HU, Y.; SUN, Y.; HU, X.; LI, J.; ZHU, C. Serine proteinase over-expression in relation to deltamethrin resistance in Culex pipiens pallens. Archives of Biochemistry and Biophysics, New York, v. 438, p. 53-62, 2005.

GUNNING, R.V.; EASTON, C.S.; GREENUP, L.R. Pyrethroid resistance mechanisms in Australian Helicoverpa armigera. Pesticide Science, Oxford, v. 33, p. 473-490, 1991.

HEINO, J. The collagen family members as cell adhesion proteins. Bioessays, Cambridge, v. 29, p. 1001-1010, 2007.

HECKEL, D.G. Molecular genetics of insecticide resistance in Lepidoptera. In. (Ed.). Molecular biology and genetics of Lepidoptera. London: CRC Publ., 2009. p. 239-269.

IQBAL, M.; WRIGHT, D. Host resistance to insecticides can confer protection to endo-larval parasitoids. Bulletin of Entomological Research, Farnham Royal, v. 86, p. 721-723, 1996.

JAMES, R.R.; XU, J. Mechanisms by which pesticides affect insect immunity. Journal of Invertebrate Pathology, San Diego, v. 109, p. 175-182, 2012.

KRAMS, I.; DAUKSTE, J.; KNIVLENIECE, I.; KRAMA, T.; RANTALA, M.J. Overwinter survival depends on immune defence and body length in male Aquarius najas water striders. Entomologia Experimentalis et Applicata, Dordrecht, v. 140, p. 45-51, 2011.

LADICS, G.S.; WOOLHISER, M.R. Mechanisms of immunotoxicity. In: LUEBKE, R.; HOUSE, R.; KIMBER, I. (Ed.). Immunotoxicology and immunopharmacology. Boca Raton: CRC Press, 2007. p. 49-62.

LAUGHTON, A.M.; BOOTS, M.; SIVA-JOTHY, M.T. The ontogeny of immunity in the honey bee, Apis mellifera L. following an immune challenge. Journal of Insect Physiology, Oxford, v. 57, p. 1023-1032, 2011.

LE GOFF, G.; HILLIOU, F.; SIEGFRIED, B.D.; BOUNDY, S.; WAJNBERG, E.; SOFER, L.; AUDANT, P.; FFRENCH-CONSTANT, R.H.; FEYEREISEN, R. Xenobiotic response in Drosophila melanogaster: sex dependence of P450 and GST gene induction. Insect

Biochemistry and Molecular Biology, Oxford, v. 36, p. 674-682, 2006.

LITTLE, T.J.; KRAAIJEVELD, A.R. Ecological and evolutionary implications of immunological priming in invertebrates. Trends in Ecology and Evolution, Amsterdam, v. 19, p. 58-60, 2004. 
LOURENÇO, A.P.; MARTINS, J.R.; BITONDI, M.G.; SIMÕES, Z.L.P. Trade-off between immune stimulation and expression of storage protein genes. Archives of Insect Biochemistry and Physiology, New York, v. 71, p. 70-87, 2009.

MUSSER, F.R.; NYROP, J.P.; SHELTON, A.M. Integrating biological and chemical controls in decision making: European corn borer (Lepidoptera: Crambidae) control in sweet corn as an example. Journal of Economic Entomology, Lanham, v. 55, p. 1538-1549, 2006.

NAKHASI, H.L.; POGUE, G.P.; DUNCAN, R.C.; JOSHI, M.; ATREYA, C.D.; LEE, N.S.; DWYER, D.M. Implications of calreticulin function in parasite biology. Parasitology Today, Amsterdam, v. 14, p. 157-160, 1998.

ODE, P.J. Plant chemistry and natural enemy fitness: effects on herbivore and natural enemy interactions. Annual Review of Entomology, Stanford, v. 51, p. 163-185, 2006.

PALLI, S.R.; LOCKE, M. The synthesis of hemolymph proteins by the larval fat body of an insect Calpodes ethlius (Lepidoptera: Hesperiidae). Insect Biochemistry, London, v. 18, p. 405-413, 1988.

PARK, Y.; TAYLOR, M.F.J. A novel mutation L1029H in sodium channel gene hscp associated with pyrethroid resistance for Heliothis virescens (Lepidoptera: Noctuidae). Insect Biochemistry and Molecular Biology, Oxford, v. 27, p. 9-13, 1997.

PARK, Y.; LEE, D.W.; TYALOR, M.F.J. A mutation Leu1029 to His in Heliothis virescens F.: hscp sodium channel gene associated with a nerve-insensitivity mechanism of resistance to pyrethroid insecticides. Pesticide Biochemestry; San Diego, v. 66, p. 1-8, 2000.

PENNACCHIO, F.; STRAND, M.R. Evolution of developmental strategies in parasitic hymenoptera. Annual Review of Entomology, Stanford, v. 51, p. 233-258, 2006.

PETTIS, J.S.; VAN ENGELSDORP, D.; JOHNSON, J.; DIVELY, G. Pesticide exposure in honey bees results in increased levels of the gut pathogen Nosema. Naturwissenschaften, Berlin, v. 99, p. 153-158, 2012.

RANTALA, M.J.; ROFF, D.A. An analysis of trade-offs in imune function, body weight and development time in the Mediterranean field cricket, Gryllus bimaculatus. Functional Ecology, Oxford, v.19, p. 323-330, 2005.

RÍOS-DÍEZ, J.D.; SALDAMANDO-BENJUMEA, C.I. Susceptibility of Spodoptera frugiperda (Lepidoptera: Noctuidae) strains from Central Colombia to two insecticides, methomyl and lambda-cyhalothrin: a study of the genetic basis of resistance. Journal of Economic Entomology, Lanham, v. 104, p. 1698-1705, 2011.

ROLFF, J.; SIVA-JOTHY, M.T. Invertebrate ecological immunology. Science, Washington, v. 301, p. 472-475, 2003.

ROSE, R.; DIVELY, G.P. Effects of insecticide-treated and lepidopteran-active Bt-transgenic sweet corn on the abundance and diversity of arthropods. Environmental Entomology, College Park, v. 36, p. 1254-1268, 2007. 
SANDLAND, G.J.; MINCHELLA, D.J. Costs of immune defense: an enigma wrapped in an environmental cloak? Trends in Parasitology, Oxford, v. 19, p. 571-574, 2003.

SCHMID-HEMPEL, P. Variation in immune defence as a question of evolutionary ecology. Proceedings of the Royal Society of London B, London, v. 270, p. 357-366, 2003.

SCHMID-HEMPEL, P.; EBERT, D. On the evolutionary ecology of specific immune defence. Trends in Ecology and Evolution, Amsterdam, v. 18, p. 27-32, 2003.

SCHULER, T.H.; MARTINES-TORRES, D.; THOMPSON, A.J. Toxicological, electrophysiological, and molecular characterization of knockdown resistance to pyrethroid insecticides in the diamondback moth, Plutella xylostella (L.). Pesticide Biochemestry, San Diego, v. 59, p. 169-182, 1998.

SHELDON, B.; VERHULST, S. Ecological immunology: costly parasite defences and tradeoffs in evolutionary ecology. Trends in Ecology and Evolution, Amsterdam, v. 11, p. 317$321,1996$.

SRYGLEY, R.B. Ontogenetic changes in immunity and susceptibility to fungal infection in Mormon crickets Anabrus simplex. Journal of Insect Physiology, Oxford, v. 58, p. 342-347, 2012.

STRAND, M.R.; WHITERELL, R.A.; TRUDEAU, D. Two Microplitis demolitor polydnavirus mRNAs expressed in hemocytes of Pseudoplusia includens contain a common cysteine-rich domain. Journal of Virology, Washington, v. 71, p. 2146-2156, 1997.

TELFER, W.H.; KUNKEL, J.G. The function and evolution of insect sotrage hexamers. Annual Review of Entomology, Stanford, v. 36, p. 205-228, 1991.

TREACY, M.F.; ZUMMO, G.R.; BENEDICT, J.H. Interactions of host-plant resistance in cotton with predators and parasites. Agriculture, Ecosystems and Environment, Amsterdam, v. 13, p. 151-157, 1985.

UETRECHT, J.P. Drug-induced autoimune disease. In: LUEBKE, R.; HOUSE, R.; KIMBER, I. (Ed.). Immunotoxicology and immunopharmacology. Boca Raton: CRC Press, 2007. p. 455-468.

UMORU, P.A.; POWELL, W. Sub-lethal effects of the insecticide pirimicarb and dimethoate on the aphid parasitoid Diaeretiella rapae when attacking and developing in insecticideresistant hosts. Biocontrol Science and Technology, Oxoford, v. 12, p. 605-614, 2002.

VIDAU, C.; DIOGON, M.; AUFAUVRE, J.; FONTBONNE, R.; VIGUES, B.; BRUNET, J.L.;TEXIER, C.; BIRON, D.; BLOT, N.; ALAOUI, E.; BELZUNCES, L.; DELBAC, F. Exposure to sublethal doses of fipronil and thiacloprid highly increases mortality of honeybees previously infected by Nosema ceranae. PLoS One, Stanford, v. 6, p. 215-250, 2011. 
VINSON, S.B.; PENNACCHIO, F.; CÔNSOLI, F.L. The parasitoid-host endocrine interaction from a nutritional perspective. In: EDWARD, J.P.; WEAVER, R.J. (Ed.).

Endocrine interactions of insect parasites and pathogens. Oxford: Bios Scientific, 2001. p. 187-206.

WHEELER, D.E.; BUCK, N.A. Storage proteins in ants during development and colony founding. Jounal of Insect Physiology, Oxford, v. 41, p. 885-894, 1995.

WILSON-RICH, N.; DRES, S.T.; STARKS, P.T. The ontogeny of immunity: development of innate immune strength in the honey bee (Apis mellifera). Journal of Insect Physiology, Oxford, v. 54, p. 1392-1399, 2008.

WU, K.; MU, W.; LIANG, G.; GUO, Y. Regional reversion of insecticide resistance in Helicoverpa armigera (Lepidoptera: Noctuidae) is associated with the use of Bt cotton in northern China. Pest Management Science, Sussex, v. 61, p. 491-498, 2005.

YANG, Q.; ZHOU, D.; SUN, L.; ZHANG, D.; QIAN, J.; XIONG, C.; SUN, Y.; MA, L.; ZHU, C. Expression and characterization of two pesticide resistance-associated serine protease genes (NYD-tr and NYD-ch) from Culex pipiens pallens for metabolism of deltamethrin. Parasitology Research, Berlin, v. 103, p. 507-516, 2008.

YU, S.J. Insecticide resistance in the fall armyworm Spodoptera frugiperda (J. E. Smith). Pesticide Biochemistry and Physiology, San Diego, v. 39, p. 91-94, 1991.

ZHU, Y.K.; FANG, Q.; HU, C.; YE, G.Y. Molecular cloning, characterization and expression profiling of a serine protease gene Pr-SP1 in Pieris rapae (Lepidoptera: Pieridae) Acta Entomologica Sinica, Peking, v. 54, p. 859-868, 2011.

ZIBAEE, A.; BANDANI, A.R. Effects of Artemisia annua L. (Asteracea) on the digestive enzymatic profiles and the cellular immune reactions of the Sunn pest, Eurygaster integriceps (Heteroptera: Scutellaridae), against Beauveria bassiana. Bulletin of Entomological Research, Farnham Royal, v. 100, p. 185-196, 2010. 


\title{
5 EFEITO DA RESISTÊNCIA A LAMBDA-CYHALOTHRIN NA RESPOSTA IMUNOLÓGICA DE Spodoptera frugiperda (J. E. SMITH, 1797) (LEPIDOPTERA: NOCTUIDAE) AO PARASITISMO POR Campoletis aff. flavicincta (HYMENOPTERA: ICHNEUMONIDAE)
}

\section{Resumo}

A resistência de Spodoptera frugiperda (Lepidoptera: Noctuidae) a inseticidas pode estar associada à ocorrência de custos adaptativos que podem interferir na eficiência de processos fisiológicos e de desenvolvimento do inseto, como, por exemplo, a capacidade de resposta imunológica. O elevado custo metabólico associado ao sistema imunológico de insetos pode influenciar as decisões de alocação de recursos nutricionais durante o desenvolvimento do inseto, sendo beneficiado ou prejudicado em relação a outros atributos biológicos do inseto. Assim, o sistema imunológico torna-se um possível alvo para a expressão de custos adaptativos em insetos resistentes. Como a existência de custos metabólicos em insetos resistentes pode, na ausência do fator de seleção (inseticida), favorecer a reversão da suscetibilidade de lagartas resistentes ao inseticida, insetos em que o custo da resistência seja expresso no sistema imunológico, tornariam o controle biológico uma ferramenta adicional na reversão da suscetibilidade ao inseticida. Diante disso, este estudo teve por objetivo avaliar o efeito da resistência ao piretroide lambda-cyhalothrin na resposta imunológica celular (contagem total do número de hemócitos) e humoral (atividade das fenoloxidases, lisozimática e antimicrobiana e concentração de óxido nítrico) de lagartas de S. frugiperda suscetíveis e resistentes a lambda-cyhalothrin sob as condições de ausência e presença do parasitismo por Campoletis aff. flavicincta em diferentes intervalos de desenvolvimento (dias) e após parasitismo (DAP). A resistência de lagartas de $S$. frugiperda a lambda-cyhalothrin só influenciou a resposta imunológica na ausência de parasitismo, sendo que todos os parâmetros de resposta imunológica avaliados entre lagartas resistentes e suscetíveis foram idênticos quando as mesmas foram parasitadas por Campoletis aff. flavicincta. $\mathrm{Na}$ ausência do parasitismo, lagartas resistentes apresentaram maior número de hemócitos totais e menor atividade antimicrobiana em relação às suscetíveis. Dos parâmetros de resposta imunológica avaliados, apenas as atividades antimicrobiana e lisozimática foram influenciadas pelo desenvolvimento do inseto, sendo a atividade antimicrobiana decrescente com a idade do inseto e a atividade lisozimática atingindo valores máximos aos 5 DAP, independentemente da presença ou não do parasitismo.

Palavras-chave: Resistência a inseticidas; Controle biológico; Resposta imunológica; Lagartado-cartucho; Custo adaptativo

\begin{abstract}
The insecticide resistance in Spodoptera frugiperda (Lepidoptera: Noctuidae) can be associated to fitness costs ocurrence which can be interfere on the efficiency of physiological process and development of insect. The possibility existance of fitness costs associated to insecticide resistance, that could be affect biological parameters of resistant specimen, as survival, development and reproduction in relation to susceptible specimen of same population in absence of insecticide selection pressure, indicate the possibility of exploration by others control methods, which can be take advantage of this biological parameters alteration, as example, the biological control by parasitoids, which can acting on susceptibility reversion of resistants individuals to insecticide by suprresion of immune system. The objective was evaluate the effect of resistance to lambda-cyhalothrin on the cellular (total
\end{abstract}


hemocytes) and humoral immune response (phenoloxidases, lisozyme and antimicrobial activity and nitric oxide concentration) of $S$. frugiperda susceptible and resistant to insecticide in the absence and presence of parasitism by Campoletis aff. flavicincta in different periods of development and after parasitism (DAP). In the absence of parasitism, significant effect of resistance to lambda-cyhalothrin was detected by the increase of cellular immune response (total hemocytes) of resistant larvae, reduction in antimicrobial activity and increase in lisozyme activity. In the presence of parasitism, significant effect of $S$. frugiperda resistance to lambda-cyhalothrin was detected during all of period evaluated with reduction of antimicrobial activity and increase of lysozyme activity at 5 DAP in S. frugiperda. The resistance of $S$. frugiperda to lambda-cyhalothrin conferred only minor changes in the host immune system (increased total hemocyte count, reduced antimicrobial activity and increased lysozyme activity), which may not interfere with fitness costs leading to higher exploitation of resistant larvae in the presence of parasitization by Campoletis aff. flavicincta.

Keywords: Insecticide resistance; Biological control; Immune response; Fall armyworm; Fitness costs

\subsection{Introdução}

O aumento do número de indivíduos de Spodoptera frugiperda (Lepidoptera: Noctuidae) resistentes a diversas classes de inseticidas (YU, 1991), como os piretroides (DÍEZ-RODRIGUEZ; OMOTO, 2001; RÍOS-DÍEZ; SALDAMANDO-BENJUMEA, 2011), compromete o manejo da resistência a esta tática de controle. A evolução da resistência a inseticidas possibilita a ocorrência de custos adaptativos mediante a seleção de indivíduos resistentes por meio da sobrevivência e reprodução diferencial que resultaria na mortalidade da maioria dos indivíduos de uma mesma população (FFRENCH-CONSTANT et al., 2004).

Alterações genéticas que conferem resistência ao inseticida aplicado podem comprometer o funcionamento normal do organismo e, desta forma, impor custo adaptativo ao indivíduo na ausência da pressão de seleção imposta pelo produto aplicado (GEORGHIU, 1972; ROUSH; McKENZIE, 1987). Na medida em que a resistência aumenta o custo adaptativo em ambientes sob pressão de seleção, a mesma pode, na maioria dos casos, reduzir a competitividade dos indivíduos resistentes em relação aos suscetíveis em ambientes sem a pressão de seleção pelo inseticida (COUSTAU et al., 2000).

Neste sentido, a resistência contribui para o custo adaptativo dos indivíduos da população que contém o genótipo resistente sob condições de uso frequente de um mesmo inseticida. Entretanto, na ausência da pressão de seleção pelo produto aplicado, a resistência pode influenciar a competitividade destes indivíduos dada a existência de custo adaptativo 
que reduza a aptidão biológica dos mesmos em relação aos indivíduos suscetíveis. Isso ocorre pela a alocação e uso diferencial de recursos energéticos pelos processos físiológicos do inseto resistente, podendo afetar processos metabólicos e de desenvolvimento (COSTAU et al., 2000; TAYLOR; FEYEREISEN, 1996).

Neste contexto, possíveis custos adaptativos associados à resistência a lambdacyhalothrin que possam afetar parâmetros biológicos e fisiológicos de S. frugiperda como a sobrevivência, atraso do desenvolvimento larval e reprodução tardia de indivíduos resistentes (BIGLER, 1989; BALE et al, 2008; MIYATAKE, 2011), indicam a possibilidade de exploração de outros métodos de controle que possam se beneficiar da alteração destes parâmetros, como por exemplo, o controle biológico por parasitoides (MUSSER et al. 2006; ODE, 2006; ROSE; DIVELY, 2007).

A possibilidade da existência de custo adaptativo associado à resistência ao piretroide, como aquele que recindi sobre a resposta imunológica (FOSTER et al., 2005; 2011), poderia afetar a aptidão do inseto resistente e influenciar o desenvolvimento e aplicação de táticas de manejo de resistência de $S$. frugiperda a inseticidas, dado ao maior sucesso esperado na exploração do hospedeiro pelo parasitoide. Isso ocorreria devido à redução da capacidade de resposta imunológica de lagartas de S. frugiperda resistentes em decorrência de custos associados à resistência. Assim, a maior suscetibilidade de lagartas resistentes ao parasitismo poderia contribuir para a diluição de alelos de resistência na população, promovendo o retardamento da evolução da resistência ao inseticida aplicado (GUSTAFSON et al., 2006), se seletivo ao parasitoide (FERNANDES et al., 2010), e o restabelecimento da suscetibilidade na ausência do uso de inseticidas (WU et al., 2005). Diante do exposto, objetivou-se verificar o efeito da resistência de $S$. frugiperda a lambda-cyhalothrin na resposta imunológica celular e humoral de lagartas suscetíveis e resistentes ao piretroide, tanto na ausência como na presença do parasitismo por Campoletis aff. flavicincta.

\subsection{Material e Métodos}

5.2.1 Efeito da resistência a lambda-cyhalothrin na resposta imunológica celular e humoral de $S$. frugiperda na ausência e presença do parasitismo por Campoletis aff. flavicincta

Para avaliação da resposta imunológica celular (contagem total do número de hemócitos) e humoral (atividade das fenoloxidases, antimicrobiana e lisozimática e 
concentração do óxido nítrico), lagartas de $S$. frugiperda suscetíveis e resistentes a lambdacyhalothrin não-parasitadas com 3, 5 e 7 dias de desenvolvimento após a muda para o $3^{\circ}$ ínstar e lagartas de $S$. frugiperda suscetíveis e resistentes a lambda-cyhalothrin de $3^{\circ}$ ínstar submetidas ao parasitismo por Campoletis aff. flavicincta conforme descrito no Capítulo 3, com 3, 5 e 7 dias após parasitismo (DAP), foram esterilizadas superficialmente via imersão em $70 \%$ etanol, seguida por banho em água destilada e secas em placa de Petri contendo papel filtro.

Em seguida, foi realizada por extravasamento, a coleta de hemolinfa em quantidade variável $(\mu 1)$ de acordo com cada experimento, após remoção de uma das falsas pernas de cada lagarta com o auxílio de uma tesoura oftalmológica, para posterior avaliação dos parâmetros de resposta imunológica mencionados anteriormente.

\subsubsection{Resposta celular - Contagem total do número de hemócitos}

A hemolinfa coletada por extravasamento, foi imediatamente misturada a tampão anticoagulante refrigerado ( $98 \mathrm{mM} \mathrm{NaOH}, 0,15 \mathrm{NaCl}$ e 1,7 mM EDTA, pH 4,5) (STRAND et al., 1997), na proporção de 1:9, totalizando um volume de $10 \mu 1$ para cada amostra.

Posteriormente, cada amostra foi agitada brevemente e uma alíquota ( $1 \mu \mathrm{l})$ foi transferida para câmara de Neubauer (Boeco Germany) sob microscópio óptico (Axiostar Plus, Zeiss) para contagem do número total de hemócitos.

\subsubsection{Resposta humoral - Atividade das fenoloxidases (PO)}

A atividade de fenoloxidase foi realizada conforme método sugerido por Ferrrarese et al. (2005). Para tanto, lagartas de S. frugiperda parasitadas e não-parasitadas pertencentes às diferentes linhagens foram higienizadas superficialmente para a coleta da hemolinfa, conforme descrito no item anterior, em cada um dos intervalos amostrais estudados.

Para cada amostra foram coletados $6 \mu 1$ de hemolinfa em tubo plástico mantido em gelo e cada amostra foi imediatamente centrifugada após a coleta $\left(2.580 \mathrm{~g}\right.$ x $\left.5 \mathrm{~min} \times 4^{\circ} \mathrm{C}\right)$ para separação do sobrenadante (plasma) da fração celular. Em seguida, $1 \mu 1$ do plasma foi transferido para um novo tubo contendo $49 \mu \mathrm{l}$ de tampão anticoagulante refrigerado $(98 \mathrm{mM}$ $\mathrm{NaOH}, 150 \mathrm{mM} \mathrm{NaCl}$ e 1,7 mM EDTA, pH 4,5) (STRAND et al., 1997) e armazenado a -20 C para posterior determinação da concentração de proteína da amostra. Do restante do plasma, foi coletada uma alíquota de $3 \mu 1$ para determinação da atividade das fenoloxidases. 
A concentração de proteína em cada amostra foi determinada por teste colorimétrico utilizando o produto comercial coomassie blue (Coomassie Plus Protein, Pierce Biotechnology, Inc., Rockford, IL), baseado em uma modificação do método de Bradford (1976), e leitura da absorbância a $595 \mathrm{~nm}$ em espectrofotômetro (BioMate 3, Thermo Electron Corp., Madison, WI). A concentração de proteínas em cada amostra foi determinada por comparação com curva-padrão produzida utilizando-se soro de albumina bovina como padrão.

A atividade de fenoloxidase de cada amostra foi realizada por espectrofotometria, registrando-se a formação de dopacromo do substrato L-DOPA (dihidroxi-fenilalanina). Para tanto, $1 \mu \mathrm{l}$ de plasma foi adicionado a $9 \mu \mathrm{l}$ de tampão PBS [10 mM de $\mathrm{NaH}_{2} \mathrm{PO}_{4}, \mathrm{pH} 8,0$, 0,9\% (p/v) de $\mathrm{NaCl}$ ], sendo esta mistura adicionada de $990 \mu \mathrm{l}$ de $5 \mathrm{mM}$ de L-DOPA $(3,4-$ dihidroxi-DL-fenilalanina) (substrato das fenoloxidases) em tampão cacodilato (10 mM

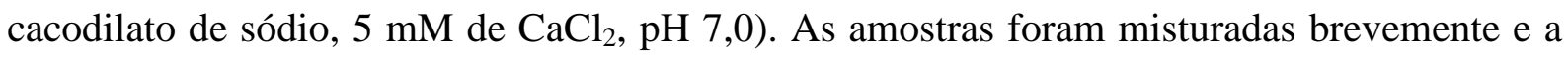
atividade avaliada medindo o produto da reação em espectrofotômetro a $490 \mathrm{~nm}$.

As medições de atividade de fenoloxidase foram realizadas a intervalos de $5 \mathrm{~min}$ durante o período de $1 \mathrm{~h}$, no qual a velocidade da reação foi proporcional à concentração da enzima. Como controle negativo, utilizou-se $10 \mu 1$ de tampão PBS adicionados aos $990 \mu 1$ de L-DOPA para leitura da absorbância a $490 \mathrm{~nm}$. A atividade de fenoloxidase foi expressa em unidades de absorbância a $490 \mathrm{~nm}$ por $\mu \mathrm{g}$ de proteína da amostra.

\subsubsection{Resposta humoral - Concentração de óxido nítrico (NO)}

Amostras de $6 \mu \mathrm{l}$ de hemolinfa foram coletadas em tubos plásticos mantidos em gelo, centrifugadas a $2.000 \mathrm{~g}$ a $4^{\circ} \mathrm{C}$ por $10 \mathrm{~min}$ para separação do plasma (sobrenadante) da fração celular (sedimento). O plasma ( $3 \mu \mathrm{l}$ ) foi coletado e transferido para um novo tubo contendo 25 $\mu l$ de tampão PBS, sendo a fração celular ressuspensa em volume semelhante do mesmo tampão.

A produção de óxido nítrico (NO) foi determinada baseando-se no reagente de Greiss (GREEN et al., 1981), sendo avaliada pela concentração do íon nitrito $\left(\mathrm{NO}^{2-}\right.$ ). Para isso, 275 $\mu 1$ de tampão PBS (diluente) foram adicionados aos $25 \mu 1$ de cada amostra.

Posteriormente, $50 \mu \mathrm{l}$ de solução de sulfanilamida a $1 \%$ em ácido fosfórico $\left(\mathrm{H}_{3} \mathrm{PO}_{4}\right)$ a $5 \%$ foram adicionados e a amostra foi incubada por 5 min a $25^{\circ} \mathrm{C}$, no escuro. Na sequência, $50 \mu \mathrm{l}$ de solução de NED (dihidrocloridrato de naftiletilenodiamina) a 0,1\% (FARALDO et al., 2005) foram adicionados e as amostras foram novamente incubadas no escuro por 5 min. Os $400 \mu \mathrm{l}$ resultantes da reação foram transferidos para cubetas para leitura das amostras a 
$490 \mathrm{~nm}$ em espectrofotômetro BioMate3 (Thermo Electron Corporation). Como controle negativo, utilizou-se $25 \mu \mathrm{l}$ de tampão PBS para leitura da absorbância a $490 \mathrm{~nm}$. A dosagem de óxido nítrico foi expressa em unidades de absorbância a $490 \mathrm{~nm}$ por nanomol de íon nitrito $\left(\mathrm{NO}^{2-}\right)$ da amostra. Para determinação da concentração de óxido nítrico no plasma + fração celular, os valores de absorbância obtidos foram comparados àqueles determinados em curvapadrão, utilizando-se concentrações conhecidas de íon nitrito (GREEN et al., 1981; LOPES, 2008).

\subsubsection{Resposta humoral - Atividade antimicrobiana}

A atividade antimicrobiana da hemolinfa de lagartas de $S$. frugiperda foi realizada após a extração de $20 \mu \mathrm{l}$ de hemolinfa em tampão metanol: água destilada: ácido fórmico (90: 9,9: 0,1).

O extrato obtido da hemolinfa foi utilizado em testes de inibição do crescimento de Escherichia coli NEB 5 $\alpha$. Para tanto, foi preparado um pré-inóculo desta bactéria, a qual foi inoculada em $5 \mathrm{~mL}$ de meio LB (Luria-Bertani) líquido e incubada a $37^{\circ} \mathrm{C}$ durante $16 \mathrm{~h}$ sob agitação constante (200 rpm). Após este período de incubação, foram retirados $50 \mu 1$ do tubo de cultivo de E. coli e transferidos para outro tubo de cultivo contendo $5 \mathrm{~mL}$ de meio LB líquido. Em seguida, este tubo foi incubado a $37^{\circ} \mathrm{C}, 200 \mathrm{rpm}$ durante $1 \mathrm{~h}$ a fim de utilizar a fase log de crescimento da bactéria no experimento. Durante este período de incubação da bactéria, as amostras de hemolinfa (equivalente a $20 \mu \mathrm{l}$ de hemolinfa diluídas em tampão de extração), foram transferidas para tubos de $600 \mu \mathrm{l}$ e completamente secas em evaporador centrífugo à vácuo a $30^{\circ} \mathrm{C}$.

Após uma hora de cultivo da bactéria, cada amostra já evaporada contendo a concentração desejada de hemolinfa foi ressuspensa em $100 \mu \mathrm{l}$ da suspensão de E. coli com $10^{4}$ unidades formadoras de colônias (ufc)/mL. Como controle, foram utilizados $200 \mu \mathrm{l}$ tampão de extração dos compostos antimicrobianos evaporado, sendo posteriormente adicionados $100 \mu \mathrm{l}$ de suspensão de E. coli. Em seguida, as amostras foram incubadas por $1 \mathrm{~h}$ a $37^{\circ} \mathrm{C}$, sob agitação constante. Após o período de incubação, diluições seriadas foram preparadas e aplicadas em placas de LB-ágar para o cultivo das células. Cada tratamento contou com seis repetições ( 1 repetição $=1$ placa), sendo as repetições realizadas em quadriplicatas. As amostras foram incubadas a $37^{\circ} \mathrm{C}$ durante $16 \mathrm{~h}$ para a posterior contagem do número de unidades formadoras de colônias (UFC). 


\subsubsection{Resposta humoral - Análise lisozimática}

A análise da atividade lisozimática da hemolinfa de lagartas de S. frugiperda foi realizada conforme protocolo modificado de Chhabra et al. (2007). Para isso, foi preparada uma suspensão de células liofilizadas de Micrococcus lysodeikticus (0,015\% p/v) (Sigma Chemicals, St. Louis, MO) em tampão fosfato $\left(0,5 \mathrm{M}\right.$ de $\left.\mathrm{KH}_{2} \mathrm{PO}_{4} ; \mathrm{pH} 6,4\right)$.

Foram coletados $15 \mu \mathrm{l}$ de hemolinfa por repetição, para cada tratamento, em um total de seis repetições/tratamento, assim como descrito anteriormente. A hemolinfa coletada foi imediatamente centrifugada a $2.000 \mathrm{~g}$ a $4^{\circ} \mathrm{C}$ durante $2 \mathrm{~min}$. Em seguida, $1 \mu \mathrm{l}$ de plasma (sobrenadante) foi coletado e adicionado a $49 \mu \mathrm{l}$ de tampão anticoagulante e armazenado a $20^{\circ} \mathrm{C}$ para posterior quantificação proteica da amostra. Do restante centrifugado, $10 \mu \mathrm{l}$ do plasma foi misturado a $5 \mu \mathrm{l}$ de tampão fosfato e armazenado a $-20^{\circ} \mathrm{C}$ para posterior determinação da atividade lisozimática.

A determinação da atividade lisozimática de cada amostra foi realizada por espectrofotometria. Para tanto, a amostra de plasma coletada foi adicionada a $485 \mu \mathrm{l}$ da suspensão de M. lysodeikticus, misturada brevemente, e a atividade lisozimática foi determinada a $570 \mathrm{~nm}$ em espectrofotômetro. As medições foram realizadas a intervalos de 3 min durante o período de $30 \mathrm{~min}$, no qual a velocidade da reação foi proporcional à concentração da enzima. Como controle negativo, utilizou-se $500 \mu 1$ da suspensão de $M$. lysodeikticus em tampão fosfato. A atividade lisozimática específica da hemolinfa de lagartas de $S$. frugiperda foi expressa em unidades de absorbância a $570 \mathrm{~nm}$ por $\mu \mathrm{g}$ de proteína da amostra.

\subsubsection{Análise estatística}

O delineamento experimental utilizado foi o inteiramente aleatorizado com 4 tratamentos, obedecendo ao esquema fatorial $2 \times 2$, com as populações de $S$. frugiperda suscetível e resistente a lambda-cyhalothrin, constituindo os níveis da primeira fonte de variação e o tempo de desenvolvimento ou tempo após parasitismo (3, 5 e 7 dias), os níveis da segunda fonte de variação. Os tratamentos foram repetidos seis vezes sendo cada amostra considerada como uma repetição. Os dados das variáveis foram analisados conforme o 
delineamento anteriormente citado (DIA) de forma independente dentro de cada condição de parasitismo (sem e com parasitismo).

Inicialmente os dados foram submetidos ao teste de normalidade de Shapiro-Wilk a $5 \%$ sendo, caso necessário, realizada a transformação em $\log (x+1)$ visando à normalização dos dados e a homogeneidade da variância. Posteriormente, as médias dos parâmetros avaliados foram submetidas à análise de variância, testando-se as fontes de variação e a interação entre as mesmas pelo teste $\mathrm{F}(\mathrm{p}<0,05)$. Constatada a significância de $\mathrm{F}$ a $5 \%$ para a interação entre as fontes de variação, realizou-se posteriormente, teste de comparação de médias de Tukey $(\mathrm{p} \leq 0,05)$. Todas as análises estatísticas foram realizadas utilizando-se os pacotes de análises fornecidos pelo aplicativo computacional estatístico SAS (SAS INSTITUTE, 2002).

\subsection{Resultados}

\subsubsection{Ausência do parasitismo por Campoletis aff. flavicincta}

O número total de hemócitos $(\mathrm{CTH})$ não apresentou diferença significativa pela ANOVA para a interação (tipo de linhagem $\times$ tempo de desenvolvimento) $(F=3,20$; g.l.= 2,34; $P=0,0562)$. No entanto, o fator linhagem isoladamente apresentou diferença significativa $(F=7,26 ;$ g.l. $=2,34 ; P=0,0118)$, com lagartas resistentes apresentando maior número médio de CTH do que as suscetíveis (Tabela 5.1).

A atividade antimicrobiana da hemolinfa apresentou diferença significativa para a interação (tipo de linhagem $\times$ tempo de desenvolvimento) $(F=16,01 ;$ g.1. $=2,35 ; P=<.0001)$, com maior atividade em lagartas suscetíveis aos 5 dias de desenvolvimento, sendo a atividade nos dias 3 e 7 semelhantes entre as lagartas suscetíveis e resistentes. Na ausência do parasitismo, tanto as lagartas resistentes, como as suscetíveis, apresentaram redução na atividade antimicrobiana ao longo do desenvolvimento avaliado (Tabela 5.1).

A atividade das fenoloxidases $(F=1,48 ;$ g.l. $=2,35 ; P=0,2433)$, a concentração de óxido nítrico $(F=1,71 ;$ g.l. $=2,35 ; P=0,1976)$ e a atividade lisozimática da hemolinfa $(F=2,16 ;$ g.l. $=2,35 ; P=0,1332)$ de $S$. frugiperda não apresentaram significância para a interação de fatores estudados (tipo de linhagem $\times$ tempo após parasitismo). Para essas variáveis, a única a apresentar alterações foi a atividade lisozimática, a qual foi influenciada 
pelo fator tempo $(F=6,35 ;$ g.l. $=2,35 ; P=0,0050)$, sendo a maior atividade lisozimática observada aos 7 dias de desenvolvimento (Tabela 5.1).

Tabela 5.1 - Resposta imunológica celular e humoral média ( \pm erro padrão) de S. frugiperda suscetível (SUS) e resistente (RES) a lambda-cyhalothrin na ausência do parasitismo por Campoletis aff. flavicincta aos 3, 5 e 7 dias de desenvolvimento $\left(25 \pm 1^{\circ} \mathrm{C}, 70 \pm 10 \% \mathrm{UR}\right.$, fotofase de $\left.14 \mathrm{~h}\right)$

\begin{tabular}{|c|c|c|c|c|c|}
\hline \multirow{2}{*}{$\begin{array}{l}\text { Resposta } \\
\text { imunológica* }\end{array}$} & \multirow{2}{*}{ Linhagem } & \multicolumn{4}{|c|}{ Tempo de desenvolvimento (dias) } \\
\hline & & 3 & 5 & 7 & Média $^{1}$ \\
\hline \multirow{3}{*}{$\begin{array}{l}\mathrm{CTH}\left(\mathrm{N}^{0} \mathrm{de}\right. \\
\text { hemócitos } \\
\left.\times 10^{5} / \mathrm{mm}^{3}\right)\end{array}$} & SUS & $96,95 \pm 13,81$ & $119,05 \pm 36,41$ & $152,66 \pm 23,6$ & $123,12 \pm 14,66 \mathrm{~B}$ \\
\hline & RES & $217,41 \pm 37,36$ & $175,4 \pm 30,12$ & $139,12 \pm 19,5$ & $177,43 \pm 18,18 \mathrm{~A}$ \\
\hline & Média $^{2}$ & $157,18 \pm 26,2$ & $147,2 \pm 24,1$ & $145,8 \pm 14,7$ & \\
\hline \multirow{3}{*}{ 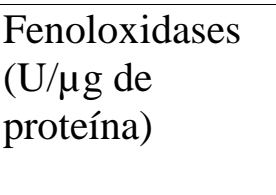 } & SUS & $0,009 \pm 0,000$ & $0,011 \pm 0,003$ & $0,003 \pm 0,000$ & $0,008 \pm 0,001$ \\
\hline & RES & $0,010 \pm 0,003$ & $0,007 \pm 0,001$ & $0,006 \pm 0,001$ & $0,008 \pm 0,001$ \\
\hline & Média $^{2}$ & $0,010 \pm 0,001$ & $0,009 \pm 0,001$ & $0,005 \pm 0,001$ & \\
\hline \multirow{3}{*}{$\begin{array}{l}\text { Óxido nítrico } \\
(\mathrm{nmol} / \mu \mathrm{l})\end{array}$} & SUS & $0,090 \pm 0,02$ & $0,253 \pm 0,12$ & $0,142 \pm 0,05$ & $0,162 \pm 0,04$ \\
\hline & RES & $0,106 \pm 0,02$ & $0,062 \pm 0,01$ & $0,132 \pm 0,05$ & $0,100 \pm 0,02$ \\
\hline & Média $^{2}$ & $0,098 \pm 0,01$ & $0,158 \pm 0,06$ & $0,137 \pm 0,03$ & \\
\hline \multirow{2}{*}{$\begin{array}{l}\text { Antimicrobiana } \\
\text { (número de } \\
\text { UFC) }\end{array}$} & SUS & $68,79 \pm 2,39 \mathrm{Aa}$ & $33,70 \pm 3,06 \mathrm{Ab}$ & $19,16 \pm 2,29 \mathrm{Ac}$ & \\
\hline & RES & $68,25 \pm 2,87 \mathrm{Aa}$ & $15,33 \pm 1,10 \mathrm{Bb}$ & $22,40 \pm 3,10 \mathrm{Ab}$ & \\
\hline \multirow{3}{*}{ 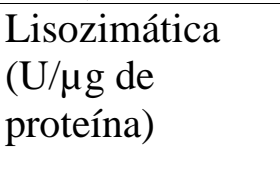 } & SUS & $0,020 \pm 0,00$ & $0,899 \pm 0,43$ & $1,588 \pm 0,49$ & $0,836 \pm 0,25$ \\
\hline & RES & $0,410 \pm 0,20$ & $0,562 \pm 0,16$ & $0,901 \pm 0,44$ & $0,624 \pm 0,17$ \\
\hline & Média $^{2}$ & $0,215 \pm 0,11 \mathrm{~b}$ & $0,731 \pm 0,22 \mathrm{a}$ & $1,244 \pm 0,33 \mathrm{a}$ & \\
\hline
\end{tabular}

*,1,2 Médias seguidas pela mesma letra maiúscula na coluna e letra minúscula na linha não diferem pelo teste de Tukey $(\mathrm{P} \leq 0,05)$.

\subsubsection{Presença do parasitismo por Campoletis aff. flavicincta}

Para lagartas de S. frugiperda parasitadas por Campoletis aff. flavicincta, nenhuma das variáveis utilizadas para avaliação do efeito da resistência na resposta imunológica desse inseto apresentou diferenças entre indivíduos suscetíveis e resistentes [interação tipo de linhagem $\times$ tempo após parasitismo: $\mathrm{CTH}(F=2,34$; g.l. $=0,23 ; P=0,7975)$; atividade das fenoloxidases $(F=0,97$; g.l. $=2,35 ; P=0,3890)$; concentração de óxido nítrico $(F=1,46$; g.l.= 2, 35; $P=0,2483)$; atividade antimicrobiana $(F=0,87 ;$ g.l. $=2,35 ; P=0,4302)$ e atividade lisozimática da hemolinfa $(F=0,09 ;$ g.l. $=2,35 ; P=0,9139)]$ (Tabela 5.2).

No entanto, as atividades antimicrobiana $(F=119,32 ;$ g.l. $=2,35 ; P=<.0001) \mathrm{e}$ lisozimática $(F=4,06 ;$ g.l. $=2,35 ; P=0,0276)$ foram as únicas a sofrerem alterações, sendo, 
porém, influenciadas apenas pelo tempo. Assim, a atividade antimicrobiana apresentou redução gradual com o período de desenvolvimento do inseto, sendo que a atividade lisozimática apresentou valor máximo aos 5 DAP (Tabela 5.2).

Tabela 5.2 - Resposta imunológica celular e humoral média (土erro padrão) de S. frugiperda suscetível (SUS) e resistente (RES) a lambda-cyhalothrin na presença do parasitismo por Campoletis aff. flavicincta aos 3, 5 e 7 dias de desenvolvimento $\left(25 \pm 1^{\circ} \mathrm{C}, 70 \pm 10 \% \mathrm{UR}\right.$, fotofase de $\left.14 \mathrm{~h}\right)$

\begin{tabular}{|c|c|c|c|c|c|}
\hline \multirow{2}{*}{$\begin{array}{l}\text { Resposta } \\
\text { imunológica* }\end{array}$} & \multirow{2}{*}{ Linhagem } & \multicolumn{4}{|c|}{ Tempo após parasitismo (dias) } \\
\hline & & 3 & 5 & 7 & Média $^{\mathrm{T}}$ \\
\hline \multirow{3}{*}{$\begin{array}{l}\text { CTH }\left(\mathrm{N}^{\mathrm{o}} \text { de hemócitos }\right. \\
\left.\times 10^{5} / \mathrm{mm}^{3}\right)\end{array}$} & SUS & $79,75 \pm 11,63$ & $75,45 \pm 5,44$ & $59,54 \pm 10,57$ & $71,10 \pm 5,51$ \\
\hline & RES & $54,37 \pm 13,14$ & $50,04 \pm 6,15$ & $59,87 \pm 16,31$ & $54,76 \pm 6,90$ \\
\hline & Média $^{2}$ & $65,9 \pm 9,37$ & $62,7 \pm 5,48$ & $59,71 \pm 9,26$ & \\
\hline \multirow{3}{*}{ 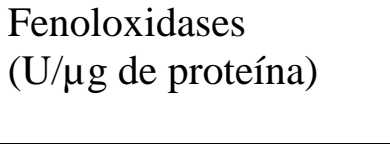 } & SUS & $0,005 \pm 0,001$ & $0,001 \pm 0,000$ & $0,005 \pm 0,001$ & $0,004 \pm 0,000$ \\
\hline & RES & $0,003 \pm 0,001$ & $0,004 \pm 0,001$ & $0,005 \pm 0,002$ & $0,004 \pm 0,000$ \\
\hline & Média $^{2}$ & $0,004 \pm 0,001$ & $0,003 \pm 0,000$ & $0,005 \pm 0,001$ & \\
\hline \multirow{3}{*}{$\begin{array}{l}\text { Óxido nítrico } \\
(\mathrm{nmol} / \mu \mathrm{l})\end{array}$} & SUS & $0,049 \pm 0,01$ & $0,272 \pm 0,12$ & $0,078 \pm 0,01$ & $0,133 \pm 0,04$ \\
\hline & RES & $0,105 \pm 0,04$ & $0,120 \pm 0,07$ & $0,040 \pm 0,00$ & $0,088 \pm 0,02$ \\
\hline & Média $^{2}$ & $0,077 \pm 0,02$ & $0,196 \pm 0,07$ & $0,059 \pm 0,01$ & \\
\hline \multirow{3}{*}{$\begin{array}{l}\text { Antimicrobiana } \\
\text { (número de UFC) }\end{array}$} & SUS & $59,37 \pm 7,18$ & $28,29 \pm 1,96$ & $15,72 \pm 1,65$ & $34,4 \pm 5,05$ \\
\hline & RES & $70,95 \pm 2,18$ & $30,16 \pm 3,07$ & $15,33 \pm 1,44$ & $38,8 \pm 5,84$ \\
\hline & Média $^{2}$ & $65,16 \pm 3,98 \mathrm{a}$ & $29,22 \pm 1,76 b$ & $15,52 \pm 1,04 \mathrm{c}$ & \\
\hline \multirow{3}{*}{ 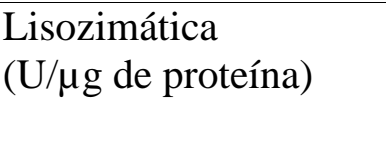 } & SUS & $0,101 \pm 0,10$ & $0,767 \pm 0,47$ & $0,192 \pm 0,05$ & $0,353 \pm 0,16$ \\
\hline & RES & $0,039 \pm 0,03$ & $0,407 \pm 0,17$ & $0,034 \pm 0,01$ & $0,160 \pm 0,06$ \\
\hline & Média $^{2}$ & $0,070 \pm 0,05 b$ & $0,587 \pm 0,24 a$ & $0,113 \pm 0,03 \mathrm{ab}$ & \\
\hline
\end{tabular}

* ${ }^{1,2}$ Médias seguidas pela mesma letra maiúscula na coluna e letra minúscula na linha não diferem pelo teste de Tukey $(\mathrm{P} \leq 0,05)$.

\subsection{Discussão}

A análise da existência de custos adaptativos associados à resposta imunológica de lagartas de S. frugiperda em decorrência da seleção de genótipos resistentes ao piretroide lambda-cyhalothrin, para a possível exploração do controle biológico via parasitoides como fator de pressão de seleção para auxiliar no reestabelecimento da suscetibilidade de $S$. frugiperda a esse inseticida quando associado a práticas de cultivo em que o uso do produto pode ser evitado, demonstrou que a resistência induz a pequenas alterações no sistema imunológico do hospedeiro. Ainda, as alterações induzidas no sistema imunológico do hospedeiro não mais são significativas quando o inseto é submetido ao parasitismo por Campoletis aff. flavicincta.

$\mathrm{Na}$ ausência do parasitismo, lagartas resistentes apresentaram um maior número de células de defesa do que as lagartas suscetíveis, assemelhando-se aos resultados obtidos para 
Rhynocoris kumarii (Hemiptera: Reduviidae) expostos a organofosforado (GEORGE; AMBROSE, 2004), porém, resposta contrária foi obtida para o mesmo inseto quando exposto a organoclorados. O efeito negativo de xenobióticos derivados de plantas, como a azadiractina, por exemplo, no número total de células de defesa do inseto também tem sido relatado para vários outras espécies (AZAMBUJA et al., 1991; ZIBAEE; BANDANI, 2010). No entanto, a forma como esses produtos agem sobre o sistema imunológico de insetos ainda é desconhecida, mas o efeito de indução no número de células de defesa em resposta ao aumento na atividade dos processos de detoxificação tem sido descrito (KURIHARA et al., 1992).

Apesar do potencial efeito de inseticidas na atividade de serina proteases, não há relatos na literatura a não ser para produtos botânicos, os quais inibiram a atividade de fenoloxidase de Rhodnius prolixus (Hemiptera: Reduviidae) e Eurygaster integriceps (Hemiptera: Scutelleridae), respectivamente (AZAMBUJA et al., 1991; ZIBAEE; BANDANI, 2010).

A resposta dada pela atividade de óxido nítrico, produção de compostos com atividade antimicrobiana e atividade lisozimática, mesmo que necessitando de indução, pode ser alterada quando o inseto é exposto a invasores multicelulares (NAPPI et al, 2000; FOLEY; O'FARREL, 2003; WHITTEN et al., 2007; LOPES, 2008). Porém, as únicas alterações observadas nesses parâmetros da resposta humoral de $S$. frugiperda em decorrência da resistência ao piretroide lambda-cyhalothrin foram em relação ao período de desenvolvimento. Há vários estudos que demonstram alterações no potencial de resposta imunológica do inseto em razão do seu crescimento e desenvolvimento (WILSON-RICH et al., 2008; LAUGHTON et al., 2011; SRYGLEY, 2012).

A completa ausência de efeito da resistência a lambda-cyhalothrin na resposta imunológica de lagartas de S. frugiperda quando o inseto foi submetido ao parasitismo demonstra que o parasitoide foi capaz de suprimir a resposta imunológica celular de lagartas resistentes com a mesma eficiência de lagartas suscetíveis, visto que o número de células de defesa em lagartas resistentes, ausência do parasitismo, foi bem superior ao das suscetíveis. O efeito de regulação do número de células de defesa do hospedeiro por parasitoides é comumente relatado na interação hospedeiro-parasitoide e derivado da ação de moléculas bioativas reguladores que são produzidas pelas fêmeas dos parasitoides (fluídos do cálice, venenos) ou de partículas virais simbiontes a elas associadas (GARDINER; STRAND, 2000; STRAND; PECH, 1995; LAVINE et al., 2005; STRAND, 2008; HUANG et al., 2009). 
Assim, apesar dos resultados obtidos não demonstrarem efeitos negativos do custo adaptativo associado à resistência ao piretroide lambda-cyhalothrin na capacidade de defesa humoral e celular de lagartas de S. frugiperda ao parasitoide Campoletis aff. flavicincta, nossos resultados não excluem a possibilidade de que lagartas resistentes tenham menor capacidade de responder a outros fatores patogênicos indutores das vias humorais analisadas, como, por exemplo, bactérias e fungos entomopatogênicos.

\subsection{Conclusões}

- Lagartas de S. frugiperda resistentes a lambda-cyhalothrin apresentam maior contagem total de hemócitos do que lagartas suscetíveis;

- O parasitismo por Campoletis aff. flavicincta reduz o número de células de defesa circulantes em lagartas resistentes aos níveis de lagartas suscetíveis de $S$. frugiperda;

- As atividades antimicrobiana e lisozimática de lagartas de S. frugiperda são influenciadas apenas pela idade do inseto, independentemente de sua resistência a lambda-cyhalothrin e ocorrência de parasitismo por Campoletis aff. flavicincta;

- A resistência a lambda-cyhalothrin não interfere no sistema imunológico de $S$. frugiperda a ponto de resultar em custos adaptativos que conduzam à maior exploração das mesmas por Campoletis aff. flavicincta, em relação as suscetíveis.

\section{Referências}

AZAMBUJA, P.; GARCIA, E.S.; RATCLIFFE, N.A., WARTHEN, JR JD. Immunedepression in Rhodnius prolixus induced by the growth inhibitor, azadirachtin. Journal of Insect Physiology, Oxford, v. 37, p. 771-777, 1991.

BALE, J.S.; VAN LENTEREN, J.C.; BIGLER, F. Biological control and sustainable food production. Philosophical transactions of the Royal of Society B: Biological Sciences, London, v. 363, p. 761-776, 2008.

BIGLER, F. Quality assessment and control in entomophagous insects used for biological control. Journal of Applied Entomology, Berlin, v. 108, p. 390-400, 1989.

BRADFORD, M. M. A rapid and sensitive method for the quantization of microgram quantities of protein utilizing the principle of protein-dye binding. Analytical Biochemestry, New York, v. 72, p. 248-254, 1976. 
CHHABRA, S.; SACHDEVA, V; SINGH, S. Influence of end groups on in vitro release and biological activity of lysozyme from a phase-sensitive smart polymer-base in situ gel forming controlled release drug delivery system. International Journal of Pharmaceutics, Amsterdam, v. 342, p. 72-77, 2007.

COUSTAU, C.; CHEVILLON, C.; FRENCH-CONSTANT, R. Resistance to xenobiotics and parasites: can we count the cost? Trends in Ecology and Evolution, Amsterdam, v. 15, p. 378-383, 2000.

DIEZ-RODRÍGUEZ, G. I. \& OMOTO, C. Herança da Resistência de Spodoptera frugiperda (J.E. Smith) (Lepidoptera: Noctuidae) a Lambda-Cialotrina. Neotropical Entomology, Londrina, v. 30, p. 311-316, 2001.

FARALDO, A. C.; NUNES; A. S.; FACCIOLI, L. H.; DEL BEL, E. A.; LELLO, E. Nitric oxide production in blowfly hemolymph after yeast inoculation. Nitric Oxide, Orlando, v. 13, p. 240-246, 2005.

FERRARESE, R.; BRIVIO, M.; CONGIU, T.; FALABELLA, P.; GRIMALDI, A.; MASTORI, M.; PERLETTI, G.; PENNACCHIO, F.; SCIACCA, L.; TETTAMANTI, G.; VALVASSORI, R.; EGUILEOR, M. Early suppression of immune response in Heliothis virescens larvae by the endophagous parasitoid Toxoneuron nigriceps. Invertebrate Survival Journal, Modena, v. 2, p. 60-68, 2005.

FERNANDES, F.L.; BACCI, L.; FERNANDES, M.S. Impact and selectivity of insecticides to predators and parasitoids. EntomoBrasilis, Londrina, v. 3, p. 1-10, 2010.

FFRENCH-CONSTANT, R. H.; DABORN, P. J.; GAELLE, L. G. The genetics and genomics of insecticide resistance. Trends in Genetics, London, v.20, p. 163-170, 2004.

FOSTER, S.P.; DENHOLM, I.; POPPY, G.M.; THOMPSON, R.; POWELL, W. Fitness trade-off in peach-potato aphids (Myzus persicae) between insecticide resistance and vulnerability to parasitoid attack at several spatial scales. Bulletin of Entomological Research, Farnham Royal, v. 101, p. 659-666, 2011.

FOSTER, S.P.; DENHOLM, I.; THOMPSON, R.; POPPY, G.M.; POWELL, W. Reduced response of insecticide resistant aphids and attraction of parasitoids to aphid alarm pheromone; a potential fitness trade-off. Bulletin of Entomological Research, Farnham Royal, v. 95, p. 37-46, 2005.

FOLEY, E.; O'FARREL, P. H. Nitric oxide contributes to induction of innate immune responses to gram-negative bacteria in Drosophila. Genes \& Development, Cold Spring Harbor, v. 17, p. 115-125, 2003.

GARDINER, E. M. M.; STRAND, M. R. Hematopoiesis in larval Pseudoplusia includens and Spodoptera frugiperda. Archives of Insect Biochemistry and Physiology, New York, v.43, p. 147-164, 2000.

GEORGE, P.J.E.; AMBROSE, D.P. Impact of insecticides on the hemogram of Rhynocoris kumarii Ambrose and Livingstone (Hem., Reduviidae). Journal of Applied Entomology, Berlin, v. 128, p. 600-604, 2004. 
GEORGHIOU, G.P. The evolution of resistance to pesticide. Annual Review of Ecological System, Stanford, v. 3, p. 133-168, 1972.

GREEN, L. C.; LUZURIAGA, K. R.; WAGNER, D. A.; RAND, W.; ISTFAN, N.; YOUNG, V. R.; TANNENBAUM, S. R. Nitrate biosynthesis in man. Procceedings of the National Academy of Sciences of the United States of America, Washington, v. 78, p. 7764-7768, 1981.

GUSTAFSON, D.I.; HEAD, G.P.; CAPRIO, M.A. Modeling the impact of alternative hosts on Helicoverpa zea adaptation to Bollgard cotton. Journal of Economic Entomology, Lanham, v. 99, p. 2116-2124, 2006.

HUANG, F.; SHI, M.; YANG, Y.; LI, J. ; CHEN, X. Changes in hemocytes of Plutella xylostella after parasitism by Diadegma semiclausum. Archives of Insect Biochemistry and Physiology, New York, v.70, p. 177-187, 2009.

KURIHARA, Y.; SHIMAZU, T.; WAGO, H. Classification of hemocytes in the common cutworm, Spodoptera litura (Lepidoptera: Noctuidae) II. Possible roles of granular lasmatocytes and oenocytoids in the cellular defense reactions. Applied Entomology and Zoology, Tokyo, v. 27, p. 237-242, 1992.

LAVINE, M. D.; CHEN, G.; STRAND, M. R. Immune challenge differentially affects transcripts abundance of three antimicrobial peptides in hemocytes from the moth Pseudoplusia includens. Insect Biochmestry and Molecular Biology, Oxford, v. 35, p. 1335-1346, 2005.

LAVINE, M. D.; STRAND, M. R. Insect hemocytes and their role in immunity. Insect Biochemestry and Molecular Biology, Oxford, v. 32, p. 1295-1309, 2002.

LAUGHTON, A.M.; BOOTS, M.; SIVA-JOTHY, M.T. The ontogeny of immunity in the honey bee, Apis mellifera L. following an immune challenge. Journal of Insect Physiology, Oxford, v. 57, p. 1023-1032, 2011.

LOPES, C.S. Regulação do desenvolvimento e resposta imune de lagartas de Diatraea saccharalis (Fabricius) (Lepidoptera: Crambidae) por Cotesia flavipes (Cameron) (Hymenoptera: Braconidae). 2008. 72 p. Dissertação (Mestrado em Entomologia) - Escola Superior de Agricultura "Luiz de Queiroz", Universidade de São Paulo, Piracicaba, 2008.

MIYATAKE, T. Insect quality control: synchronized sex, mating system, and biological rhythm. Applied and Entomological Zoology, Tokyo, v.46, p. 3-14, 2011.

MUSSER, F. R.; NYROP, J. P.; SHELTON, A. M. Integrating biological and chemical controls in decision making: European corn borer (Lepidoptera: Crambidae) control in sweet corn as an example. Journal of Economic Entomology, Lanham, v. 55, p. 1538-1549, 2006.

NAPPI, A. J.; VASS, E.; FREY, F.; CARTON, Y. Nitric oxide involvement in Drosophila immunity. Nitric-Oxide: Biology and Chemistry, Cambridge, v. 4, p. 423-430, 2000. 
ODE, P.J. Plant chemistry and natural enemy fitness: effects on herbivore and natural enemy interactions. Annual Review of Entomology, Stanford, v. 51, p. 163-185, 2006.

RÍOS-DÍEZ, J.D.; SALDAMANDO-BENJUMEA, C.I. Susceptibility of Spodoptera frugiperda (Lepidoptera: Noctuidae) strains from Central Colombia to two insecticides, Methomyl and Lambda-Cyhalothrin: a study of the genetic basis of resistance. Journal of Economic Entomology, Lanham, v. 104, p. 1698-1705, 2011.

ROSE, R.; DIVELY, G. P. Effects of insecticide-treated and lepidopteran-active Bt-transgenic sweet corn on the abundance and diversity of arthropods. Environmental Entomology, College Park, v. 36, n. 5, p. 1254-1268, 2007.

ROUSH, R. T.; MCKENZIE, J. A. Ecological genetics of insecticide and acaricide resistance. Annual Review of Entomology, Stanford, v. 32, 361-380, 1987.

SAS INSTITUTE. SAS/STAT: user's guide. Version 8: Cary, 2002.

SRYGLEY, R.B. Ontogenetic changes in immunity and susceptibility to fungal infection in Mormon crickets Anabrus simplex. Journal of Insect Physiology, Oxford, v. 58, p. 342-347, 2012.

STRAND, M.R. Insect hemocytes and their role in immunity. In: BECKAGE, N.E. (Ed.). Insect Immunology. San Diego: Academic Press; Elsevier, 2008. chap. 2, p. 25-47.

STRAND, M.R.; PECH, L.L. Immunological basis for compatibility in parasitoid-host relationships. Annual Review of Entomology, Stanford, v. 40, p. 31-56, 1995.

STRAND, M.R.; WHITERELL, R.A.; TRUDEAU, D. Two Microplitis demolitor polydnavirus mRNAs expressed in hemocytes of Pseudoplusia includens contain a common cysteine-rich domain. Journal of Virology, Washington, v. 71, p. 2146-2156, 1997.

TAYLOR, M.; FEYEREISEN, R. Molecular biology and evolution of resistance to toxicants. Molecular Biology and Evolution, Chicago, v. 13, p. 719-734, 1996.

WHITTEN, M. M. A.; SUN, F.; TEWA, I.; SCHAUBD, G.; SOUKOUD, C.; NAPPIE, A.; RATCLIFFE, E. Differential modulation of Rhodnius prolixus nitric oxide activities following challenges with Trypanossoma rangeli, $T$. cruzi and bacterial cell wall components. Insect Biochemestry and Molecular Biology, Oxford, v. 37, p. 440-452, 2007.

WILSON-RICH, N.; DRES, S.T.; STARKS, PT. The ontogeny of immunity: development of innate immune strength in the honey bee (Apis mellifera). Journal of Insect Physiology, Oxford, v. 54, p. 1392-1399, 2008.

WU, K.; MU, W.; LIANG, G.; GUO, Y. Regional reversion of insecticide resistance in Helicoverpa armigera (Lepidoptera: Noctuidae) is associated with the use of Bt cotton in northern China. Pest Management Science, Sussex, v. 61, p. 491-498, 2005.

YU, S.J. Insecticide resistance in the fall armyworm Spodoptera frugiperda (J. E. Smith). Pesticide Biochemistry and Physiology, San Diego, v. 39, p. 91-94, 1991. 
ZIBAEE, A.; BANDANI, A.R. Effects of Artemisia annua L. (Asteracea) on the digestive enzymatic profiles and the cellular immune reactions of the Sunn pest, Eurygaster integriceps (Heteroptera: Scutellaridae), against Beauveria bassiana. Bulletin of Entomological Research, Farnham Royal, v. 100, p. 185-196, 2010. 